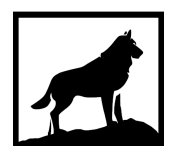

Michigan Technological

1 8 8 5 University
Michigan Technological University Digital Commons @ Michigan Tech

2016

RESERVOIR CHARACTERIZATION THROUGH PRE-STACK SEISMIC ANALYSIS AND INVERSION IN THE THRACE BASIN, NORTHWEST TURKEY

Emre Doguturk

Michigan Technological University, edogutur@mtu.edu

Copyright 2016 Emre Doguturk

Recommended Citation

Doguturk, Emre, "RESERVOIR CHARACTERIZATION THROUGH PRE-STACK SEISMIC ANALYSIS AND INVERSION IN THE THRACE BASIN, NORTHWEST TURKEY", Open Access Master's Thesis, Michigan Technological University, 2016.

https://doi.org/10.37099/mtu.dc.etdr/158

Follow this and additional works at: https://digitalcommons.mtu.edu/etdr

Part of the Geophysics and Seismology Commons 


\title{
RESERVOIR CHARACTERIZATION THROUGH PRE-STACK \\ SEISMIC ANALYSIS AND INVERSION IN THE THRACE \\ BASIN, NORTHWEST TURKEY
}

\section{By}

Emre Doguturk

\begin{abstract}
A THESIS
Submitted in partial fulfillment of the requirements for the degree of MASTER OF SCIENCE

In Geophysics

MICHIGAN TECHNOLOGICAL UNIVERSITY

2016

(C) 2016 Emre Doguturk
\end{abstract}


This thesis has been approved in partial fulfillment of the requirements for the Degree of MASTER OF SCIENCE in Geophysics.

Department of Geological and Mining Engineering and Sciences

Thesis Advisor: Dr. Wayne D. Pennington

Committee Member: Dr. Roger M. Turpening

Committee Member: Dr. Roohollah (Radwin) Askari

Department Chair: Dr. John S. Gierke 


\section{Table of Contents}

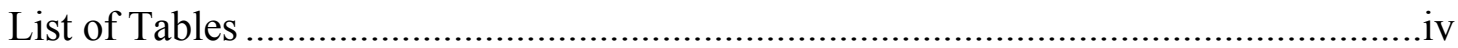

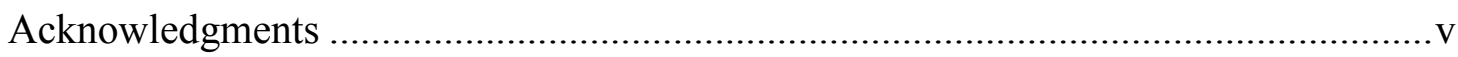

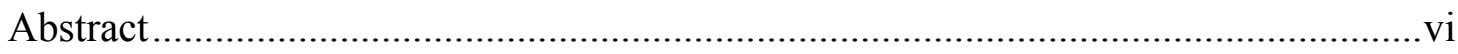

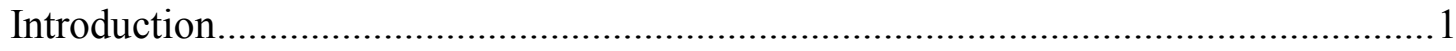

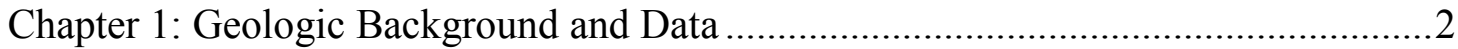

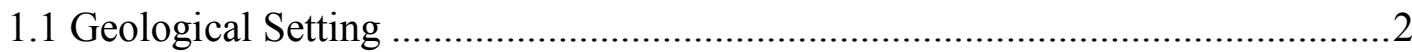

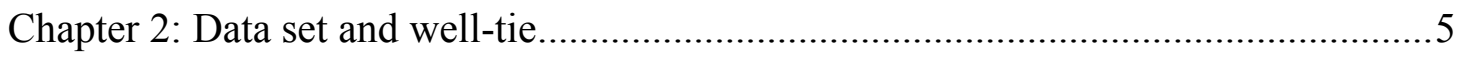

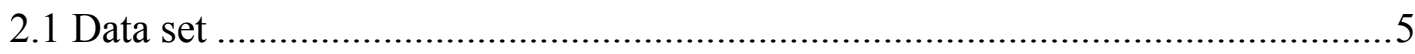

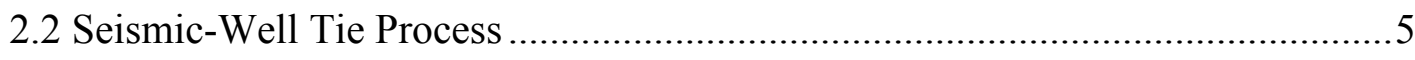

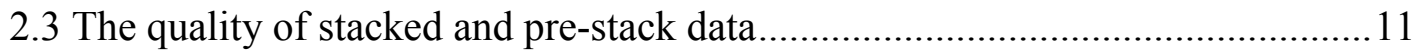

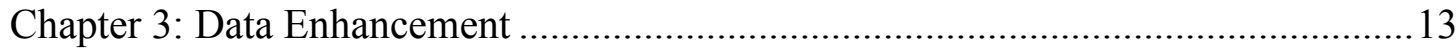

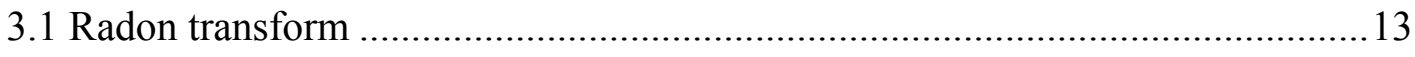

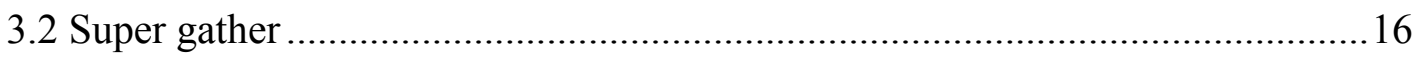

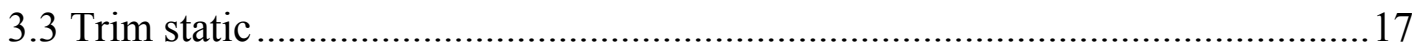

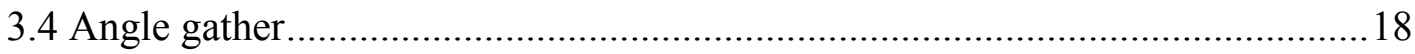

Chapter 4: AVO Analysis and Inversion Techniques.............................................20

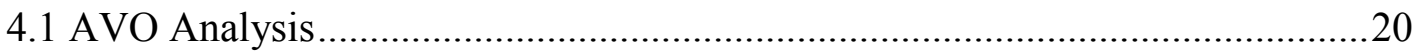

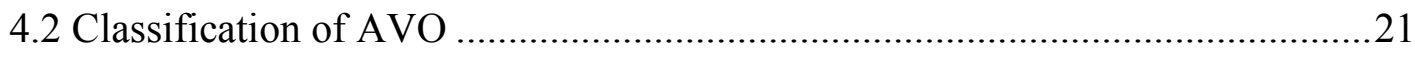

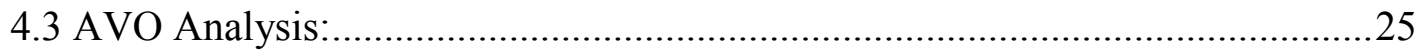

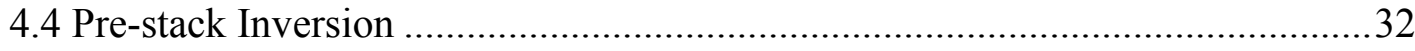

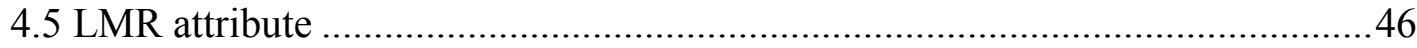

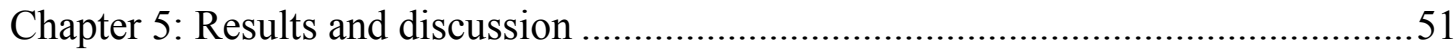

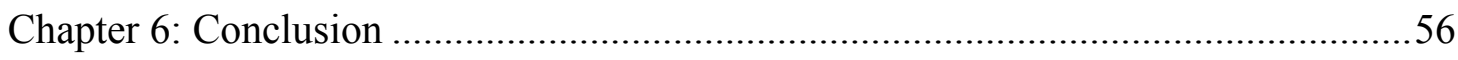

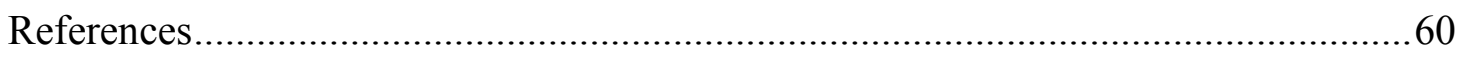

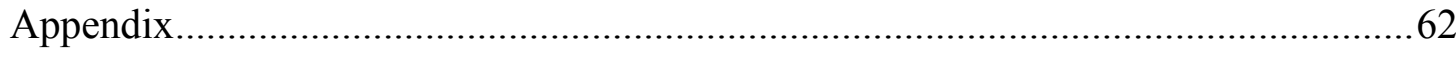




\section{List of Tables}

\section{TABLES}

Table1: Seismic data acquisition parameters............................................................5 


\section{Acknowledgments}

I would like to thank my advisor Wayne D. Pennington who supported and encouraged me, and improved my ideas throughout the research, and also I would like to thank Roger Turpening who supported and helped me a lot.

This work was conducted using Hampson-Russell Software; I gratefully acknowledge their support. I am also thankful for my company Turkish Petroleum Corporations (TPAO) for supplying the seismic data set and a great master opportunity.

I want to express my appreciation to my mother Ayse Doguturk, my father Yunus Doguturk and his memories, my lovely sisters Aydan Doguturk Yaskaya, Tugba Doguturk, and I also want to thank to Ozgur, Alya Yaskaya. They support, love and help to me every time and any situation. 


\section{Abstract}

This study analyzes hydrocarbon reservoirs by using Amplitude-Versus-Offset (AVO) analysis and different inversion methods to investigate hydrocarbon reservoir in the Thrace Basin which is located in northwest Turkey.

A 3D seismic survey containing prestack data was provided by Turkish Petroleum Corporation as true amplitude NMO corrected 3D gathers.

The quality of this land data was poor for AVO applications, and steps were taken to make it useful. Radon filtering proved to be extremely useful for this purpose. Although the application of this filter affected the AVO characteristics differently depending on the parameters selected for the filter, relative AVO characteristics remained useful for moderate filters.

This use of this data for prestack interpretation was undertaken in two parts. AVO analysis of the amplitude trends in the prestack gathers provided insight into rock properties and anomalous behavior, apparently related to hydrocarbon content. Prestack simultaneous inversion was also applied to the data, yielding images of the elastic properties of the potential reservoir rock.

While it remains uncertain whether or not the anomalies observed represent hydrocarbon deposits of economic quality, this study does demonstrate that the data quality in this survey is sufficient to identify anomalies that are consistent with hydrocarbon-bearing zones. The use of prestack processing techniques, particularly the Radon filter, improves the signal-to-noise ratio, allowing use of AVO studies and prestack inversion, but it also decreases the range of AVO differences, limiting the use of traditional AVO guidelines, but the relative differences between background and potential pay remain observable. 


\section{Introduction}

This study attempts to improve the exploration for hydrocarbon deposits in the Thrace basin by investigating the use of analysis of amplitude variations with angle of incidence of seismic reflections. A 3D seismic volume is analyzed through the use of AngleVersus-Offset (AVO) techniques and the use of simultaneous inversion of the prestack data.

The area of interest is the most productive and massive sedimentary basin in Turkey, the Thrace basin, in terms of onshore gas presence. Three main formations are located in the basin; the Danisment, Osmancik and Mezadere Formations. Sandstones and carbonate provide good reservoir potential in the early Oligocene. Stratigraphic and Structural traps are located in the basin and crucial for reservoir localization.

The Osmancik, Mezadere, Hamitabat and Sogucak formations, are the potential reservoir rocks. They are a sandstone, shales and sandy limestone structures.

The quality of prestack data in the survey used here is poor and less than that often used for AVO and prestack inversion, largely as a result of difficult land conditions. In order to prepare the data for such studies, Radon filtering was applied to the prestack gathers, and the AVO and inversion processes followed. 


\section{Chapter 1: Geologic Background and Data}

\subsection{Geological Setting}

The Thrace Basin is one of the most significant hydrocarbon fields in Turkey. The basin is located in the European part of Turkey, in the northwestern part of the country. The Thrace Basin is a triangular shaped Tertiary basin is surrounded Strandja Massif to the north, the Sakarya Continent and the Marmara Sea to the south, and Rhodope Massif to the west, and Istanbul Palaeozoic Sea of Marmara to the east. The basin was created by extension at the end of in Mid Eocene to Late Oligocene times (Turgut et al., 1991).

The Tertiary clastic sediments in the Thrace Basin have a maximum thickness of about $7.5 \mathrm{~km}$ and are very prolific for natural gas potential. The Turkish Petroleum Corporation has investigated the oil and gas potential of the Thrace Basin with over 400 wells, 19 gas-condensate and three oil fields (Huvaz et al., 2005).

Large quantities of gas associated with oil hydrocarbons are being produced in the basin. Source rocks occur in deep basin formations and central parts of the basin where transgressive marine sections are dominantly composed of shales and siltstones with abundant organic materials that generate hydrocarbon. Within this context, most favorable source rocks are the Gazikoy (mid-Eocene), Hamitabat (late-Eocene) and Mezardere (early-Oligocene) formations. Potential reservoir horizons in the Thrace Basin are the sandstone layers in the Hamitabat, Mezardere and Osmancik (lateOligocene) formations. The primary porosity is variable, but around $20 \%$ on average (Huvaz et al., 2005).

The most significant formation of this study is the Oligocene Osmancik Formation. The formation is a fine to coarse delta-front sandstone, sometimes pebbly grained crossbedded, and interbedded with greenish brown shales and siltstones. The Osmancik formation has $10-25 \%$ porosity and $0.1-10-m d$ permeability. The formation consists of cross-bedded delta-front sandstones. The thickness of the Osmancık formation is about $700 \mathrm{~m}(2296 \mathrm{ft})$. 
The Northern part of the sedimentary structure is cut by NW-SE trending normal, lateral and transpressional faults. Main faults are the Babaeski Fault Zone, Luleburgaz Fault Zone, Kirklareli Fault Zone, Terzili Fault and Osmancik Fault. All of these faults are accepted as the plays of the northern branch of the North Anatolian Fault, and they were reactivated during the mid to Late Miocene Neo-tectonic period (Şen, 2009).

The Osmancik formation, which is our study formation, is associated with structural traps in the Korudağ anticlinorium and its subparallel anticlines which represent a supergiant petroleum trap complex. Structural and stratigraphic traps are both exploration targets and the deeper section of the basin is like kitchen area for all source rock formations. These formations are buried more than $3000 \mathrm{~m}$ deep, and are exposed to temperatures $80-140{ }^{\circ} \mathrm{C}$ (Turgut, 1991). 


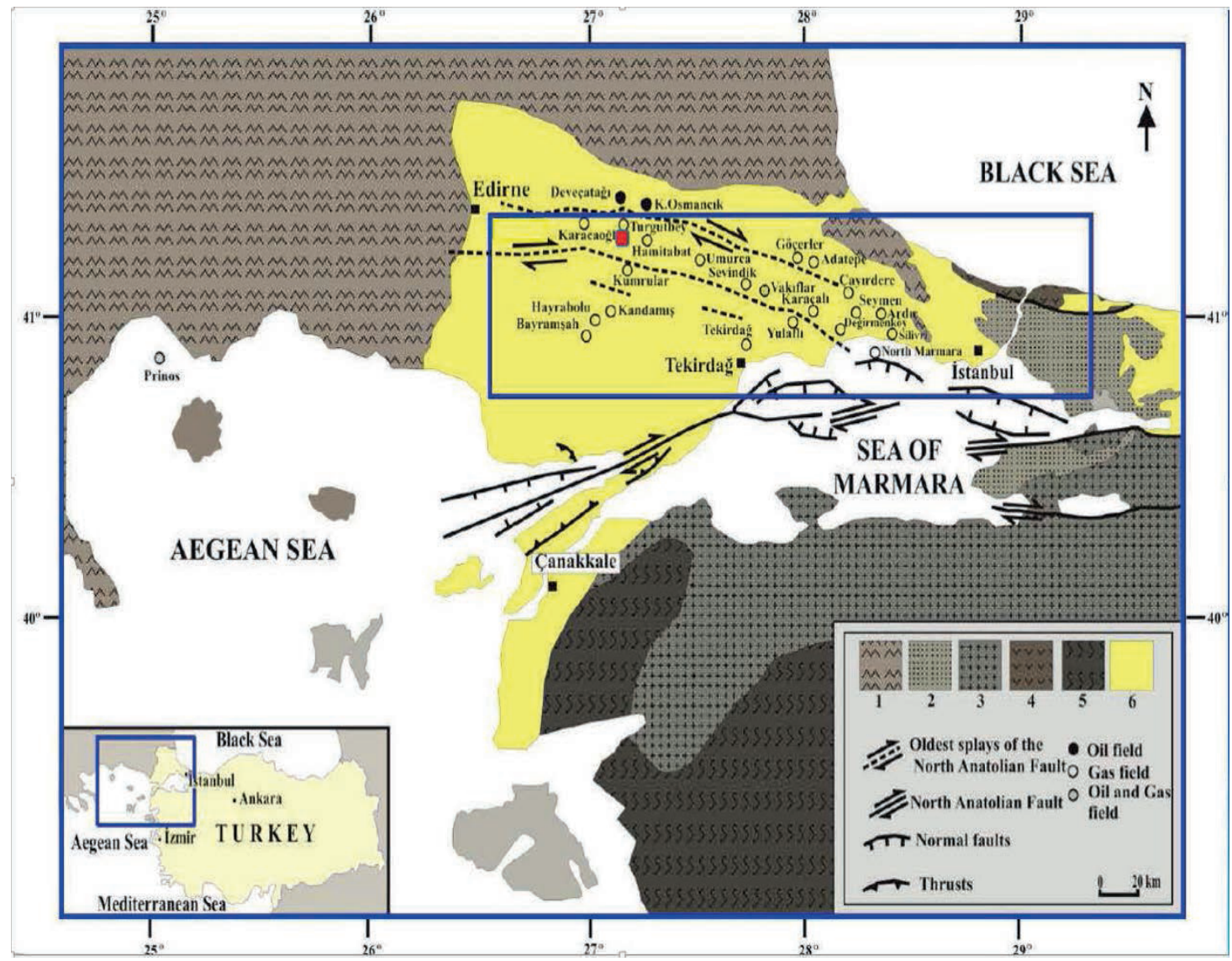

Figure 1. Location map of northwestern Turkey (inset shows general location). The small red square indicates the rough location of the seismic data set used in the study. The blue box shows the faulted potential reservoir area (Sen et al., 2009) (used by permission, documentation seen on page 62). 


\section{Chapter 2: Data set and well-tie}

\subsection{Data set}

The Thrace Basin dataset came from TPAO for the purpose of my thesis studies. The 3D data contains 494 inlines and 466 crosslines covering an area of $123 \mathrm{~km}^{2}$. We have three wells (well 1, well 2 and well 3) in the area. The Well 1 was chosen for correlation with the seismic data because it contains logs of high quality and appears to intersect a shaly sand layer with low P-wave velocity and density $(1535-1565 \mathrm{~m})$ which could be useful to track as a potential reservoir rock.

Table 1: Seismic data acquisition parameters

\begin{tabular}{|l|l|}
\hline Near-offset & $35 \mathrm{~m}$ \\
\hline Far-offset & $3385 \mathrm{~m}$ \\
\hline Fold & 24 \\
\hline Bin sized & $25 \mathrm{~m}$ by $25 \mathrm{~m}$ \\
\hline Receiver Spacings & $50 \mathrm{~m}$ \\
\hline Shot point spacing & $50 \mathrm{~m}$ \\
\hline 3D data obtained in rectangular grid & N-S and Crosslines E-W \\
\hline Source & Dynamite \\
\hline
\end{tabular}

\subsection{Seismic-Well Tie Process}

The target zone was chosen based on the low P-wave velocity and density at $1555 \mathrm{~m}$. A complete set of logs identifying this layer is shown in Figure 2. 


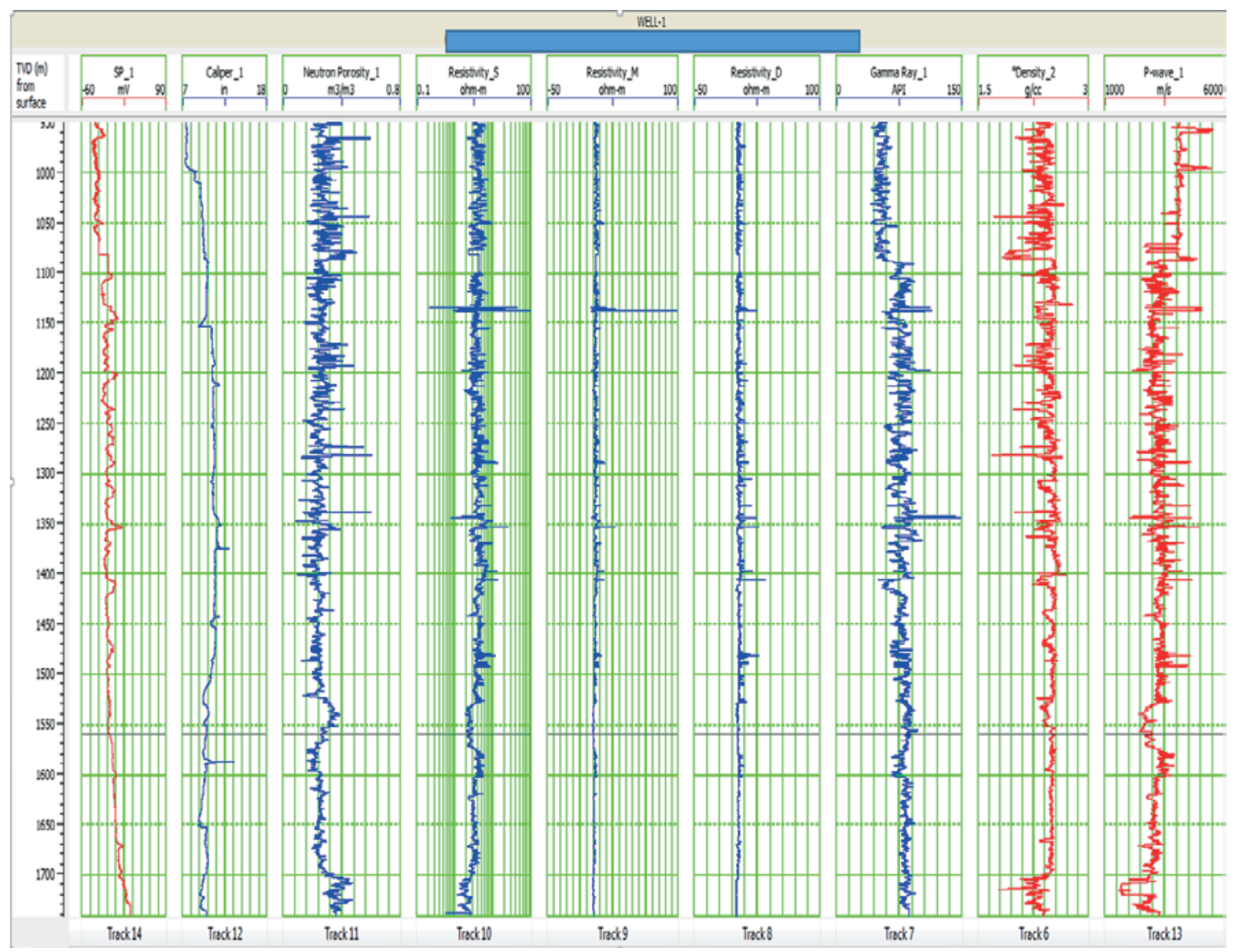

Figure 2. Potential hydrocarbon target marked with a black line based on well log top data from Well-1. The target zone was chosen at 1555 m based on low P-wave and Density logs. 
To tie the well logs to the seismic data, several Ricker wavelets were created and an extracted statistical wavelet was extracted. Synthetic traces were obtained using Ricker wavelets, and using the extracted statistical wavelet from the seismic data. The statistical wavelet extracted from the seismic data produced the best synthetic trace based on correlation coefficients.

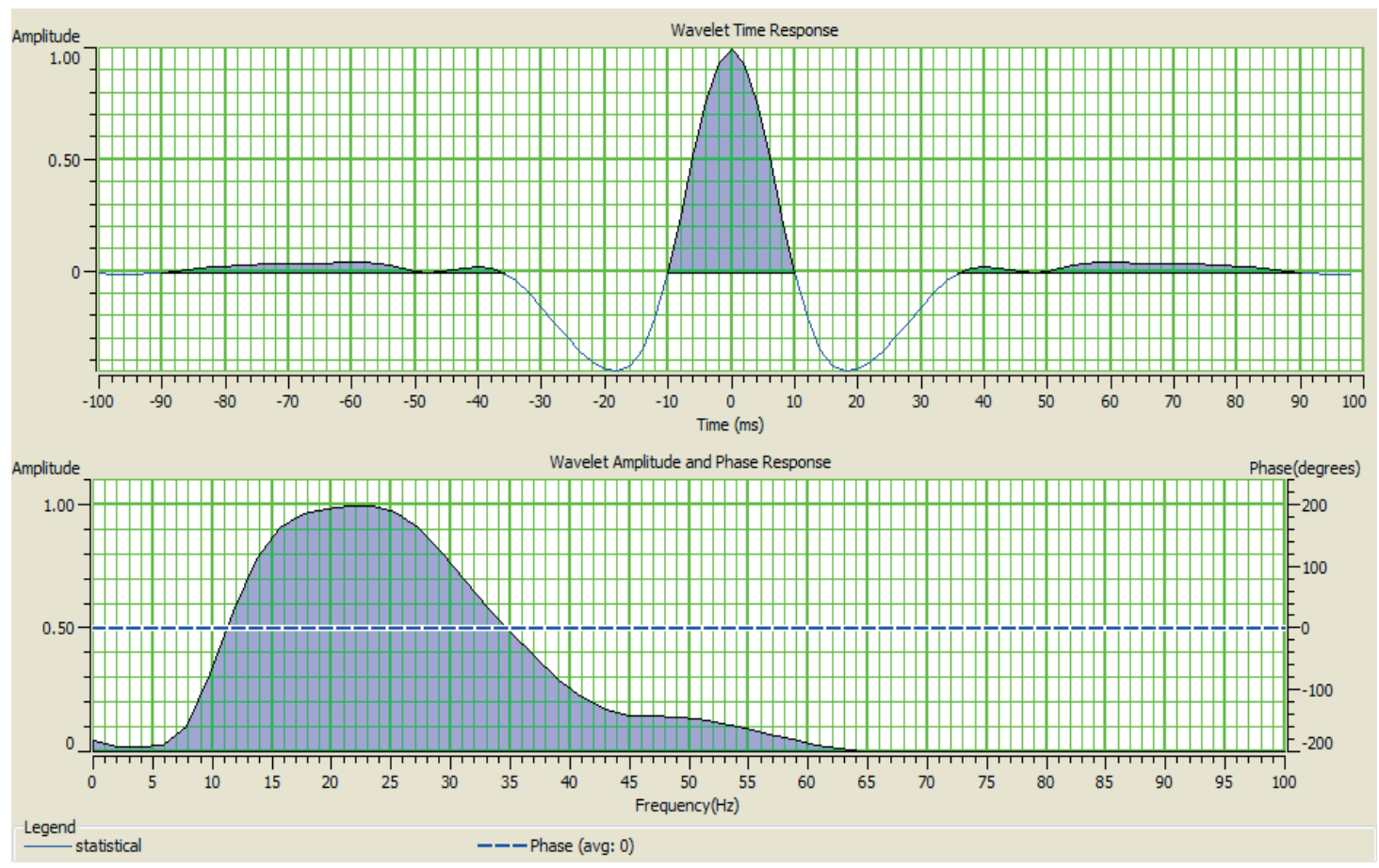

Figure 3. The extracted statistical wavelet extracted from the pre-stack data. 
A zero-offset synthetic seismogram is shown in Figure 3, along with a seismogram obtained from stacking of the gather shown. After carefully adjusting the velocities, we achieved the best correlation coefficient (0.72) and more importantly the consistency between the seismic data and log by using statistical wavelet. In spite of the good correlation coefficient, the tie is not as good as one would like; this seems to be due to the rapidly varying nature of the seismic data in the vicinity of the well, itself a result of faulting and steeply dipping beds. The tie is only for correlation purposes, the pre-stack data will be used for improved interpretation. After the well-tie process, two horizons were selected and tracked: horizon 1 is a negative reflection at the top of the target, and horizon 2 a positive reflection at the base of the target. We will use horizon 1 for most of the AVO analysis. 


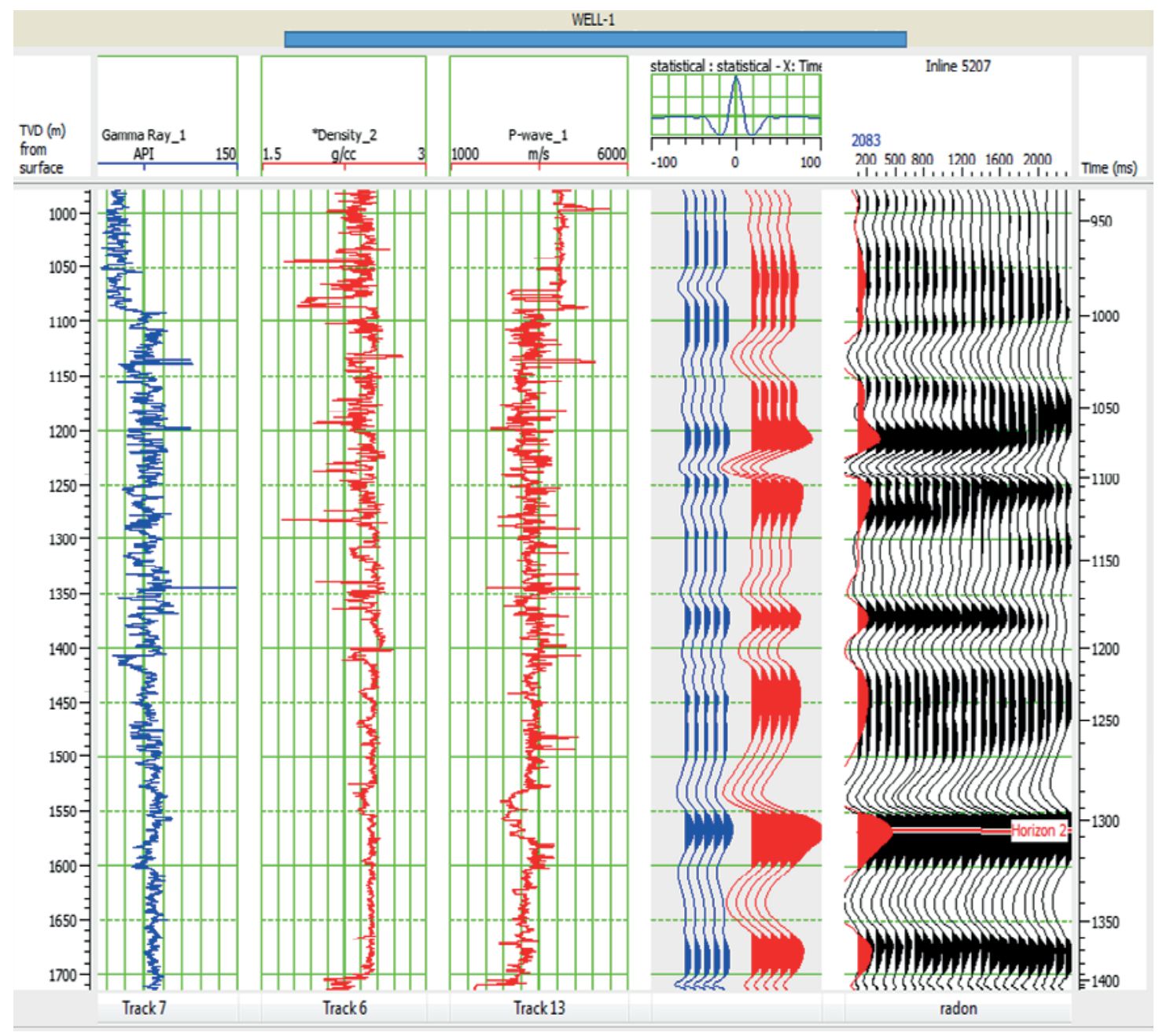

Figure 4. Well-tie summary. The synthetic seismogram (zero-offset) is shown in blue, and compared with the seismic seismogram data (red) obtained from stacking of the black gather traces. The statistical wavelet used is shown at top, and the logs (resistivity, density, and sonic) are shown at left. 
A summary of the survey is shown in Figure 5, with horizon 2 displayed.

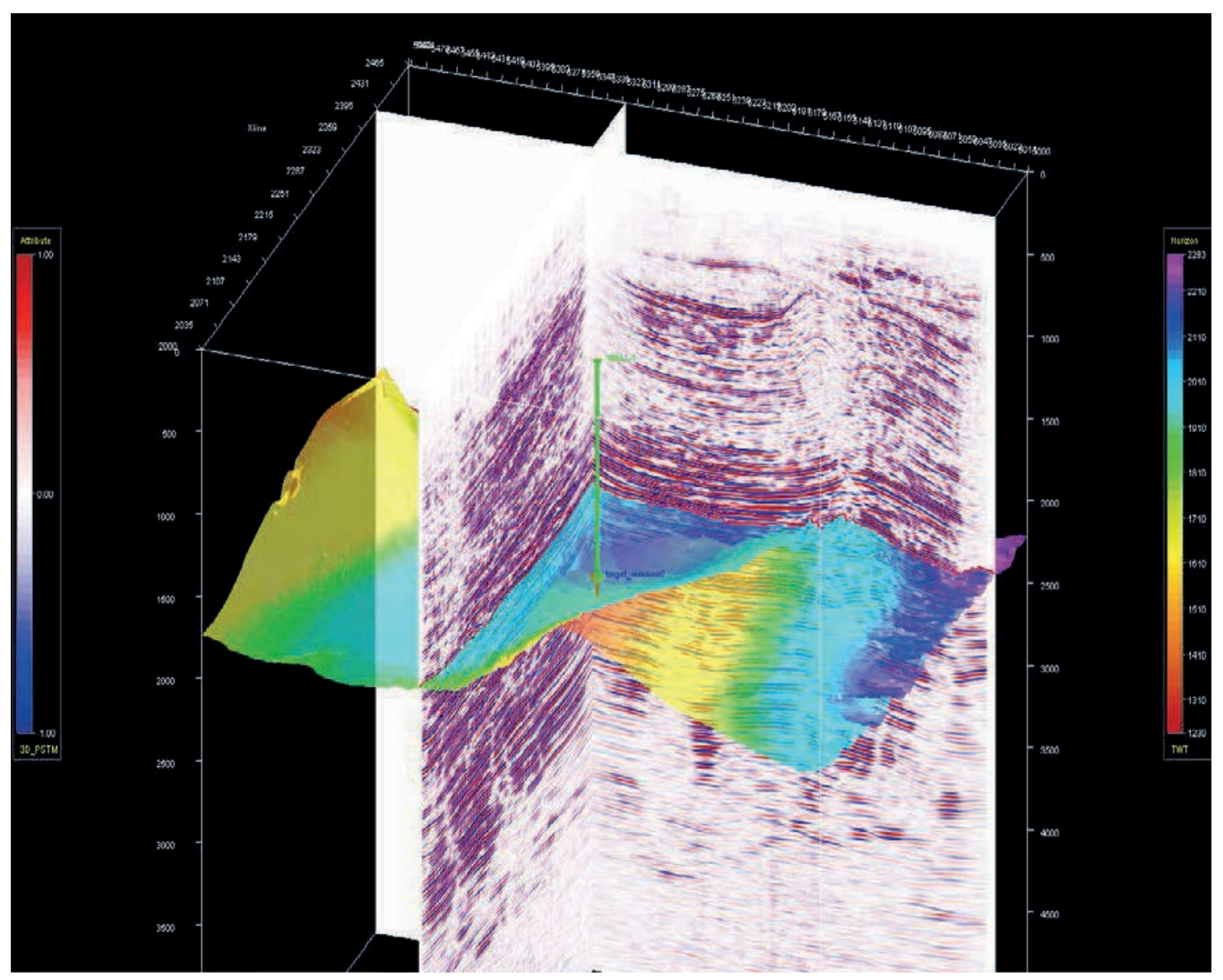

Figure 5. 3D model of the target horizon. The scale on the left shows the seismic amplitude as displayed in the sections, and the color on surface displayed with a scale on the right is two-way travel time (TWT). 


\subsection{The quality of stacked and pre-stack data}

In order to provide a cleaner and more interpretable image in post-stack data, we can look to noise removal in the pre-stack gathers. In addition, we will look for attributes from the pre-stack data that may be useful.

Figures 5 and 6 show the post-stack data that was provided by Turkish Petroleum Company. Notice that discontinuous reflections are present in the data, due to complex fault structures in the formation. While there may be some post-stack processing steps that could improve the image, for the purposes of this study, we are going to focus on improvements that we can make to the pre-stack data for the purpose of AVO analysis and pre-stack inversion.

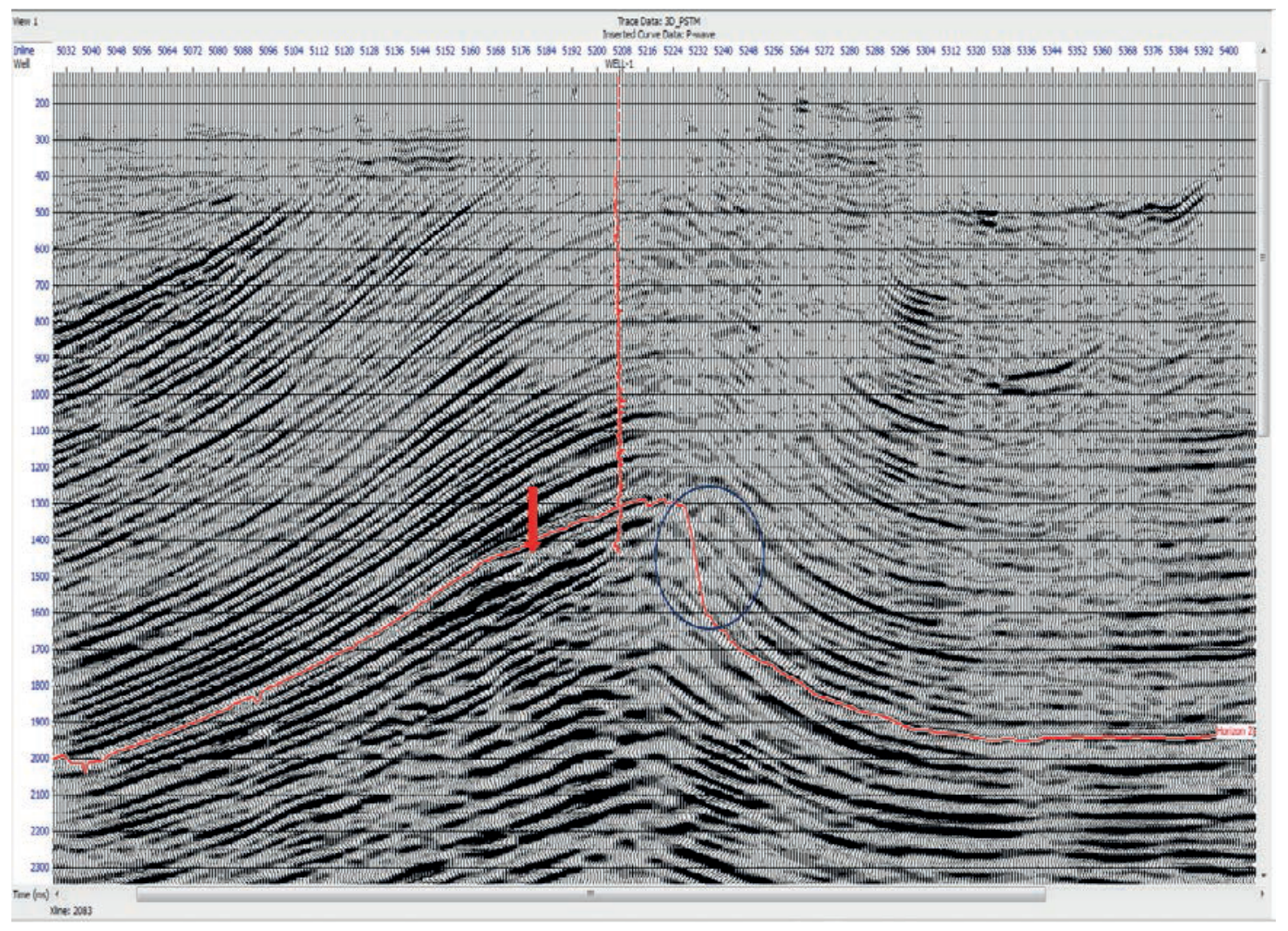

Figure 6. Seismic section, inline 5207, showing typical data quality of the post-stack seismic volume. The red arrow shows discontinuous reflectors and the blue circle shows low resolution within the faulted, steeply dipping area. 


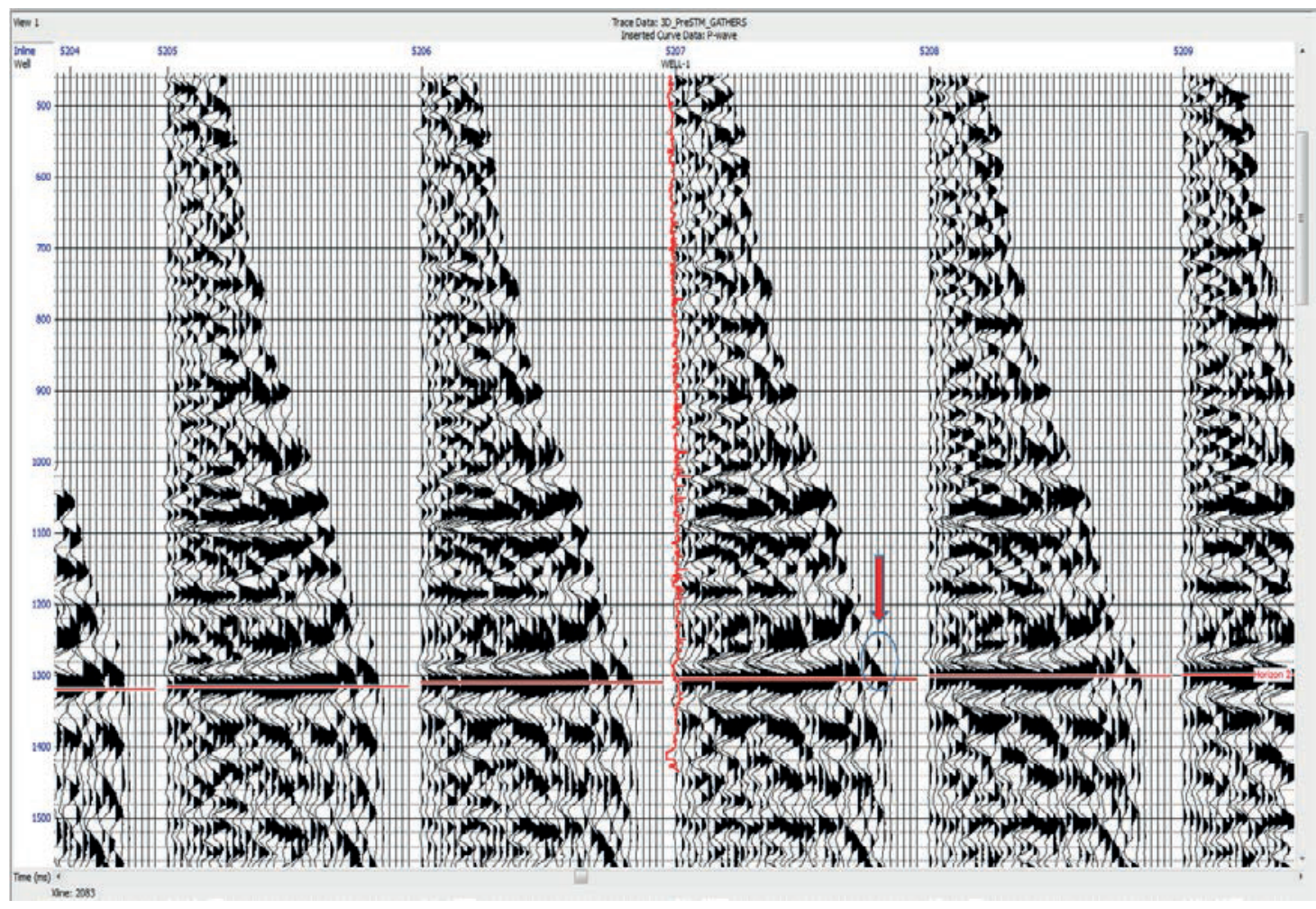

Figure 7. Examples of pre-stack gathers along one crossline (2083). At the horizon of interest, the data are noisy, and the amplitudes seem to be affected by noise, particularly at large offsets (red arrow). 


\section{Chapter 3: Data Enhancement}

\subsection{Radon transform}

Noise data can cause misleading results and unrealistic interpretation. Pre-stack processing is necessary for successful AVO analysis. Radon filtering has some advantages when used before AVO analysis. For example, while the Radon method leaves some multiple energy (10\%) at near offset, the f-k method leaves $30 \%$ of it (Ross, 1999). In addition, Rickett et al. (2002) and DuBose (2003) report similar observations regarding the effect of a parabolic Radon transform on the preservation of AVO effects. Mahob et al. (1997) demonstrates a significant improvement in the extracted AVO information after Radon filtering and point out that the filtered data is in agreement with theoretical AVO behavior.

The AVO data points before Radon filtering (Figure 8; left side) do not reveal a consistent trend. After Radon filtering (Figure 8, right side), the noise, apparently due to multiples, seems to be removed and in addition, the primary seismic-reflection events cluster more toward the theoretical curve. On the other hand, the amount of amplitude increase observed with an offset in the raw data has been greatly reduced, to a much smaller AVO effect. 


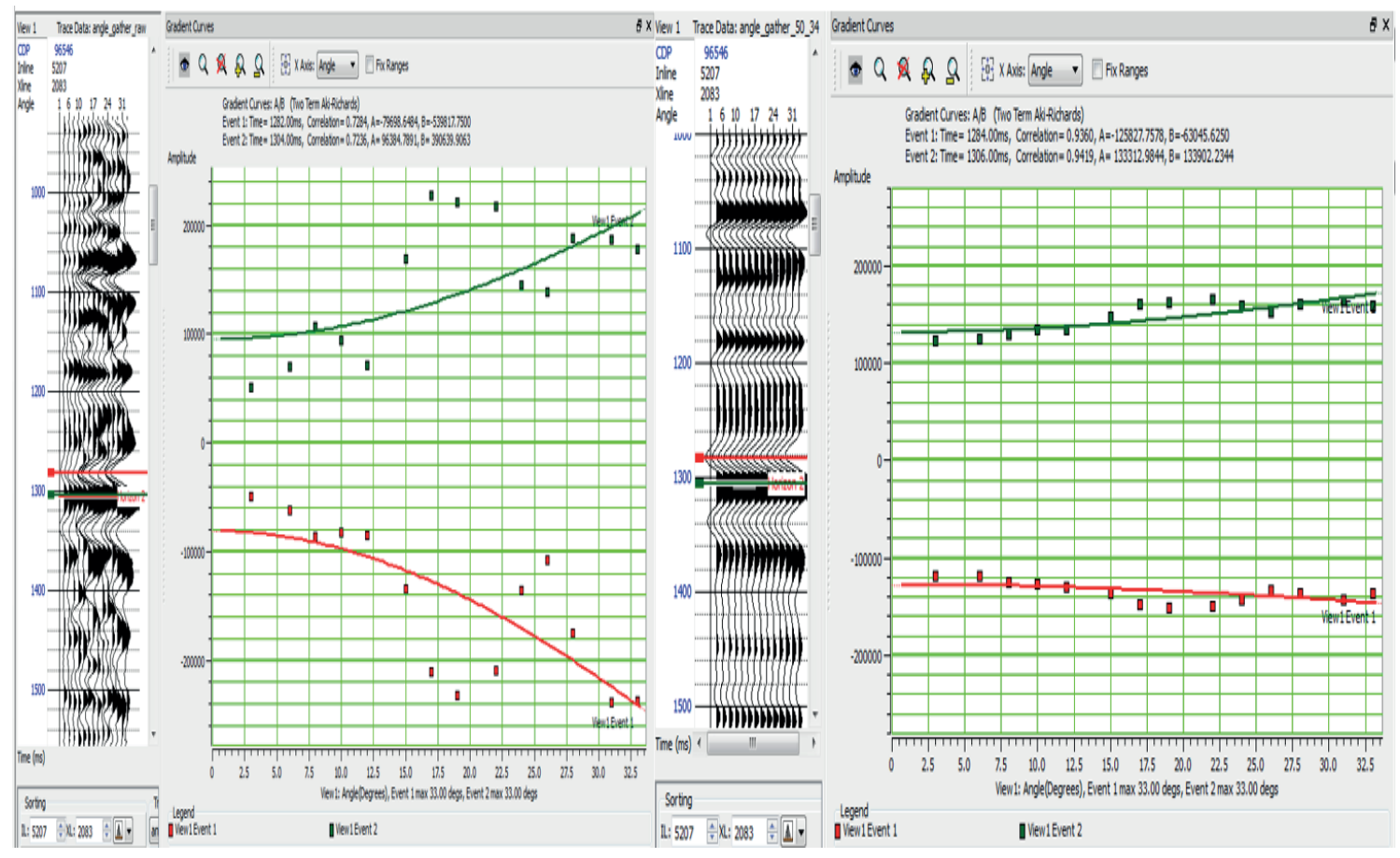

Figure 8. The AVO data points before Radon filter (left pair), and after Radon

\section{filter (right pair).}

Radon noise suppression was applied to the data, after experimenting with different ranges of filter settings to remove the noise from the pre-stack data. In order to see how noise would affect our results, five different AVO analyses are displayed in the Appendix. The filter uses a parabolic Radon approach. The parabola is defined by two parameters: amplitude and curvature. The curvature is defined by the moveout, or "Delta-T", defined as the difference in time between the parabola at zero-offset and at some "far" offset. A negative value means that the parabola curves upward (towards time zero) with increasing offset, and a positive value curves downwards. The most significant parameter distinguishing between multiples and primaries is the Low Delta$\mathrm{T}$ parameter in this section because that is what eliminates or allows multiples. Multiples have a lower "stacking" velocity than primaries at the same twoway time, and consequently, exhibit a residual moveout after NMO correction. If the Low Delta-T parameter is set to $50 \mathrm{~ms}$, it is assumed that this multiple-energy residual moveout is at least $50 \mathrm{~ms}$ at the far offset. The optimum parameters chosen for 
this study are low delta-T $-50 \mathrm{~ms}$ and high delta- $\mathrm{T}+50 \mathrm{~ms}$. The key point is preserving real data while removing noise; examples are provided in Figure 9. Examination of the various Radon filters, and gathers at other locations indicates that use of the $+/-50 \mathrm{~ms}$ filter allows the relative importance of AVO effects to be preserved, which is important for the AVO analysis.
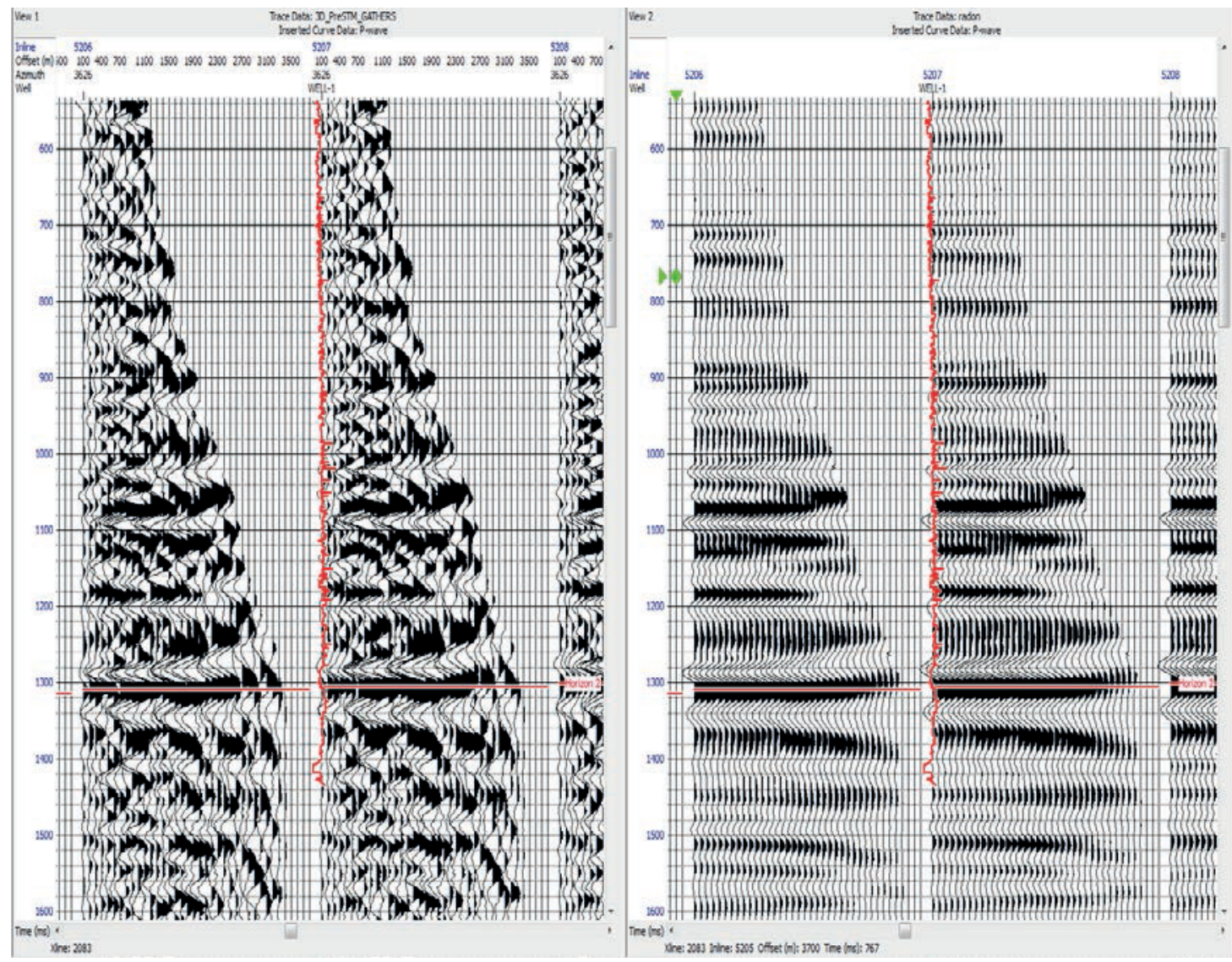

Figure 9. Two seismic gathers. Before Radon filter (left pair), and after Radon filter (right pair). 


\subsection{Super gather}

Even after processing with Radon filters, there is still random noise within each gather.

If the noise is truly random, stacking of neighboring gathers should reduce it. A "super gather" is formed by combining a given number of adjacent CMP gathers. Creating super gathers is a crucial step enhancing the signal noise ratio, increasing fold of the data, and eliminating noise but it also results in data mixing and loss of resolution (Chopra, 2014). We tested $3 \times 3,5 \times 5$ and $7 \times 7$ rolling window ranges for constructing the super gathers to be used here, selecting a $3 \times 3$ window (Figure 10) as the best compromise between losing resolution and reducing noise. It was observed that application of $5 \times 5$ rolling window was removing the real data (Figure 47).

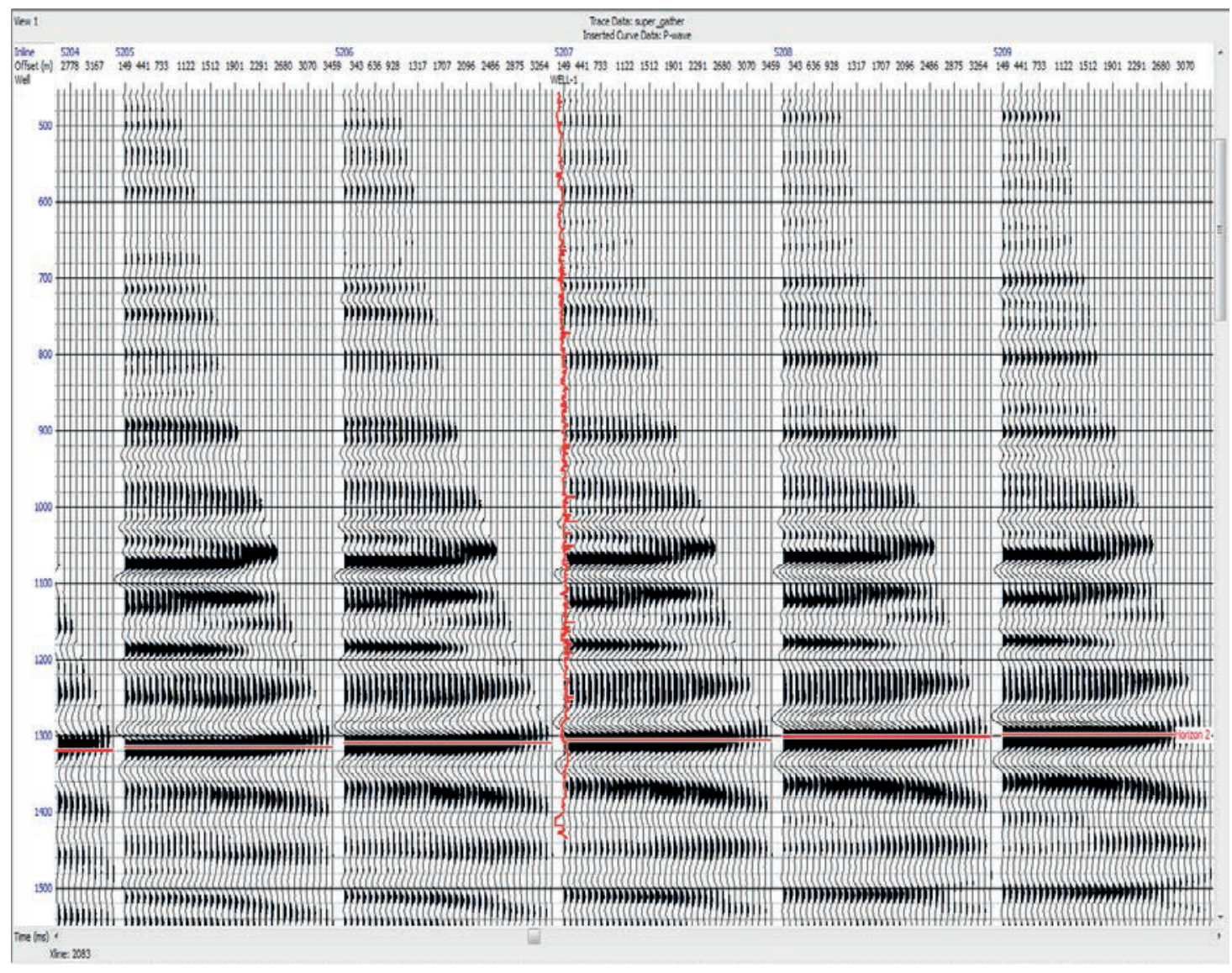

Figure 10. A super gather created by averaging $3 \times 3$ CDP bin location. 


\subsection{Trim static}

Even after application of the optimal Radon filter, some residual moveout problems remain, particularly evident at the farthest offsets. The trim static attempts to determine an optimal shift to apply to each trace in a gather in order to better align reflectors. The shift is determined by cross-correlating each trace with a reference trace to make the input trace better align with the reference trace, usually the CDP stacked trace. The trim static was applied to the data to reduce the residual moveout, up to a maximum time shift of $10 \mathrm{~ms}$. The careless application of trim static can cause errors to appear in the data (Bancroft, 2000), but those seem to have been avoided here (Figure 11).
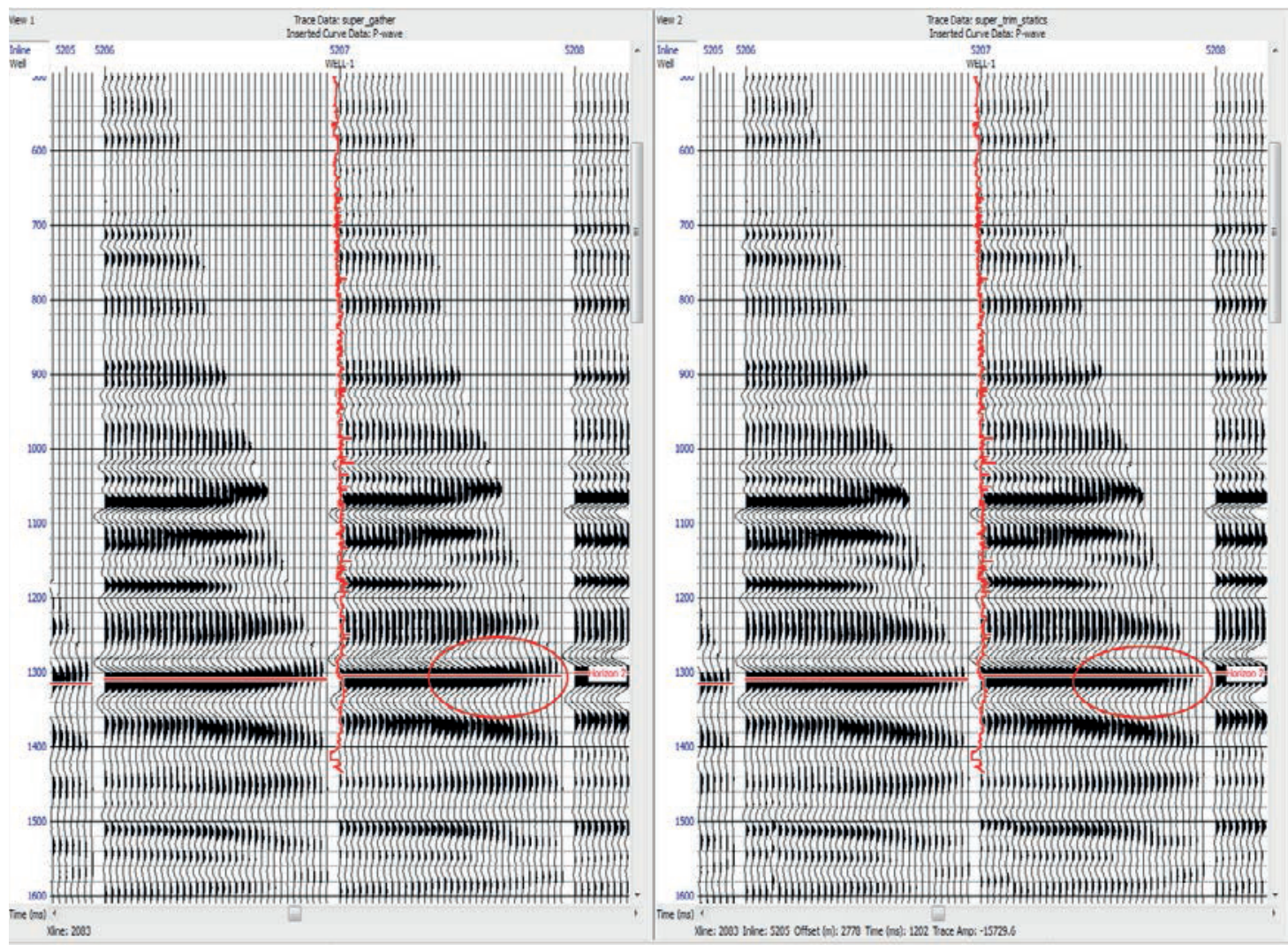

Figure 11. Super gather before (left) and after (right) application of trim static 


\subsection{Angle gather}

While we think of AVO, we usually interpret our data in terms of angles-of-incidence, rather than offset. Angle gathers are obtaining by converting CMP gathers from the offset domain to angle domain through ray-tracing using the P-wave velocity obtained from log data (Chopra et al., 2014). First, however, we examine a suite of super gathers and overlay the incident angle in color (Figure 12).

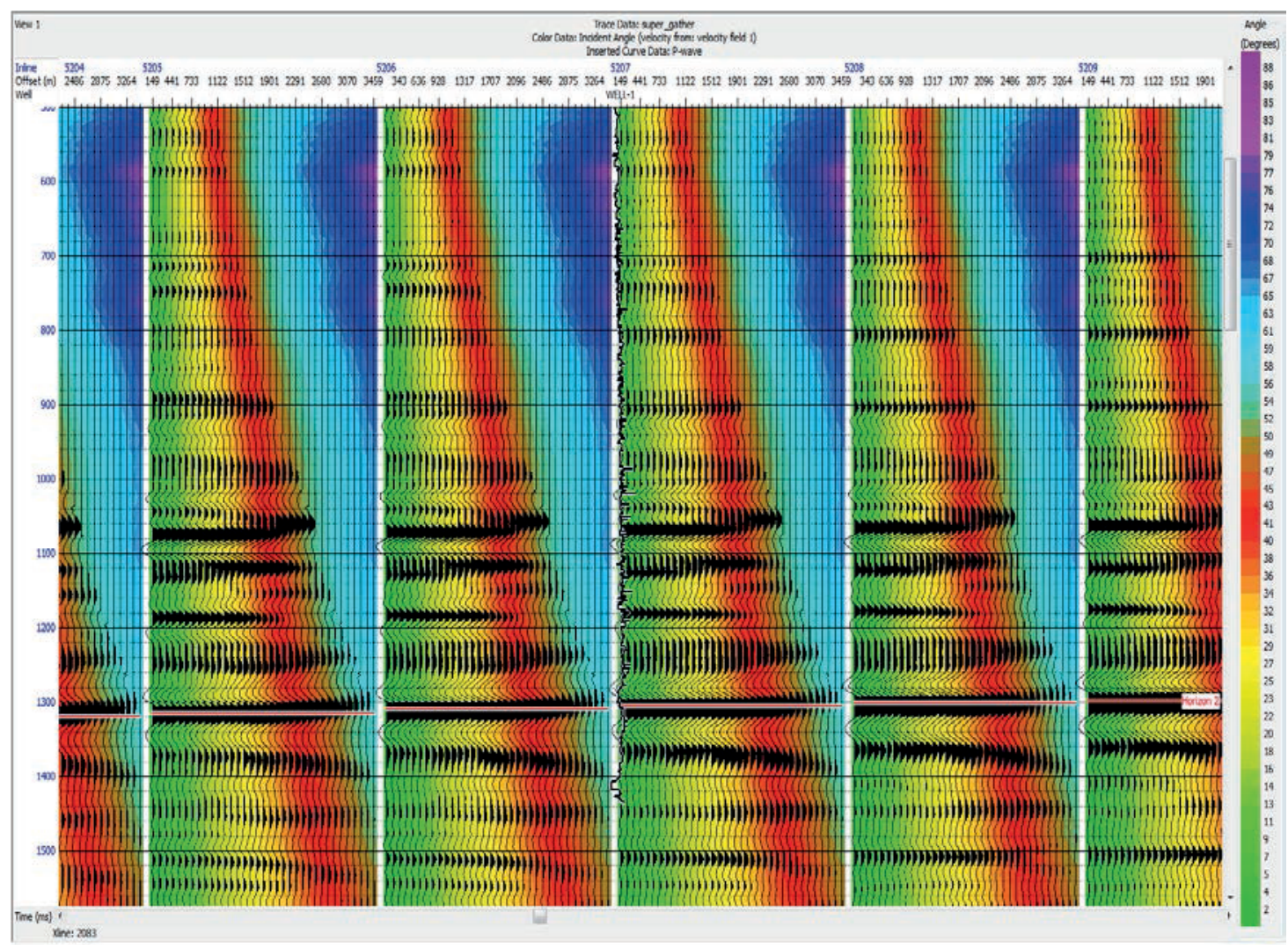

Figure 12. A suite of super gathers with incident angle overlain in color. The maximum angle at the target zone is approximately 33 degrees.

We can transform the super gathers into the angle-gather domain, as shown in Figure 12. The $\mathrm{P}$ wave velocity obtained from the sonic $\log$ was used to create the angle gathers. The angle gather will be utilized for pre-stack inversion and AVO analysis in the further process. Note that the maximum angle at the target zone is approximately $33^{\circ}$. 


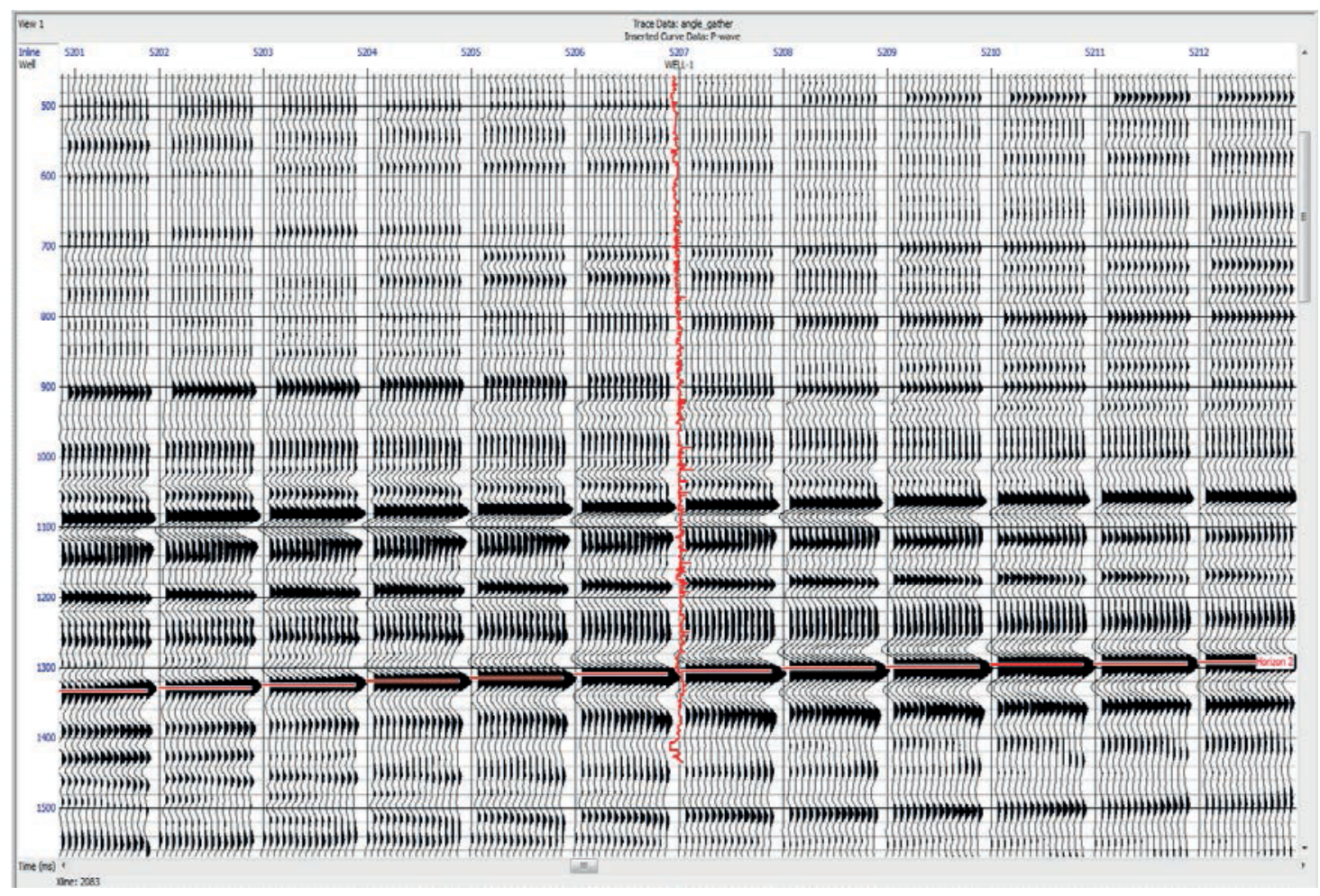

Figure 13. Angle gathers, with individual angle gather traces displayed from $1^{\circ}$ to $33^{\circ}$. 


\section{Chapter 4: AVO Analysis and Inversion Techniques}

\subsection{AVO Analysis}

We are able to make use of reflected P-wave amplitudes to determine changes in elastic constants (Acoustic Impedance and Shear Impedance, or Vp, Vs, density) across an interface, using pre-stack data. When an incident $\mathrm{P}$ wave propagates from one layer into another, as it strikes the interface at an oblique angle, it splits into four components: reflected and refracted S waves, and reflected and refracted P-waves. The Zoeppritz equations provide the amplitudes of the various waves, given the elastic properties of the media on either side of the interface. Many approximations have been used to simplify the expressions describing this amplitude behavior, up to the critical angle, for reflected P-waves. For smaller $\left(<35^{\circ}\right)$ angles, a two-term approximation, which includes Acoustic (P) impedance (AI) and Shear(S) impedance (SI), can be used; for larger angles $\left(>40^{\circ}\right)$, a three-term approximation in P-wave velocity $(\mathrm{Vp})$, S-wave velocity (Vs), and density can be used (Aki and Richards, 1980).

The three-term equation usually takes the form of:

$R(\theta)=A+B \sin ^{2}(\theta)+C \sin ^{2}(\theta) \tan ^{2}(\theta)$

Where $R(\theta)$ is the reflection coefficient at the incident angle $\theta$; $A$ is called the AVO intercept or zero-offset reflection coefficient. B is referred to as the AVO slope or gradient and is a measure of the rate of change of the amplitude with an angle. $\mathrm{C}$ is called the curvature. These coefficients can be related to the elastic properties across the interface.

The two-term equation (Shuey, 1976) for small angles $\left(35^{\circ}\right)$ :

$\mathrm{R}(\theta)=\mathrm{A}+\mathrm{B} \sin ^{2}(\theta)$

Extracted P-impedance and S-impedance information are reasonable and acceptable for a two-term solution. Density estimation is not available for a two-term approximation. 


\subsection{Classification of AVO}

In order to simplify discussions of AVO behavior, it has proven useful to refer to standard classifications. The first AVO classification for gas sands based on the normal incidence P-wave reflection coefficient was proposed by Rutherford and Williams (1989); in 1998 the classification was expanded by Castagna. Figure 13 shows the general classifications with the addition of a "flat spot" curve, representing typical hydrocarbon-water contacts.

AVO studies often look for a feature that is different from the general trend, or anomalous. The classes for AVO can, in certain cases, be interpreted in terms of sandshale relationships if we assume that the interface being studied is at the transition from a shale layer to the underlying sand layer. The following discussion assumes that we are dealing with sands beneath shale in the first four classes and that the $\mathrm{Vp} / \mathrm{Vs}$ ratio in sands is lower than in shales.

\section{Class 1: High Impedance Sands}

Class 1 reflections occur when a high impedance sand lies beneath a lower-impedance shale layer. The zero offset reflection coefficient (and therefore the intercept) is positive; in general, the amplitude decays with increasing angle of incidence. The reflectivity can change polarity at great angles when sufficient offset range is available (Rutherford et al., 1989).

\section{Class 2: Small Contrast in Impedance}

This occurs when the shale and underlying sand have comparable values of impedance. It is undetectable in noisy data. Phase or polarity reversals often are observed with increasing offset (Rutherford et al., 1989).

\section{Class 3: Low Impedance Sand}

Class 3 reflections occur when a low-impedance sand underlies a higher-impedance shale. The zero offset reflection coefficient is negative and the intercept and gradient 
are both strongly negative; the negative amplitudes increase in size with increasing angle of incidence. Class 3 is typical of "bright spots" (Rutherford et al., 1989).

\section{Class 4: Low Impedance Sand with Higher Vp/Vs ratio}

In this case, the intercept is negative at zero offset, and then the amplitudes become smaller (less negative) with increasing angle (Castagna et al., 1997). 


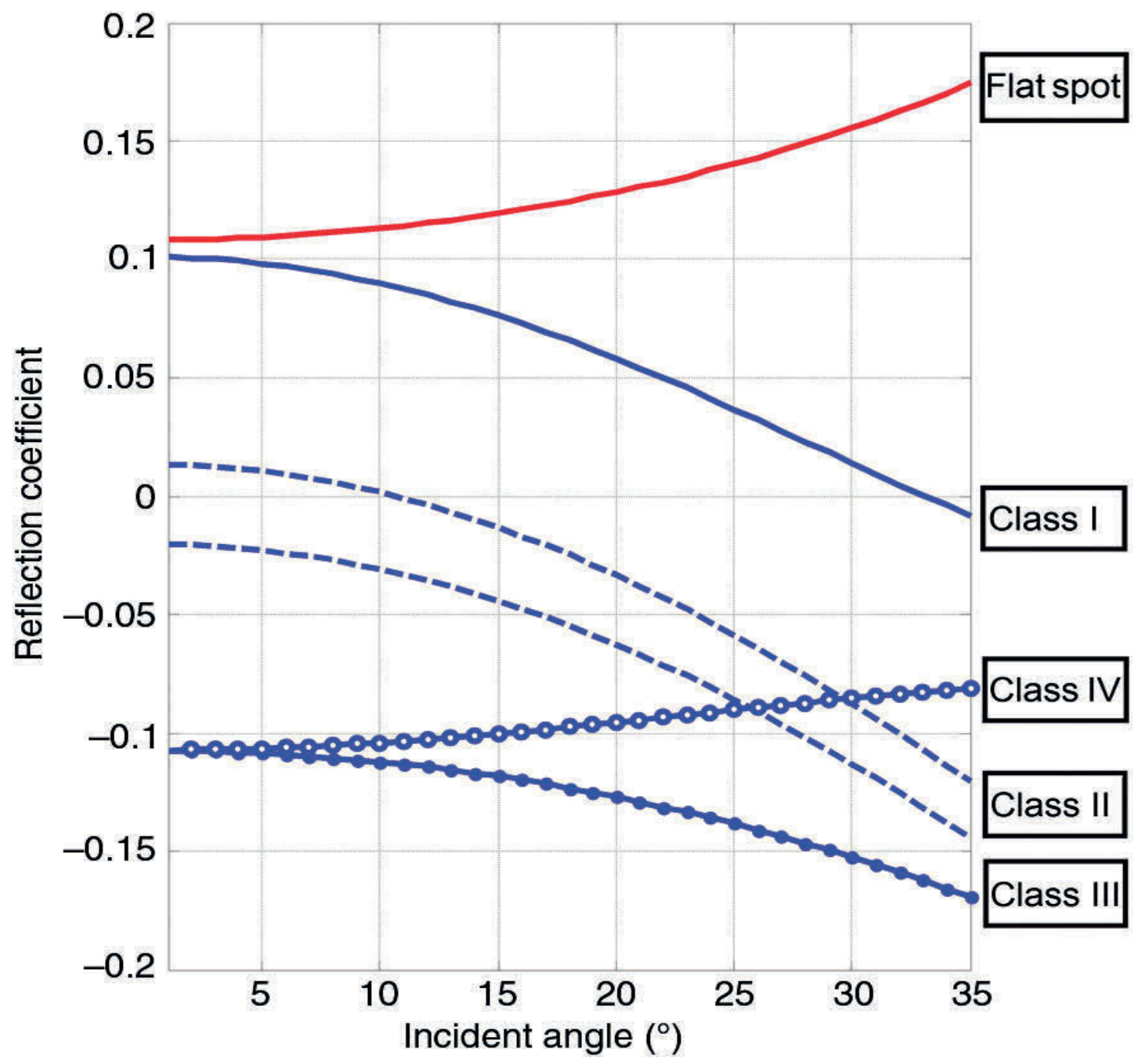

Figure 14. The four usual AVO classification defined by Rutherford and Williams (1989), Castagna et al., (1998). The figure shows the four classes and the flat spot curve. 


\section{Review of data enhancement steps}

The following section reviews the processing steps used in this study, as have been described in the previous sections.

1. The Radon transform was applied to reduce multiples and random noise in order to improve the signal-to-noise ratio in the pre-stack domain, as shown Figure 9. A high delta $\mathrm{T}$ of $+50 \mathrm{~ms}$ and a low delta $\mathrm{T}$ of -50 were chosen.

2. Trim static was applied to remove the residual NMO, as shown figure 11. A maximum of $10 \mathrm{~ms}$ shift was applied to the data.

3. Identified a possible target zone at $1306 \mathrm{~ms}$ on seismic based on low P-wave velocity and density values at depths of $1555 \mathrm{~m}$ in well 1, as shown Figure 4.

4. Extracted a statistical wavelet, as shown figure 3, and performed well-tie with the seismic data. We achieved 0.72 correlation coefficient and better consistency synthetic and real data, as shown Figure 4.

5. Two horizons were picked on the CDP gathers involving the target zone. Horizon 1 for the top of the layer and horizon 2 for the base of the layer.

6. Super gathers were created by averaging over 3 CDP bin locations, further enhancing the signal to noise ratio, as shown Figure 10.

10. Angle gathers were created from the super gathers using the P-wave velocity from a well log. The maximum incident angle is $33^{\circ}$, as shown figure 13 .

12. After angle gathers were created, we are ready to use it for AVO analysis and for pre-stack inversion. 


\subsection{AVO Analysis:}

Having obtained low-noise angle gathers (super gathers), we are ready to proceed with the AVO analysis.

\section{AVO Gradient Analysis:}

A plot of amplitude versus $\sin ^{2}$ of the angle of incidence can be fit with a two-term approximation to Zoeppritz equations, following the equation provided earlier. The yintercept is the same as the zero-offset reflection amplitude, usually referred to as the "intercept" (A) in AVO studies. The slope of the straight line through the data points is referred to as the "gradient" (B). We calculate and interpret the intercept and gradient values for the target zone and nearby intervals.

AVO behavior was calculated using the least squares method by fitting a two-term curve that approximates the Zoeppritz equation to all reflection amplitudes as a function of angle of incidence for each CMP gather. The AVO gradient analysis was to examine seismic gathers and show the intercept and gradient values for specific events within those gathers. AVO gradient curves were plotted by using a two-term approximation because of small angles at the target horizon, as shown Figure 15. Notice that data points follow the curves with very high correlations of 0.94 and 0.94 . Intercept A is minus (-) and B gradient is minus (-) which indicates AVO Class 3. 


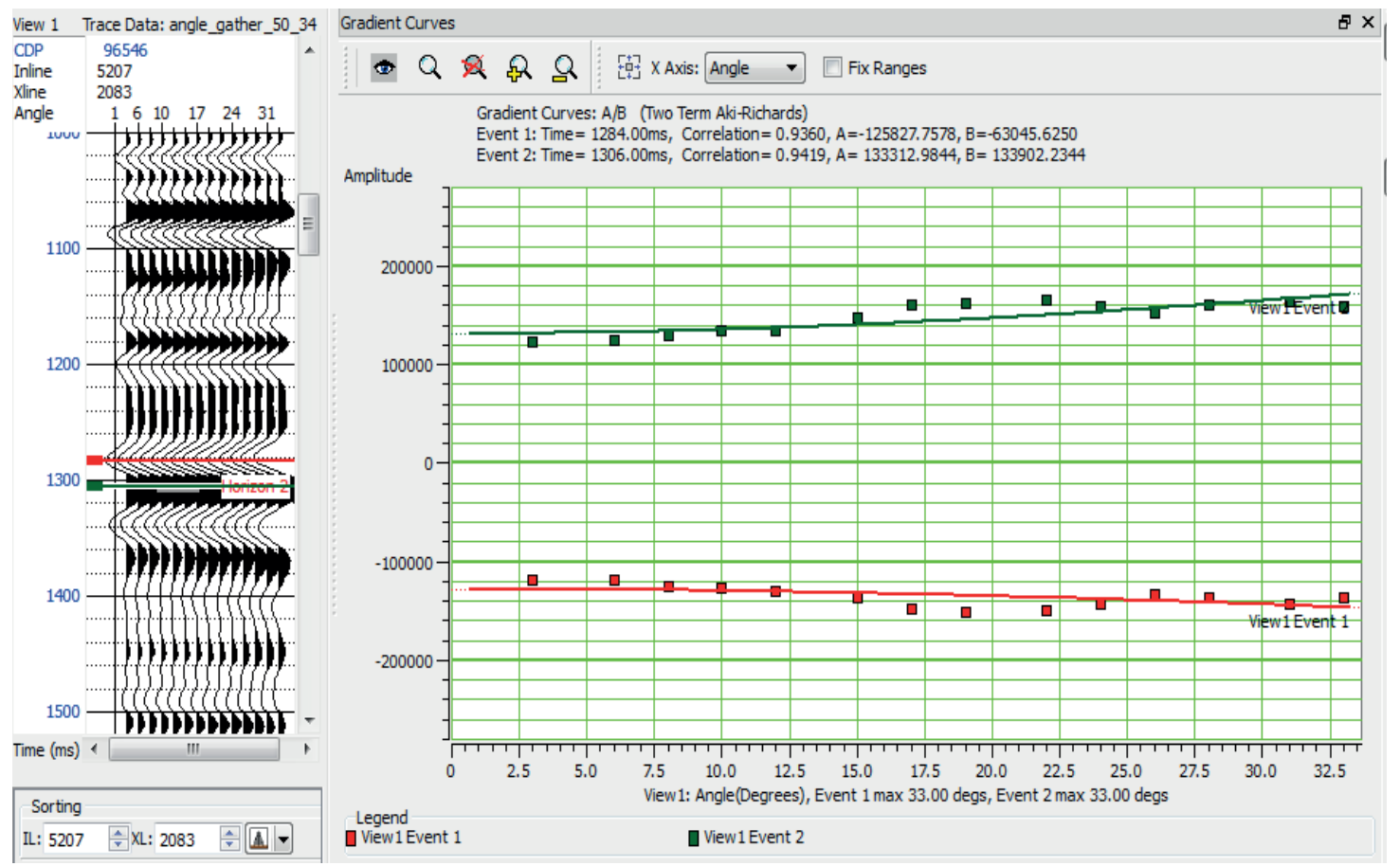

Figure 15. AVO gradient curves were plotted by using horizon 1(red curve) and horizon 2 (green curve). Data points come from the super gather in angle domain, while lines represent the best-fit two-term solution. The red curve and points represent the top of the target zone and the green curve the base. 


\section{AVO attribute volume:}

AVO Attribute Volumes were created to analyze a subset of our gathers in order to examine various attributes available from this analysis. Here we used $\mathrm{A} * \mathrm{~B}$ product and scaled Poisson`s ratio.

\section{A*B product:}

The product of intercept and gradient, $\mathrm{A}^{*} \mathrm{~B}$, is shown in a seismic section in Figure 16. The AVO product shows a positive response at the top (in red) and base of the reservoir (also in red), which may suggest the presence of hydrocarbons. This attribute is often observed to work well for a class $3 \mathrm{AVO}$ response. Both the top and base of the potential reservoir show positive values for $\mathrm{A}^{*} \mathrm{~B}$ because the product in one case both numbers are negative (top of the reservoir) and in the other case both numbers are positive (base of the reservoir). 


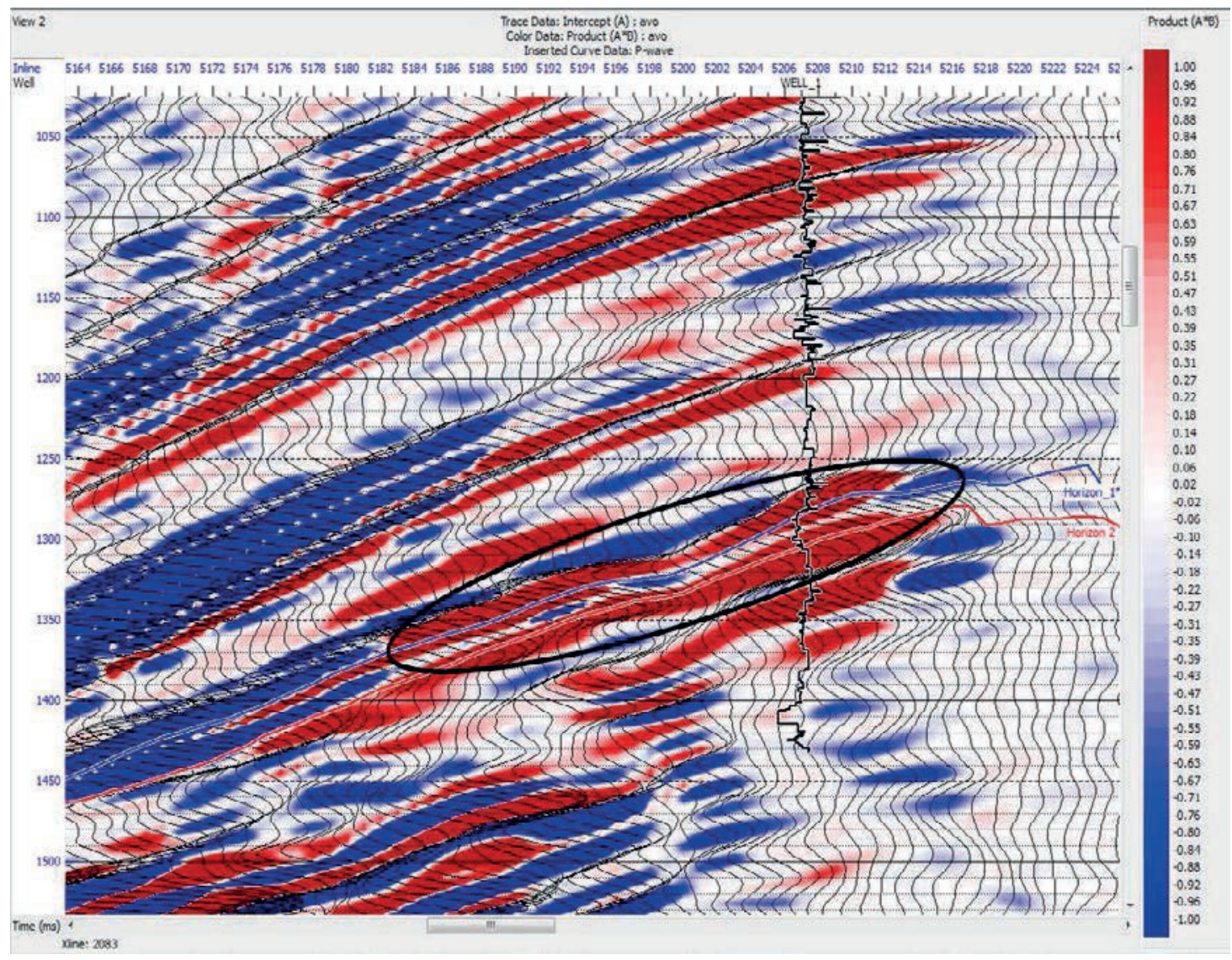

Figure 16. $A * B$ product in a seismic section. The scale shows $A * B$ values from 1 to

-1. The ellipse shows the target zone. 


\section{Scaled Poisson`s ratio:}

As the ratio of $V_{P}$ to $V_{S}$ can provide indications of fluid content (gas, oil, water), the $\mathrm{V}_{\mathrm{P}} / \mathrm{V}_{\mathrm{S}}$ ratio, or, equivalently, Poisson's ratio, is very useful. Scaled Poisson's ratio change was derived from the AVO attributes, as shown figure 17. Normally Poisson's ratio has an upper limit of 0.5 and lower limit of 0 . The scale in Figure 17 is for "scaled" Poisson's ratio change, emphasizing the changes at interfaces, and recognizing that the true value is not calibrated; as such, it ranges between -1 and +1 . For the target zone, scaled Poisson`s ratio change shows a negative response at the top of the reservoir (in orange, a decrease in Poisson's ratio) and a positive response at the base (in yellow, an increase in Poisson's ratio) suggesting hydrocarbon potential at the reservoir.

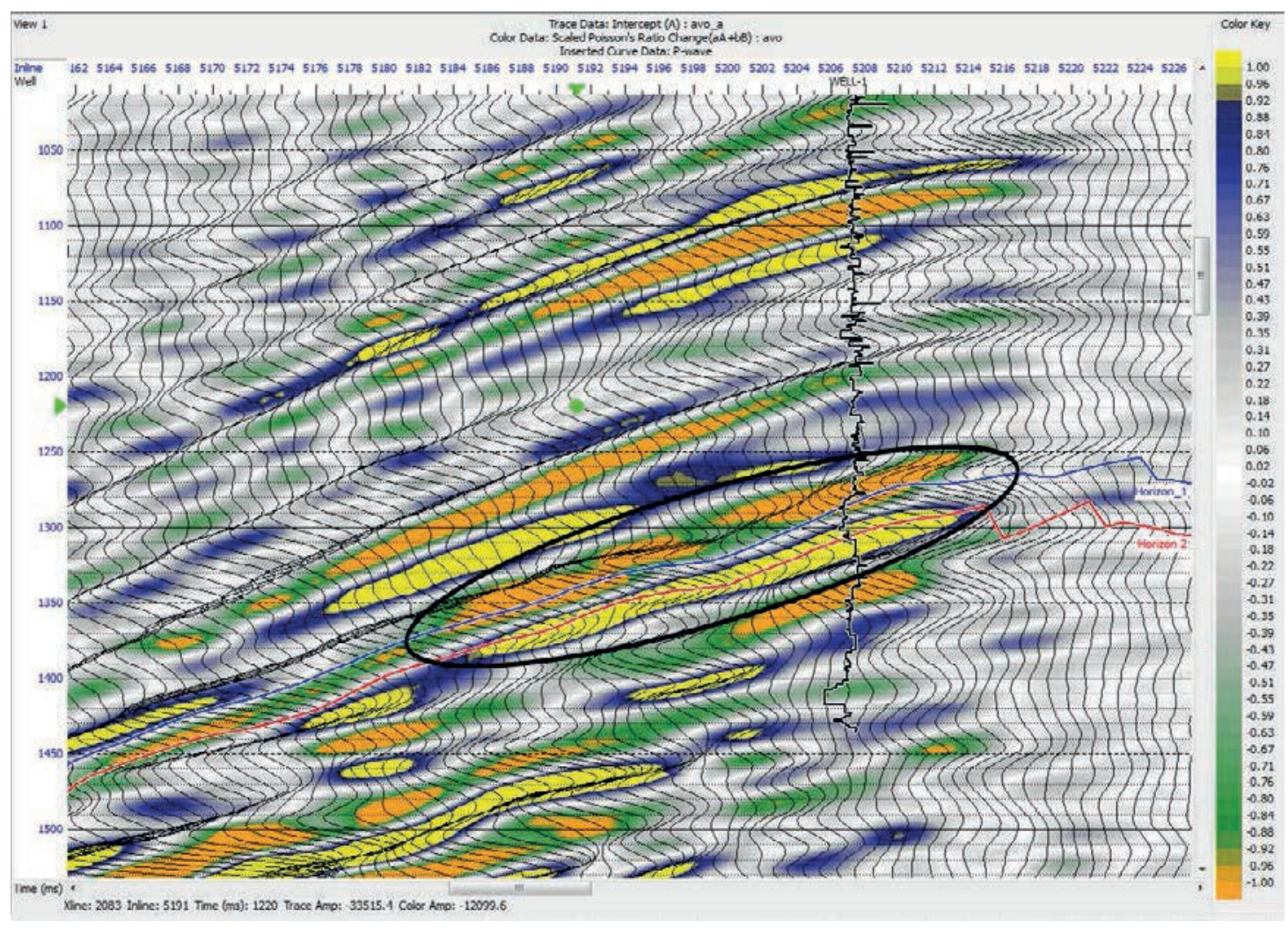

Figure 17. Scaled Poisson's ratio change. The scale shows the relative change in Poisson's ratio. The circle shows the target zone. Scaled Poisson's ratio change is negative at the top of the reservoir (in orange) and positive at the base (in yellow). 


\section{AVO cross plot:}

After AVO attributes were created, we are ready to display AVO cross plot. AVO cross plot helps to determine background trends and to identify anomalies, or departures from those trends. Hydrocarbon related "AVO anomalies" may show increasing or decreasing amplitude variation with offset. Conversely, brine-saturated "background" rocks may show increasing or decreasing AVO. "AVO anomalies" are properly viewed as deviations from this background and may be related to hydrocarbons or lithologic factors (Castagna, 1997). AVO cross plot was plotted as intercept versus gradient, shown Figure 18. The scale shows time in color. The red ellipse includes points that likely represent the top of a potential reservoir, and the blue ellipse includes points that likely represent the base of a reservoir; the general background trend is shown in green. 


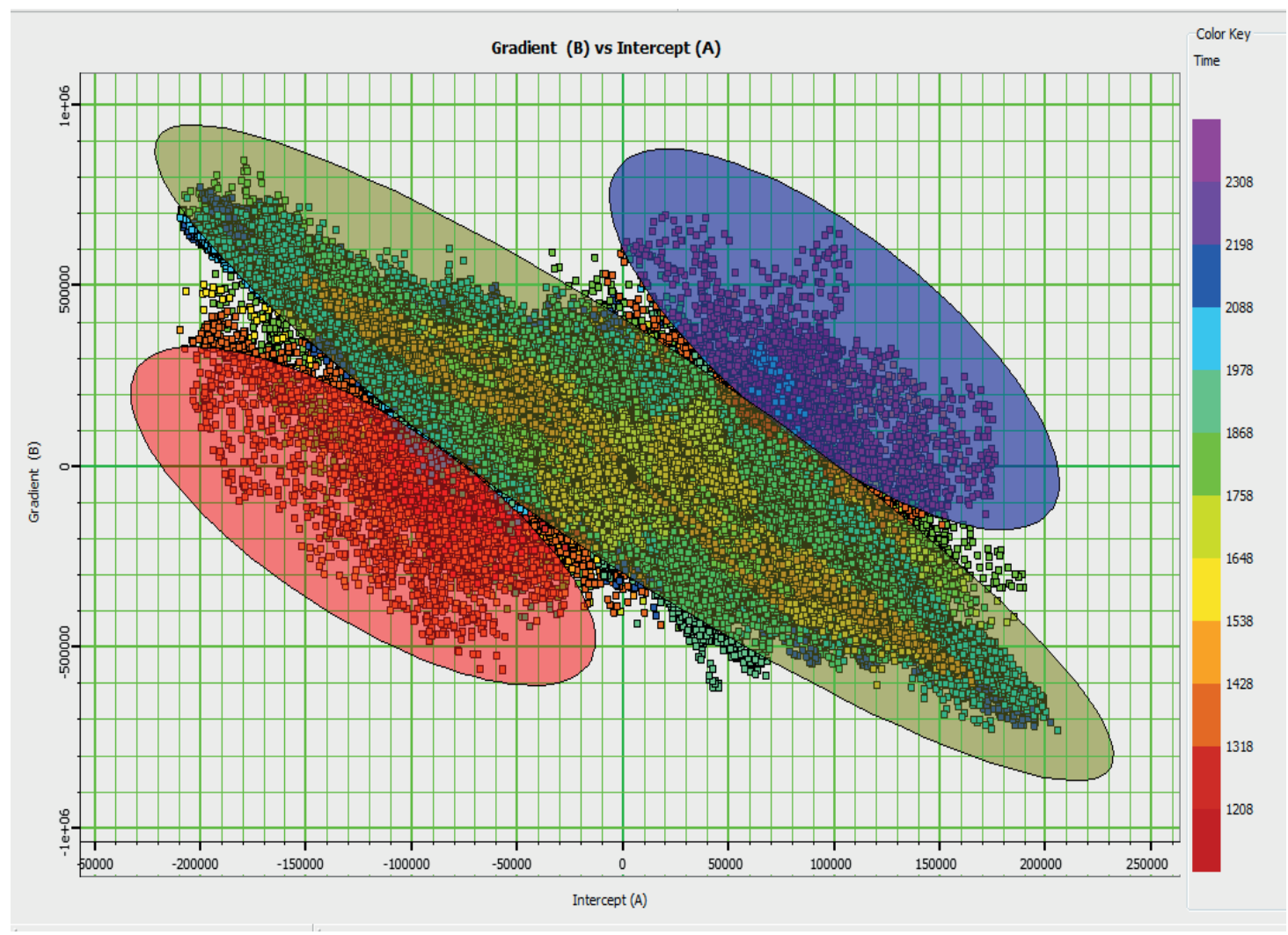

Figure 18. AVO cross plot. Gradient (B) versus intercept (A). The scale shows time (ms) in color. AVO cross plot was plotted as intercept versus gradient. The red ellipse shows the top of the reservoir, the blue circle shows the base of the reservoir and the general trend is in green.

Prior to discussion of the AVO analysis results, we will investigate another AVOdependent form of interpretation, Pre-stack, or AVO, inversion. 


\subsection{Pre-stack Inversion}

Pre-stack seismic inversion techniques provide valuable information of rock properties, lithology, and fluid content for reservoir characterization, based on the AVO characteristics of the seismic data. Pre-stack inversion is often conducted by fitting a 3term solution to the data, and the reliability of the results increases with increasing incident angle. The most accurate result of simultaneous pre-stack inversion of P-wave seismic data is P-impedance, which can be performed on short-offset data. S-impedance estimation becomes reliable as incident angles approach $30^{\circ}$, whereas density evaluation (and other derived elastic constants) becomes reliable only as incident angles approach $45^{\circ}$.

\section{Advantage of the pre-stack inversion:}

We now extend the AVO theory to the pre-stack inversion case. In a post-stack inversion, we assume that the seismic ray strikes the boundary between two geological layers at an angle of zero degrees. In the pre-stack case, the angle of incidence is greater than zero, and an incident $P$-wave at any non-normal angle results in both reflected and transmitted $P$ and $S$-waves, and the amplitudes of those reflected and transmitted waves can be computed using the Zoeppritz equations (Zoeppritz, 1919). Simultaneous inversion refers to performing the AVO extraction and computing the seismic impedance together. The inversion can be performed either to solve for a 3-term approximation to Zoeppritz (sometimes incorrectly called the complete solution) or a 2term solution. In practice, we use a modification of this solution.

\section{Equations for pre-stack inversion:}

Hampson et al. (2005) extend the work of Simmons and Backus (1996) and Buland and Omre (2003) to develop a new approach to yield P-impedance, S-impedance, and density as inversion products. Fatti et al. `s equation is formulated as (Buland et. al., 2003):

Modified Fatti equation:

$\mathrm{R}(\theta)=0.5 \mathrm{c}_{1} \mathrm{~W}(\theta) \mathrm{DLp}+0.5 \mathrm{c}_{2} \mathrm{~W}(\theta) \mathrm{DLs}+\mathrm{c}_{3} \mathrm{~W}(\theta) \mathrm{DL} \mathrm{D}_{\mathrm{D}},($ Fatti, 1994) 
$\mathrm{W}(\theta)$ are the angle-dependent wavelets, $\mathrm{D}$ is the derivative matrix, and the $\mathrm{L}$ parameters are the natural logarithms of impedances and density: $\mathrm{Lp}=\ln (\mathrm{AI}), \mathrm{L}_{\mathrm{D}}=\ln (\rho)$ and $\mathrm{Ls}=$ $\ln (\mathrm{SI})$.

The Fatti equation solves AI reliably, but SI is less reliable, and density is poorly resolved. This is because the $c_{2}$ factor defining the shear wave is smaller than the $\mathrm{c}_{1}$ factor, and the $\mathrm{c}_{3}$ factor is small. Again, SI requires offsets out to about $30^{\circ}$, and density requires greater angles (as do all other parameters that require density to be removed from acoustic or shear impedances, such as Vp, Vs, bulk modulus, and shear modulus or rigidity).

\section{Pre-stack inversion analysis:}

Many aspects of pre-stack inversion are similar to those for post-stack (or "acoustic") trace inversion. One needs to identify a wavelet and to create a "low-frequency" volume

of the parameters being solved for. But because some parameters are different from the post-stack case, they need special attention. We initially use a 3-term solution in this study, in spite of the angle range limitation in our data.

\section{Estimation shear modulus:}

We need a shear-wave velocity log to perform pre-stack inversion, yet none was available from the wells in the area. Castagna's equation was used to create a shearwave velocity log from the Vp log, using the mudrock equation (Castagna, 1985).

$$
\left.V_{P}=1.16 V_{S}+1.36 \text { (with units in } \mathrm{km} / \mathrm{s}\right)
$$

\section{Extracted wavelets:}

Two wavelets were extracted; a $16^{\circ}$ near-angle wavelet and a $31^{\circ}$ far-angle wavelet, as shown Figure 18. This helps to counter frequency-dependent absorption and NMOstretch that usually cause the far angle wavelets to be lower in frequency. 


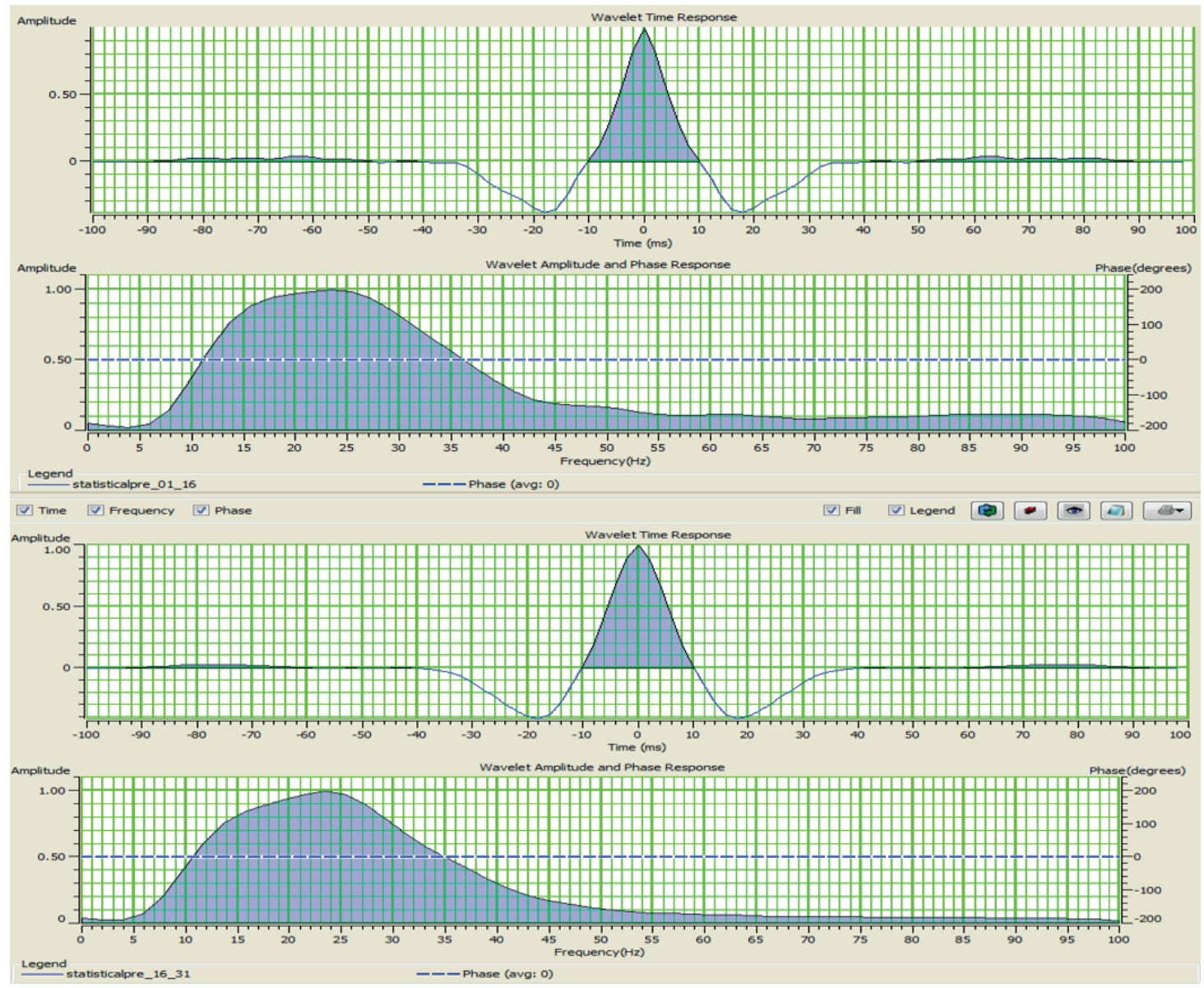

Figure 19. Two extracted wavelets, a $16^{\circ}$ (top figure) near-angle and a $31^{\circ}$ (bottom figure) far-angle wavelet. 


\section{Initial model:}

Initial models were created for S-impedance (SI), P-impedance (AI) and density (Dn) from the well logs, as shown Figure 20, in order to provide a starting point for the inversion process and to guide the low-frequency trends.

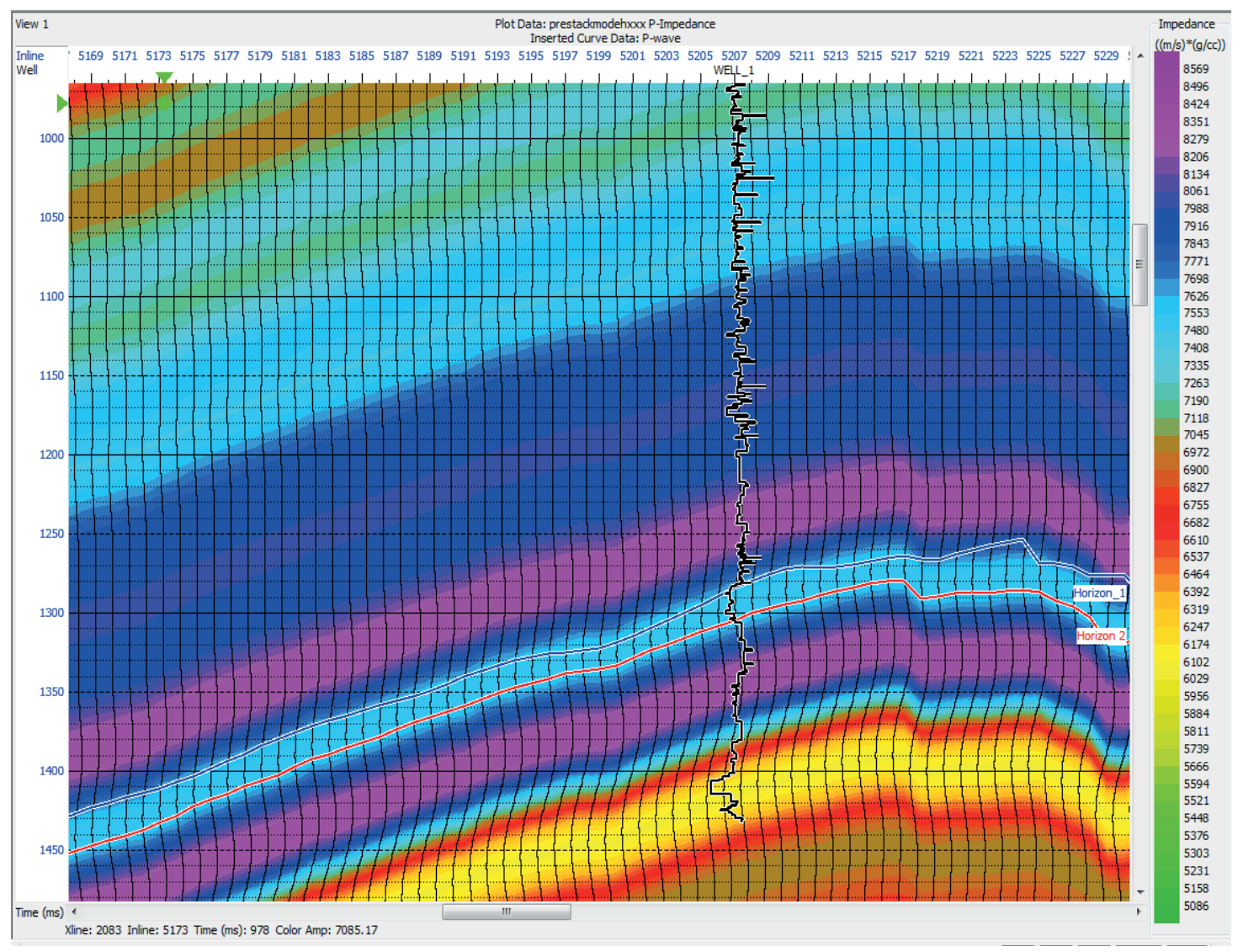

Figure 20. Initial pre-stack inversion model (P-impedance) with picked horizons on crossline 2083 intersecting Well-1. The color scale shows P-impedance in $\mathbf{m} / \mathbf{s} * \mathbf{g} / \mathbf{c c}$. 


\section{Background trend coefficients, synthetic and misfit calculations:}

Regression line fitting and regression coefficients were calculated via well logs. Synthetic traces were generated for each angle using the extracted wavelets. The difference between these synthetic gathers and the real gathers was minimized in an iterative solution, retaining adherence to AVO characteristics required by solutions to the 3-term approximation, yielding $\mathrm{P}$ impedance (AI), S-impedance (SI) and density (Dn). From these parameters, Vp, Vs, bulk modulus, and shear modulus or rigidity can also be calculated.

\section{P-impedance Volume:}

Lines from the final P-impedance volume are shown in Figures 21 and 22 along with the picked horizons. Our target horizon displays lower P-impedance value than surrounding formations. Low acoustic impedance can suggest potential reservoir rock and hydrocarbon content for our target zone, but is not proof of that. 


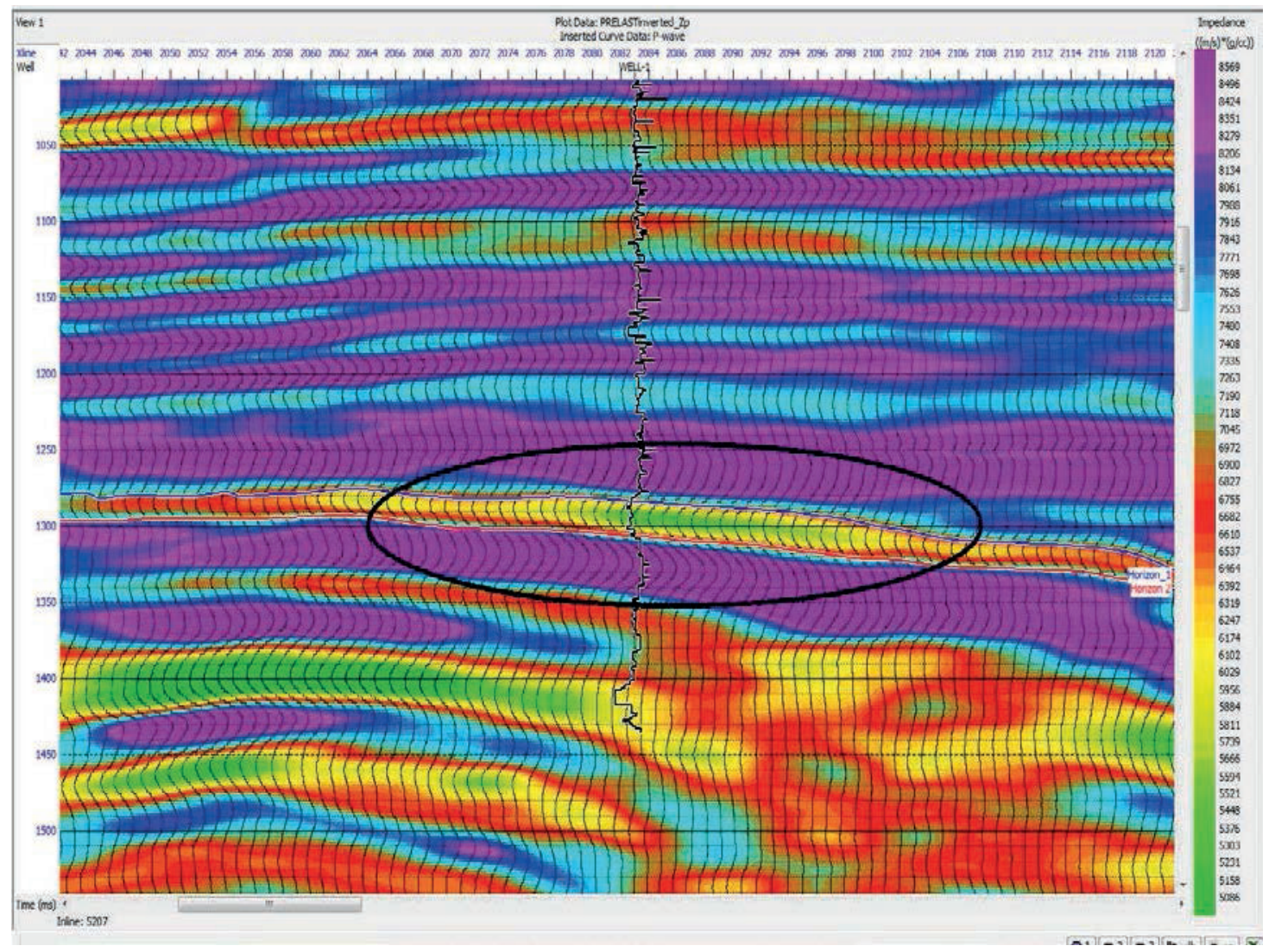

Figure 21. P-impedance volume (inline \#2083). The color scale shows the values, with green representing low values and purple representing higher values. The ellipse shows the target zone. 


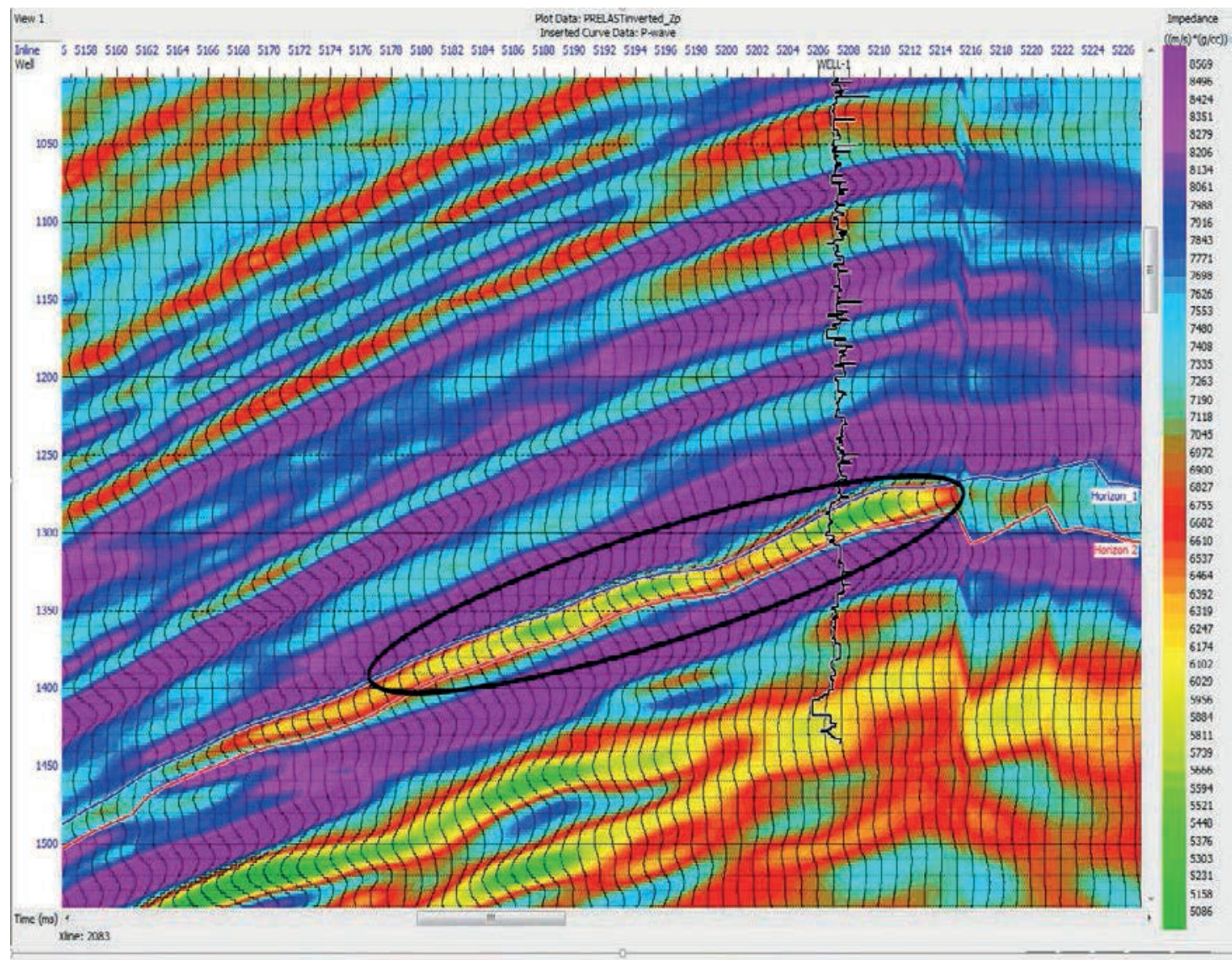

Figure 22. P-impedance volume (crossline \#5207). Scale and other features as in

Figure 21. 


\section{S-impedance volume:}

S-impedance volume is displayed in Figures 23 and 24. It can be observed that the target zone exhibits a lower S-impedance than surrounding formations. This may or may not be indicative of good reservoir rock, and has little bearing on hydrocarbon content by itself.

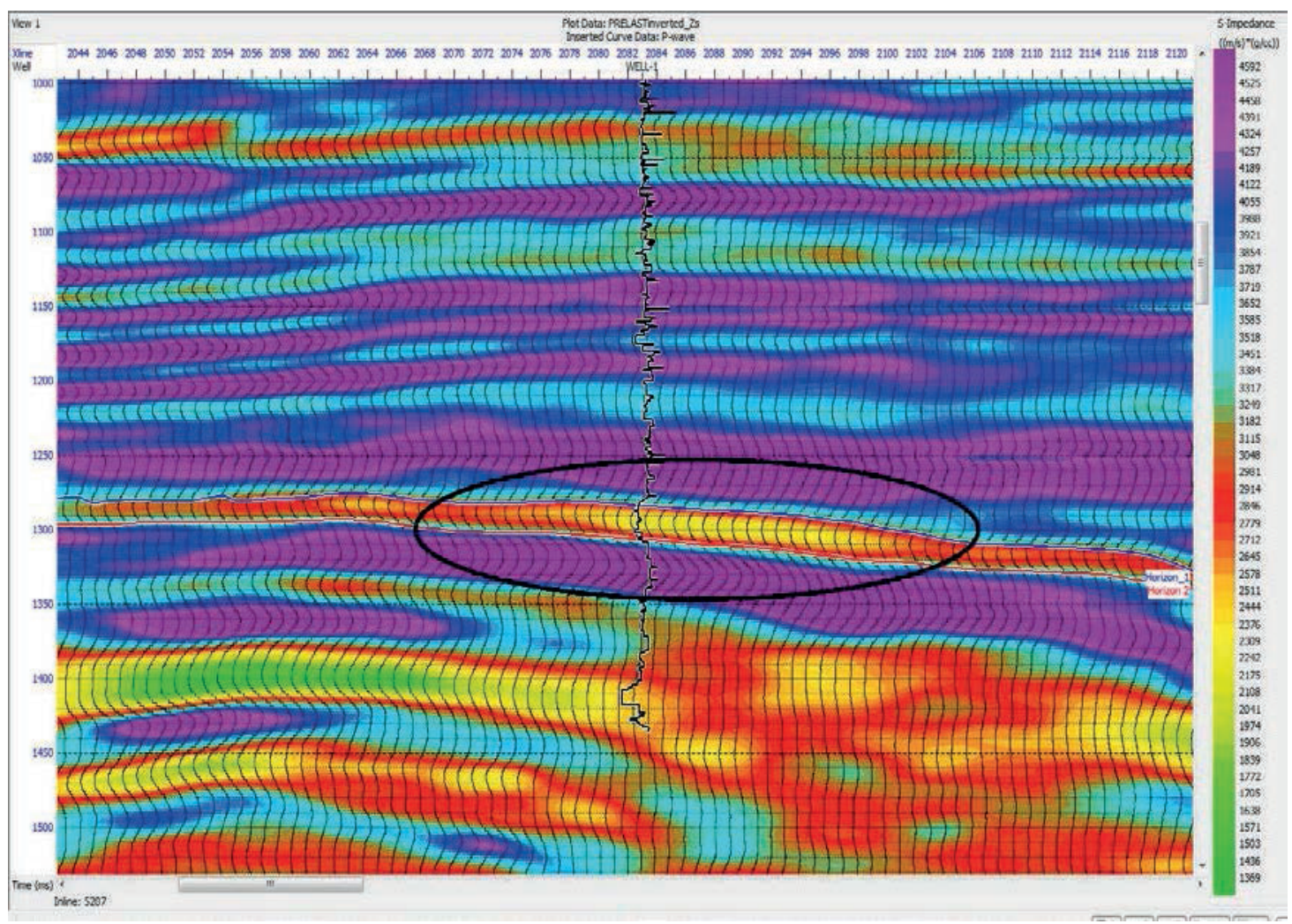

Figure 23. S-impedance volume (inline \#2083). Scale and other features as in Figure 21. 


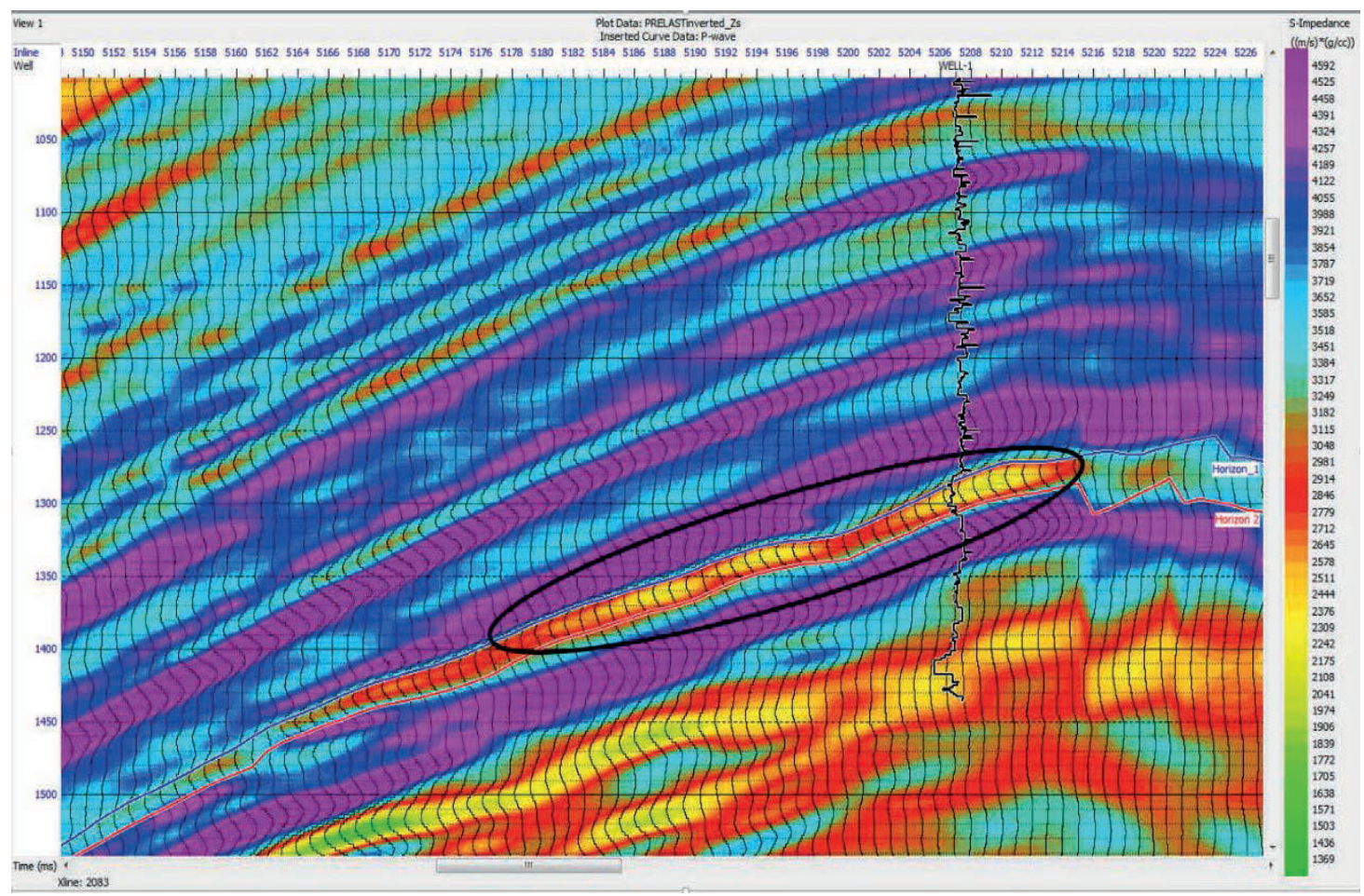

Figure 24. S-impedance volume (crossline \#5207). Scale and other features as in Figure 21.

\section{Density volume:}

Density volume is displayed in Figures 24 and 25. Notice that the target zone marked with ellipse has lower density values then surrounding formations, but also recall that if the angle range is limited, as in this case, the density results will mimic the AI results. 


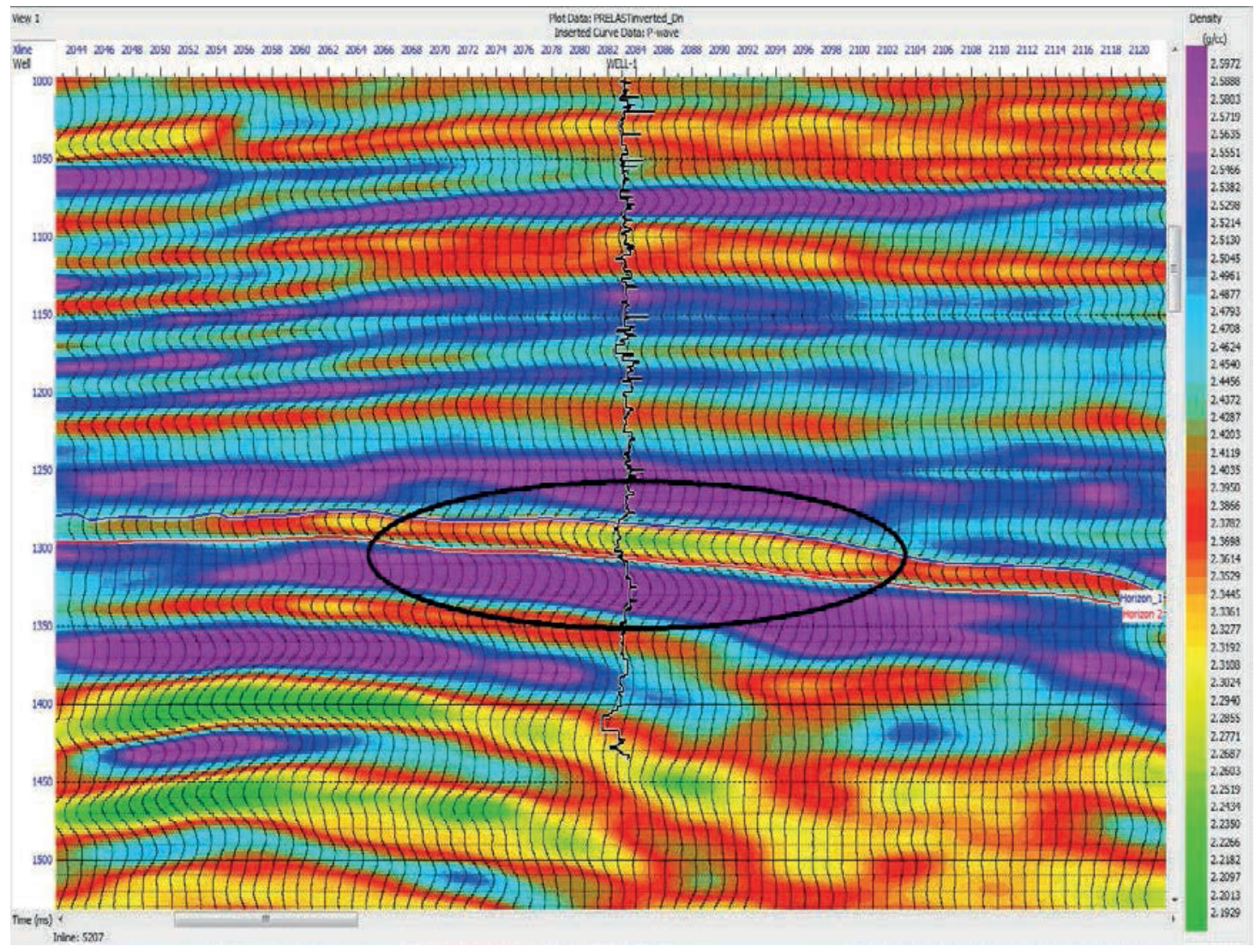

Figure 25. Density volume (inline \#2083). Scale and other features as in Figure 21. 


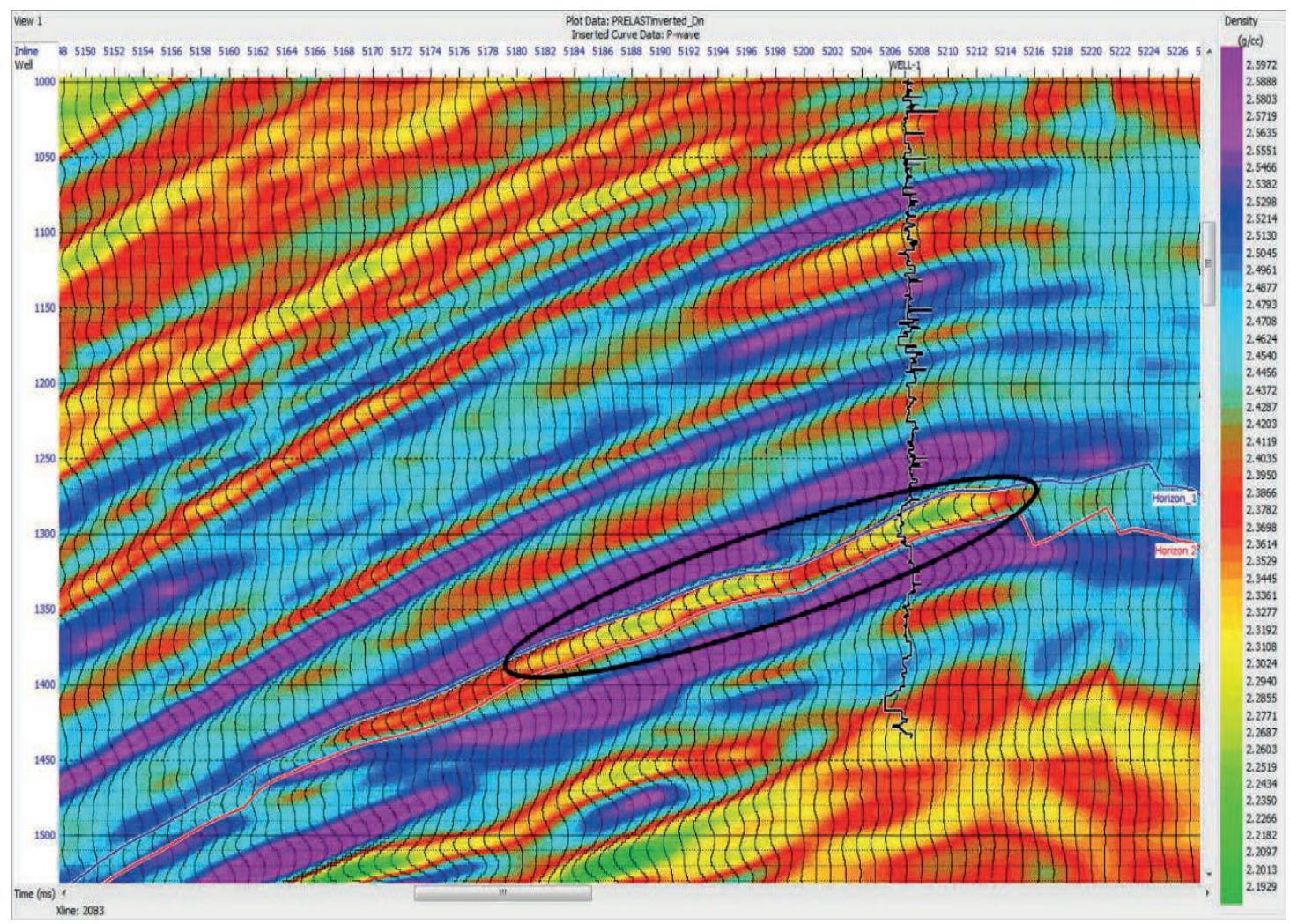

Figure 26. Density volume (crossline \#5207). Scale and other features as in Figure

\section{1.}

\section{Shear modulus:}

The shear modulus (or rigidity) should be unaffected by fluid content (e.g., Mavko, et al., 1998). This was calculated from S-impedance and density, with the results shown in Figures 26 and 27. Notice that the target zone marked with ellipse has lower shear modulus values than surrounding formations. 


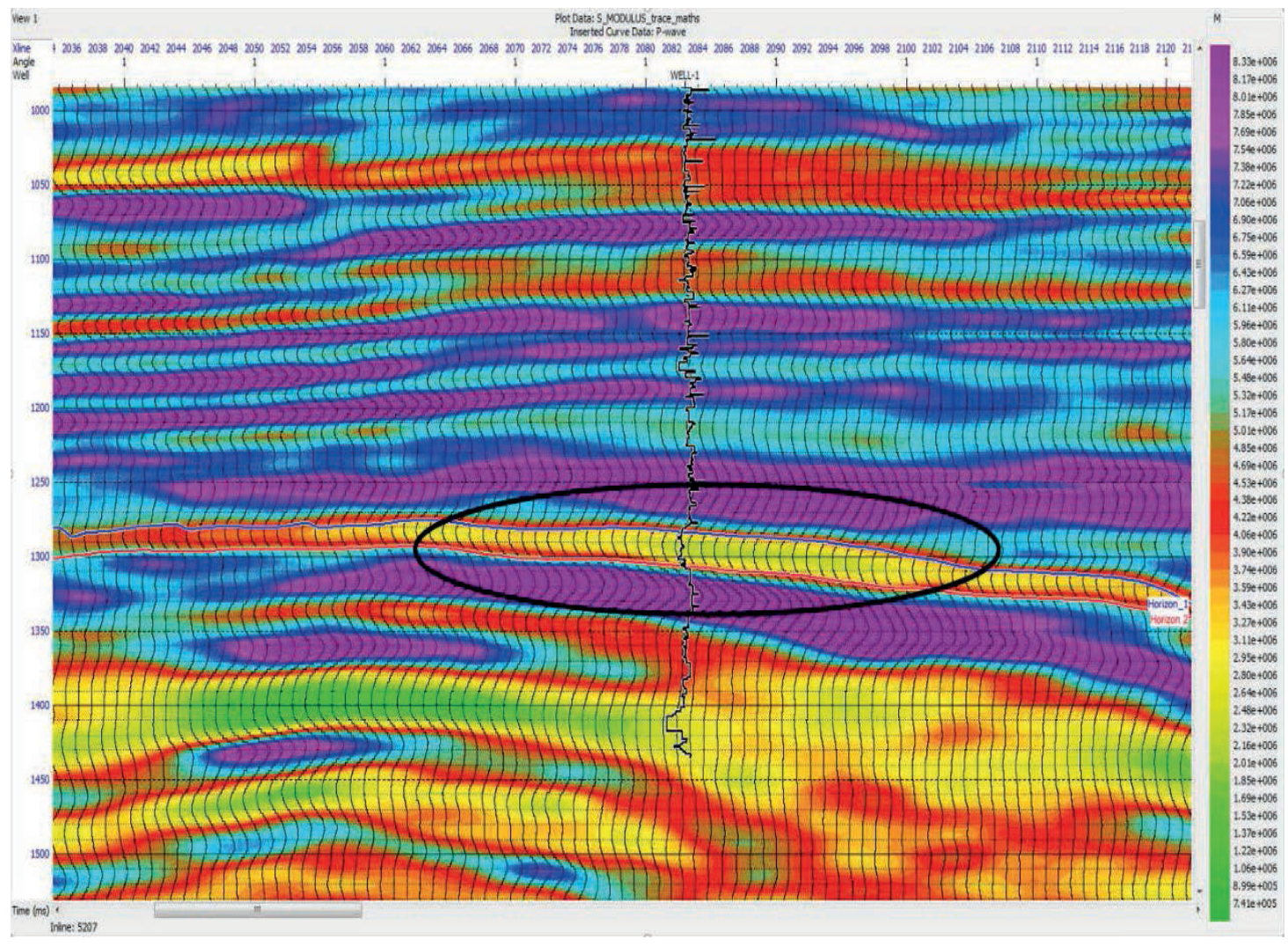

Figure 27. Shear modulus volume (crossline \#2083). Scale and other features as in

Figure 21. 


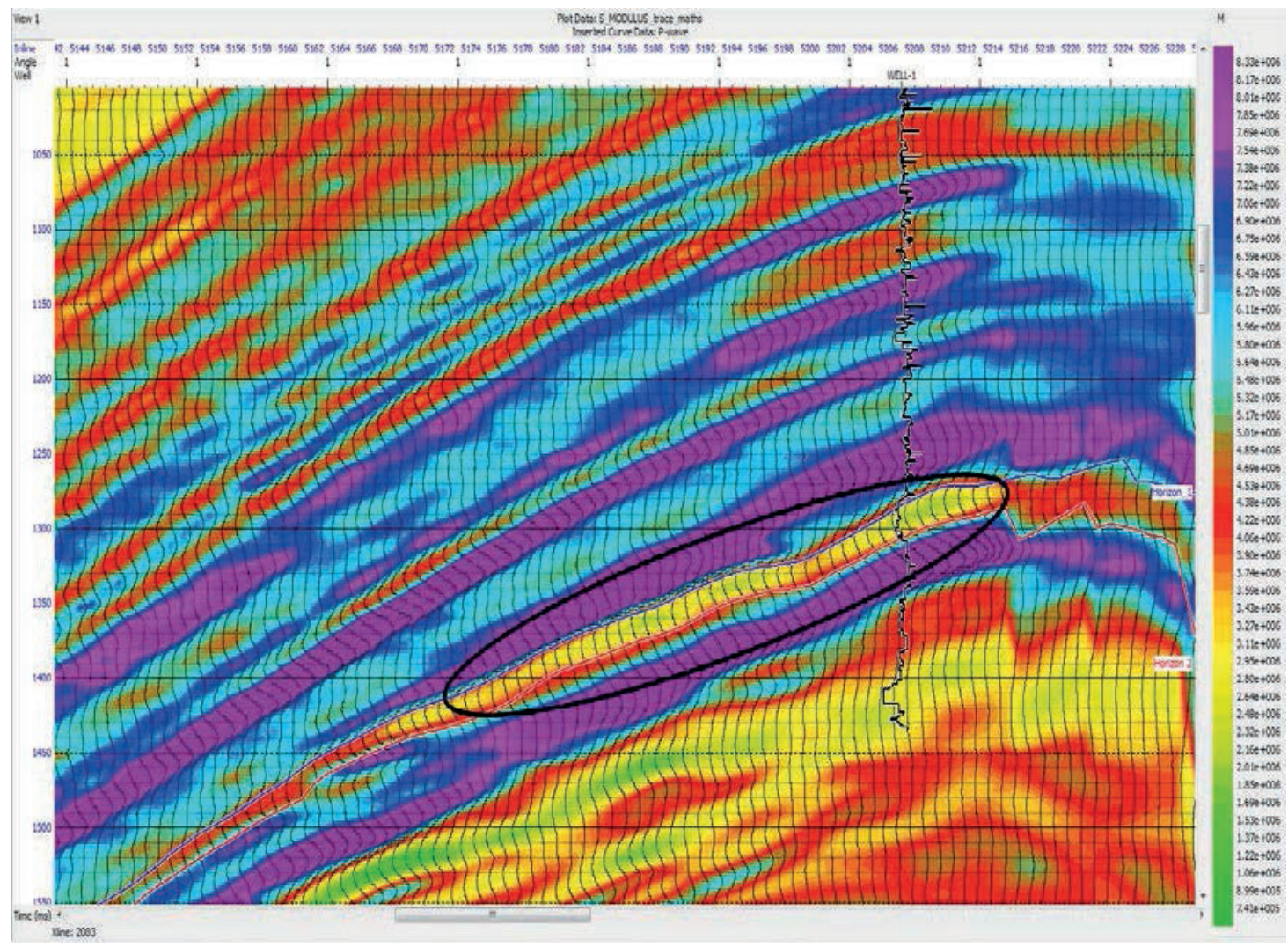

Figure 28. Shear modulus volume (inline \#5207). Scale and other features as in

Figure 21. 
The volumes of lowest $\mathrm{P}$ impedance 3D model can be extracted from pre-stack inversion.

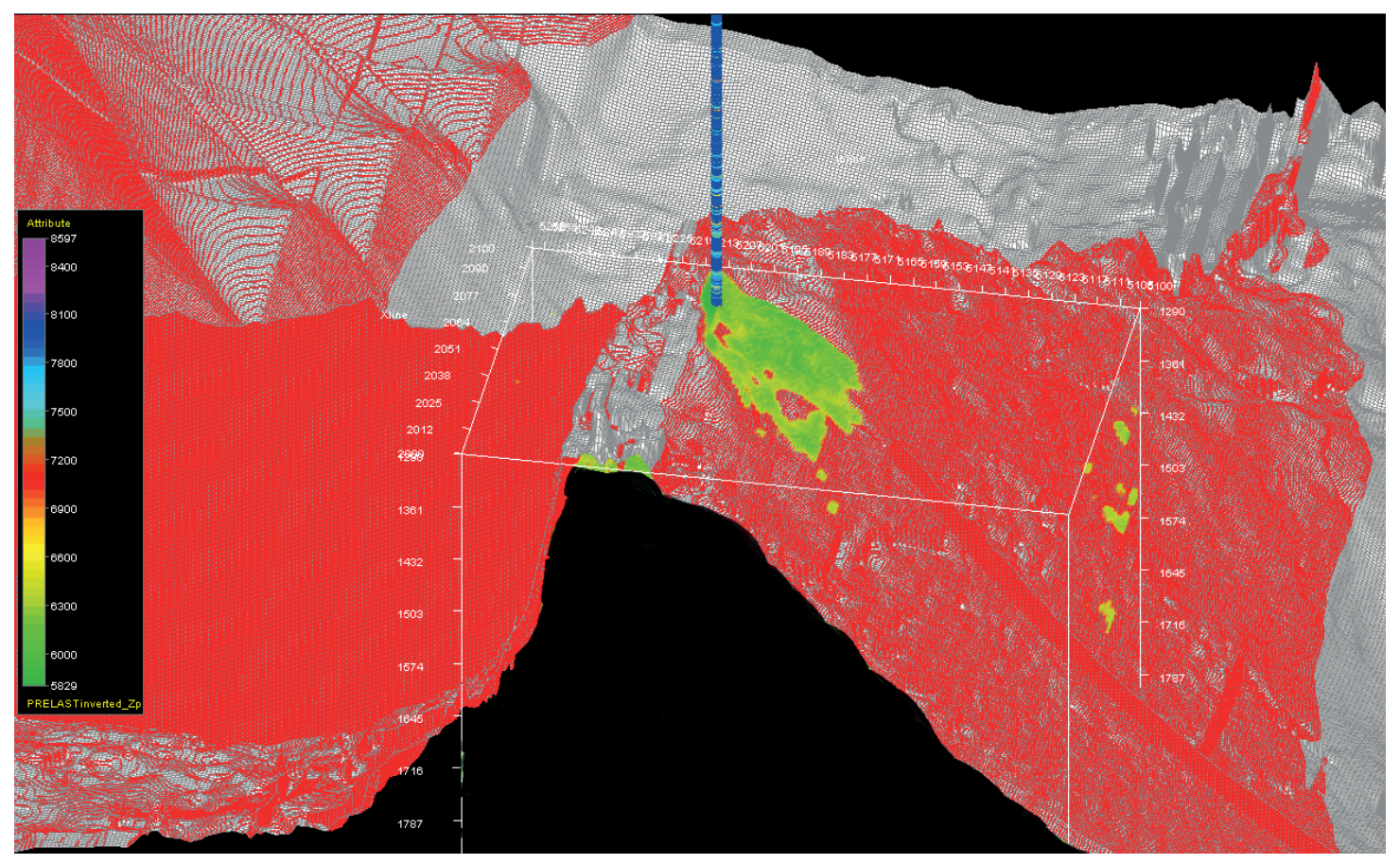

Figure 29. The volume of lowest $P$ impedance 3D model for the target horizon. 


\subsection{LMR attribute}

The lambda-mu-rho (LMR) attribute was proposed by Goodway (1997) for the purpose of finding an "incompressibility" (lambda) related primarily to fluid-like properties, and rigidity $(\mathrm{mu})$ related primarily to rock-like properties, to help determine fluid and lithology (Chopra et al., 2014). By keeping the density (rho) is a factor with each elastic constant, the solution could be obtained from a 2-term solution, and is less dependent on very wide angles. We can estimate LMR parameters, Lambda-Rho $(\lambda \rho)$ and Mu-Rho $(\mu \rho)$, volumes from the equations below (Goodway, 1997):

$\lambda \rho=\mathrm{AI}^{2}-2 \mathrm{SI}^{2}$

$\mu \rho=\mathrm{SI}^{2}$ 


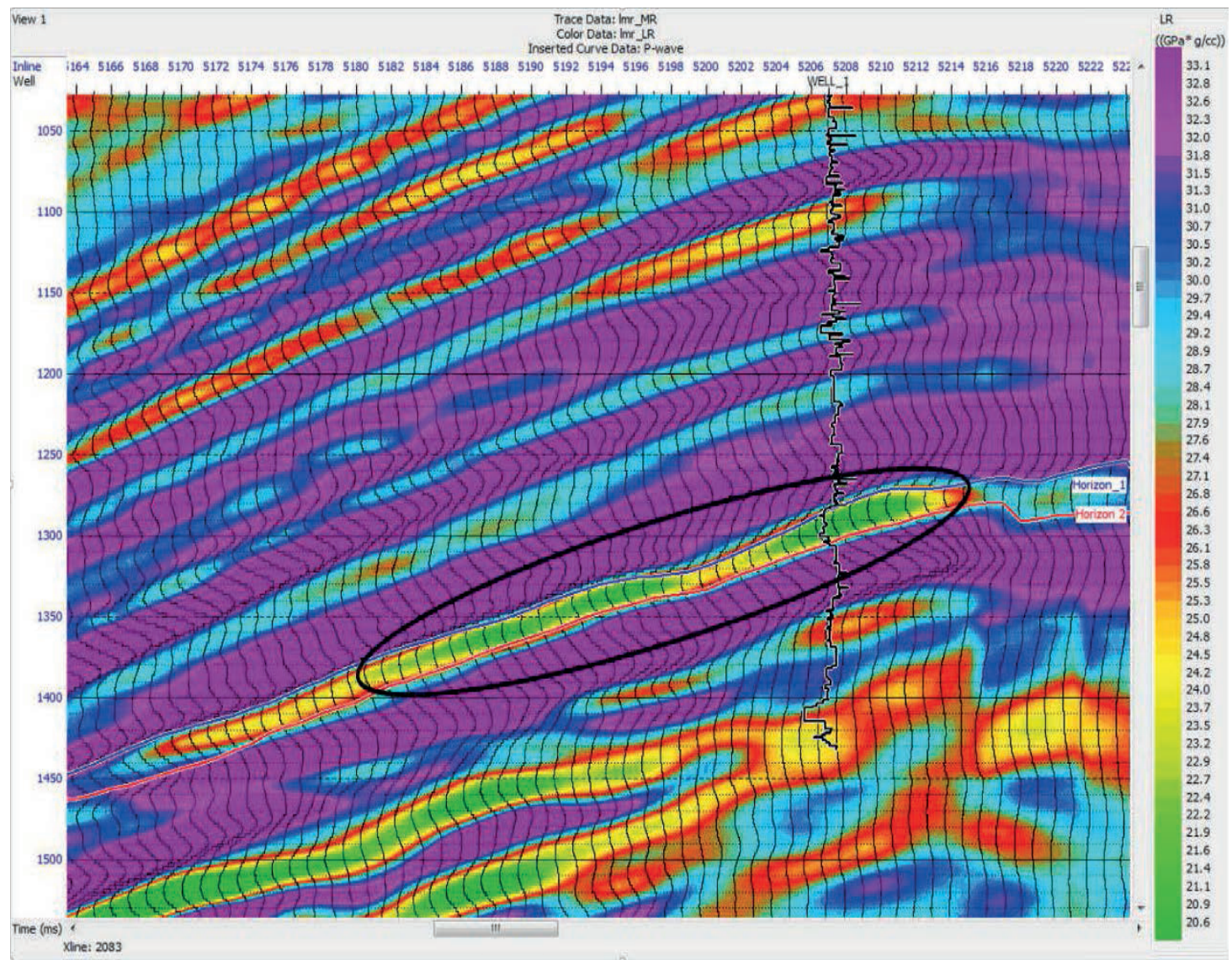

Figure 30. Lambda-rho volume (crossline \#2083). The color scale shows values $\left(\mathrm{GPa}^{*} \mathrm{~g} / \mathrm{cc}\right)$. The ellipse shows the target zone. 


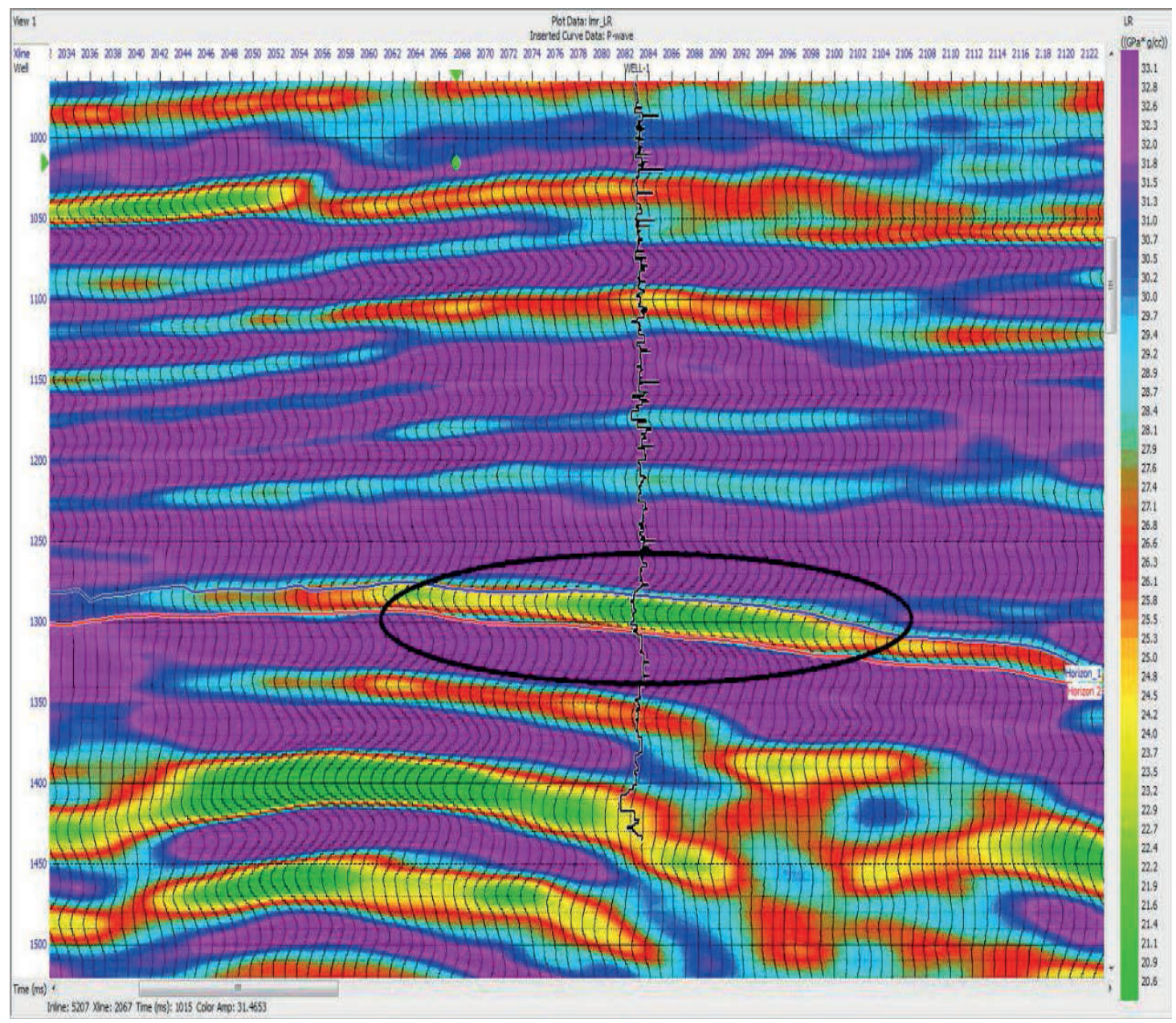

Figure 31. Lambda-rho volume (inline \#5207). Scale and other features as in

Figure 30. 


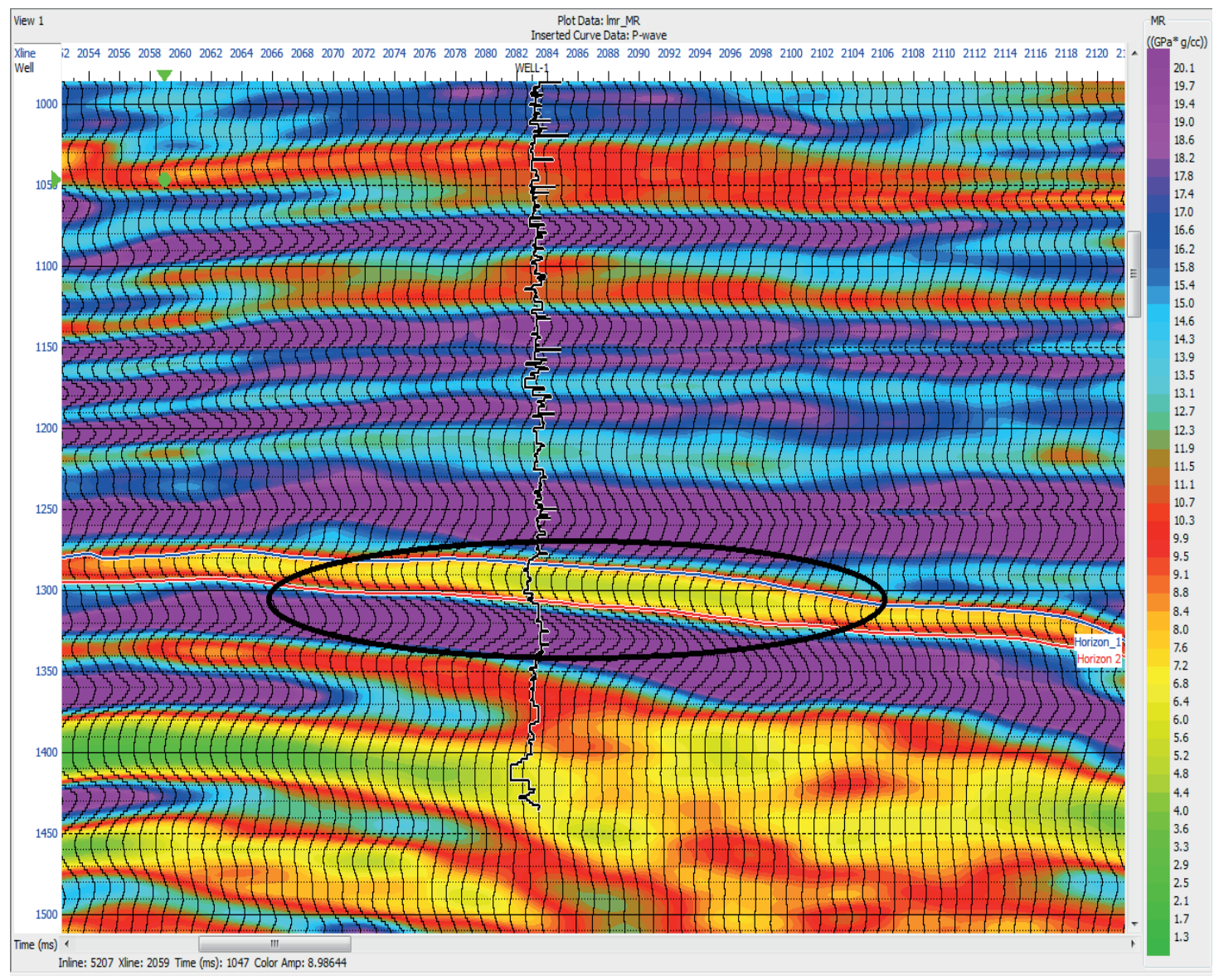

Figure 32. Mho-rho volume (inline \#2083). Scale and other features as in Figure 30. 


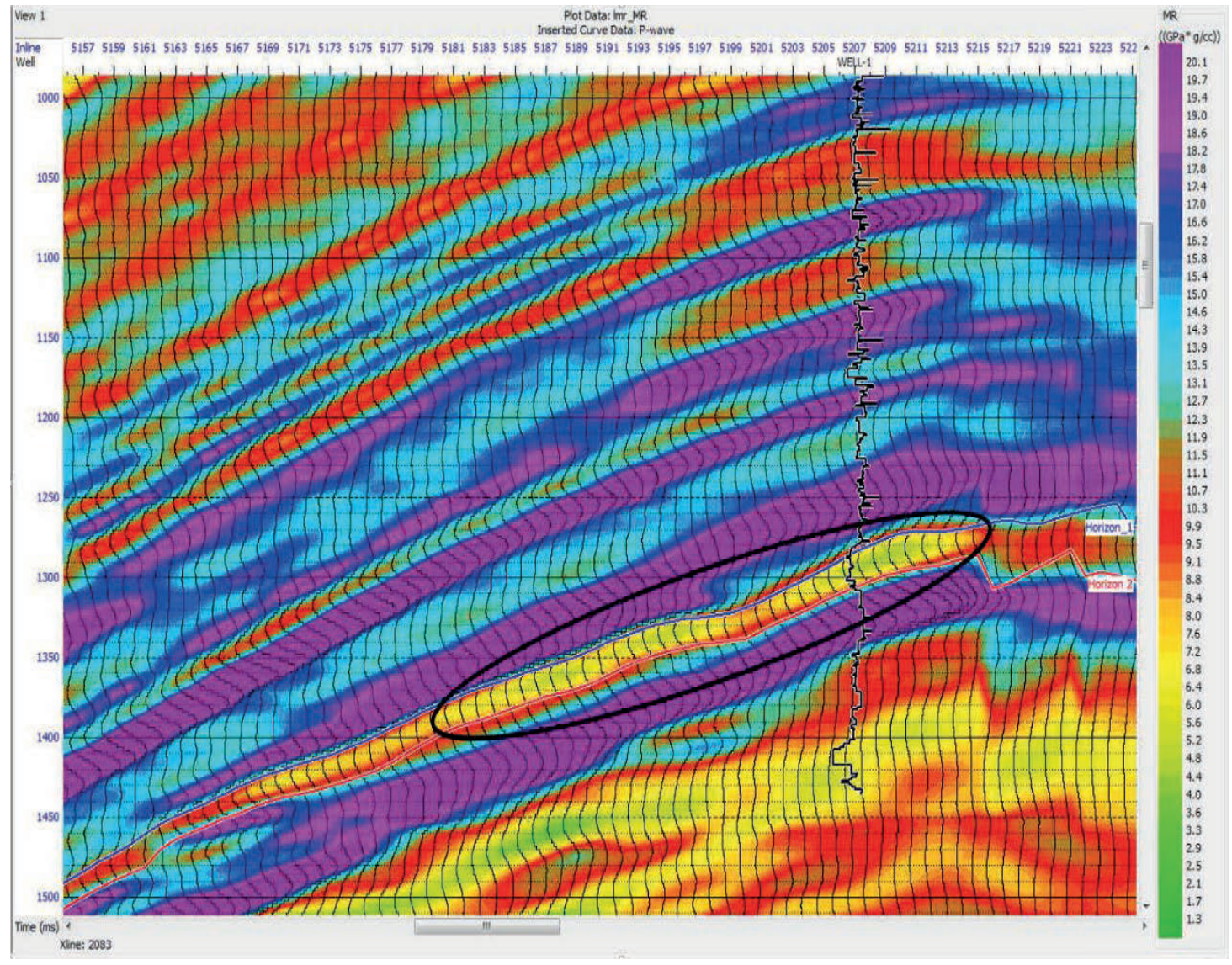

Figure 33. Mho-rho volume (crossline \#5207). Scale and other features as in Figure 30. 


\section{Chapter 5: Results and discussion}

AVO analysis and pre-stack inversion were performed in the Thrace Basin, Turkey. After pre-stack data enhancement process (super gather, trim static and angle gather), AVO analysis was performed for four different ranges of the Radon filter (Figure 3942). It was observed that the data points best fit the theoretical AVO curves at the $+/-50$ ms range (Figure 3). In addition, the potential-hydrocarbon deviation from the general trend can be observed using data filtered with this setting (Figure 18).

A two-term approximation to Zoeppritz equations fit the data well after the Radon filtering, recognizing a maximum angle of approximately $33^{\circ}$. Density solutions were not obtained from angle gathers because of small angles at the target horizon.

The results of the AVO analysis seem, at first glance, to support the possibility that good reservoir rock is present, and hydrocarbons may be indicated. The intercept-gradient product, $\mathrm{A} * \mathrm{~B}$ (Figure 16) shows a classical bright spot response with AVO class 3 anomaly in the target horizon. Scaled Poisson's ratio change (Figure 17) suggests a potential reservoir zone due to the strong contrast, with the top of the reservoir displaying a decrease; this may often be interpreted to be a result of the presence of hydrocarbons. The AVO cross plot (Figure 18) suggests that deviations from the background may be interpreted as hydrocarbons or unusual lithologies.

We plot the seismic data, with the departures from background $\mathrm{A} * \mathrm{~B}$ values highlighted, in Figure 33. The top of the reservoir (horizon 1) is displayed in red, indicating lower values (larger negative values) of A and B the base of the target reservoir (horizon 2) in blue (larger positive values), and the general background trend is shown in green. 


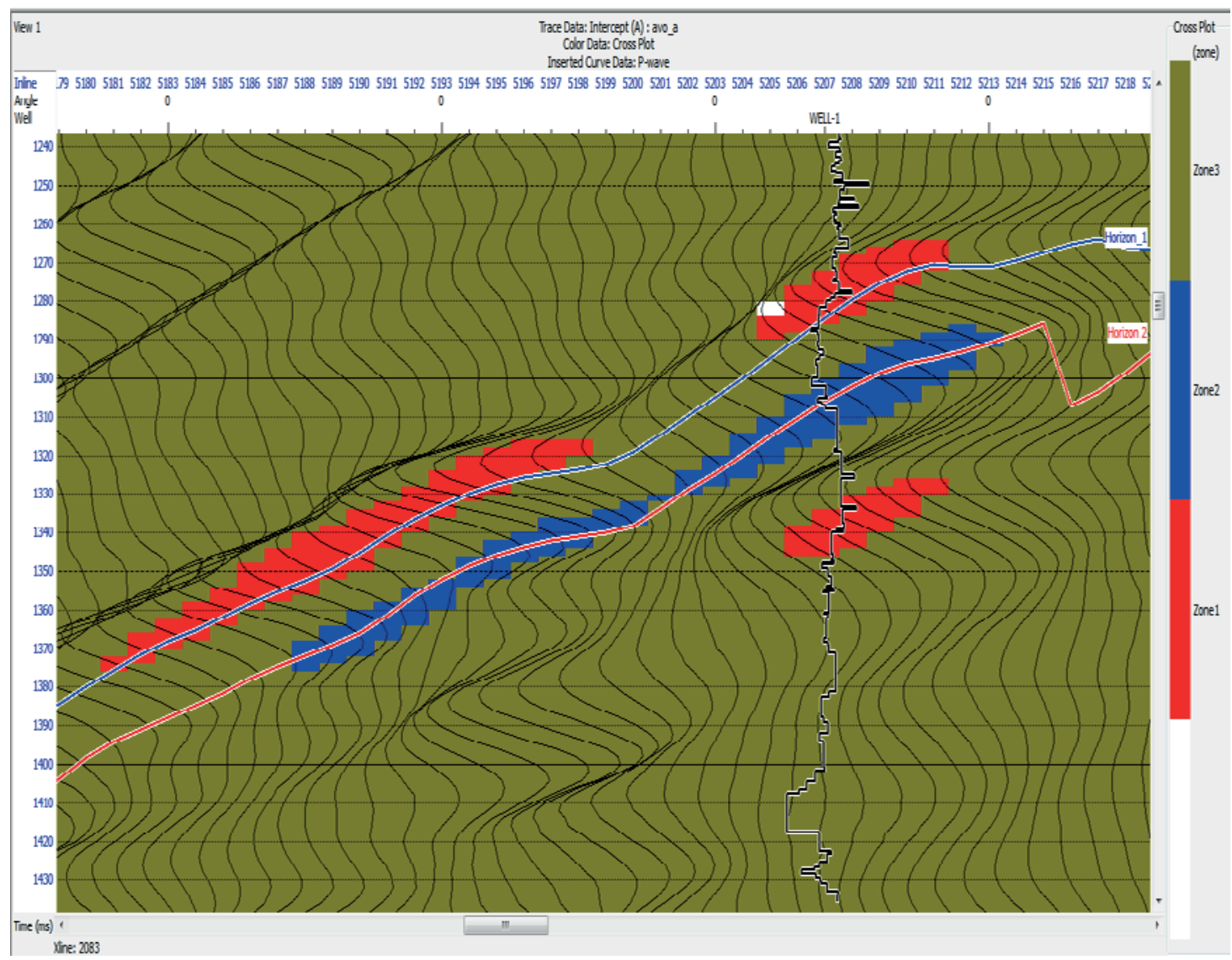

Figure 34. AVO anomalies plotted on trace data. (Figure 18 was used to obtain this figure. The data points included in the red ellipse represent as the red color (the top) on trace data, the data points included in the blue ellipse represent as the blue color (the base) on the trace data and the data points included in the green ellipse represent as the green color (the general trend) on the trace data. In Figure 18, the ellipses were drawn based on the deviation of the data points from the general trend). The scale shows three zones in color. The top of the target reservoir displays large negative values of intercept $(A)$ and gradient $(B)$ is in red. The base of the target reservoir displays large positive values and is in blue. The general background trend is in green. 
The 3D AVO anomalies throughout the volume have also been extracted from the trace data and are shown Figure 35.

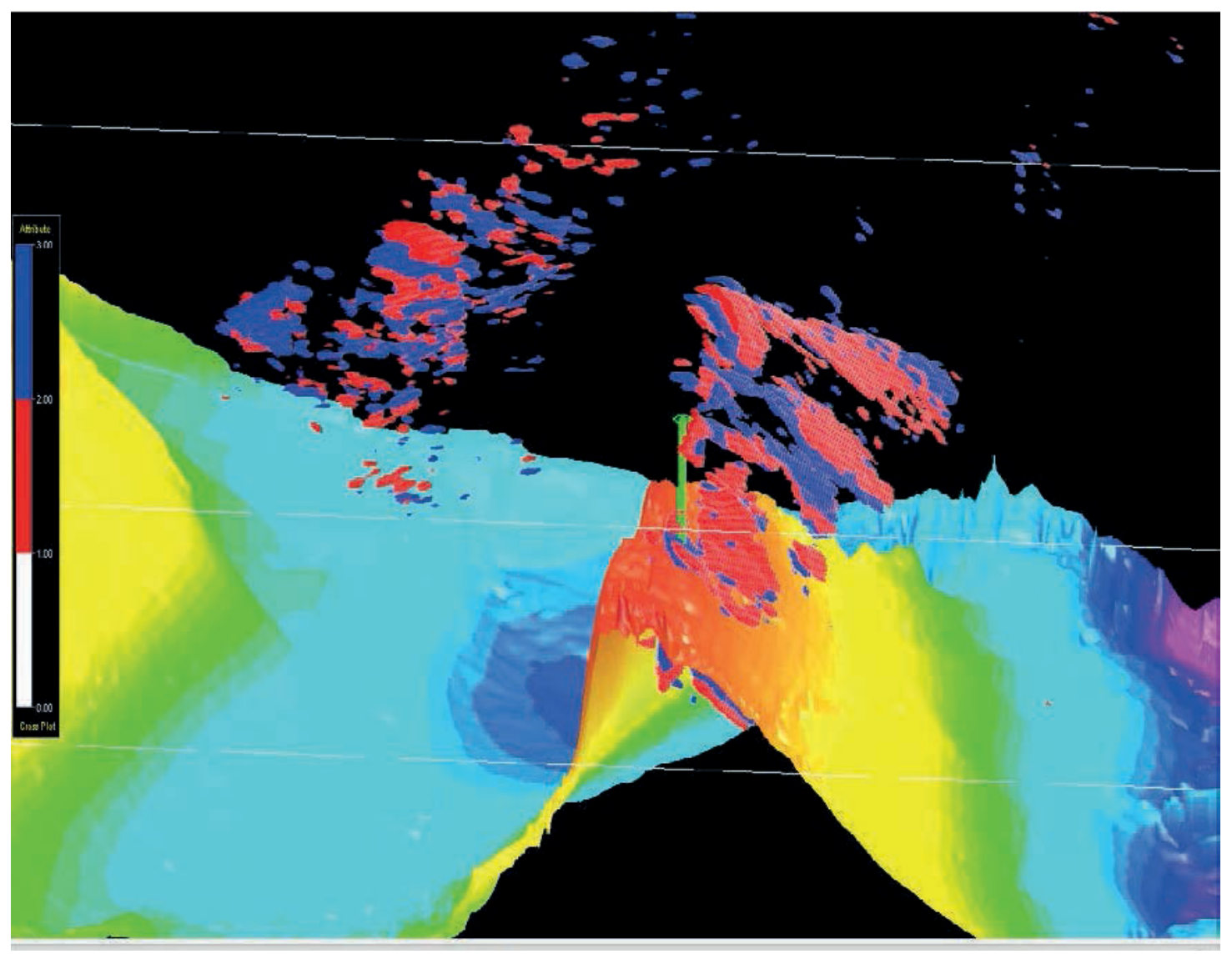

Figure 35. A 3D volume showing the AVO anomaly for the nearby region. The zones and coloring are as in Figure 34, except that the background trend is rendered transparent. 
We also display a 3D view of the AVO anomaly for our target horizon, shown in Figure 36.

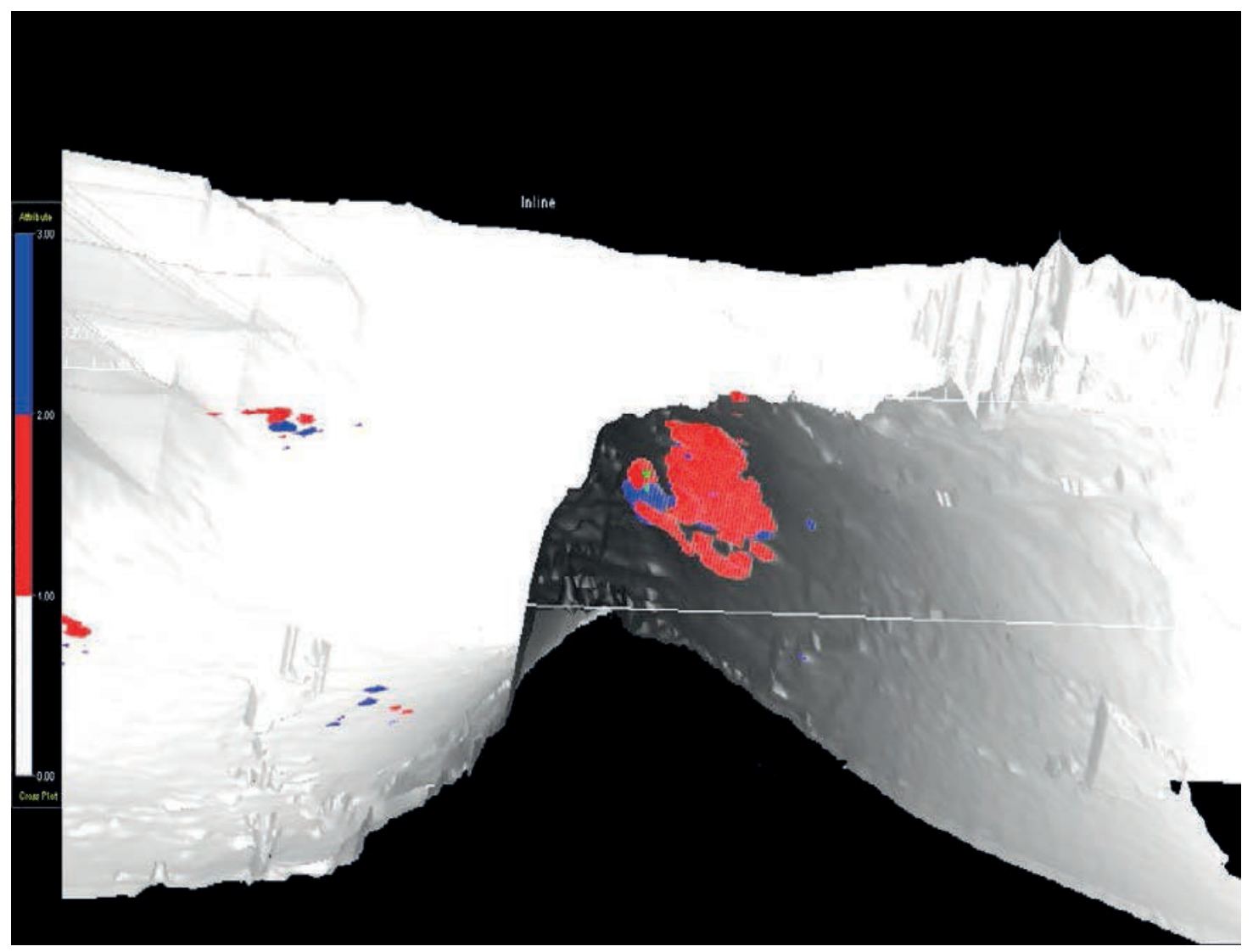

Figure 36. The AVO anomaly for the target horizon. The red represents the top of the target horizon, and the blue represents the base of the target horizon. 
While AVO analysis themselves are often used for interpretation, we wish to strengthen our interpretation, and we incorporated pre-stack inversion and extracted LMR attributes for this purpose. Fatti equation was used to control the pre-stack inversion, and P-impedance, S-impedance, and Density volumes were extracted. Because of the small angles at the target horizon $\left(33^{\circ}\right)$, the density estimation is not very reliable. However, P-impedance and S-impedance estimation are considered reliable.

According to the composite log provided by the operator, the target formation appears to represent a shale oil reservoir at depths of $1535-1565 \mathrm{~m}$. Both methods (AVO analysis and pre-stack inversion) used in this study provided attributes (A, B, A*B, LMR, etc) that are consistent with a potential hydrocarbon reservoir target at 1284-1306 ms at the location of Well-1 (1535-1565 m). 


\section{Chapter 6: Conclusion}

There were many features of the data that could lead an interpreter to conclude that there is a likely hydrocarbon reservoir located at the location indicated in Figure 34, and perhaps others as indicated in Figure 35. But it is worthwhile to take a critical view of these results, as there are some fundamental weaknesses in the analysis so far. These are due to the use of the Radon filter, which affected the AVO results, and to the use of a pseudo-shear log in the simultaneous inversion.

After displaying AVO analysis for four different ranges of the Radon filter, we could observe the intercept (A) and the gradient (B) behaviors in the target formation. It was observed that the gradient (B) is reduced for each subsequent (smaller setting) Radon filter while the intercept (A) stays at approximately the same value. The gradient value is reduced for each the Radon filters that we applied, as shown in the Figure (change in $\mathrm{B}$ as function offset). This is because the far offsets are changed but the near offsets are not, as a result of the Radon filter. B is related to Poisson ratio`s change. Poisson`s ratio change can be used as a fluid indicator in the formation, and is often used for distinguishing fluid effects from the lithologic effects; minimizing the value of B may cause misleading results.

The intercept-gradient product, $\mathrm{A} * \mathrm{~B}$ (Figure 16) shows a classical bright spot response with AVO class 3 anomaly in the target horizon. Scaled Poisson's ratio change (Figure 17) suggests a potential reservoir zone due to the strong contrast, with the top of the reservoir displaying a decrease; this may often be interpreted to be a result of the presence of hydrocarbons. A*B product and Scaled Poisson`s ratio changes are due to the change in the gradient (B).

Castagna`s mudrock equation was used to create a shear-wave velocity log from the $\mathrm{Vp}$ $\log$ in order to perform pre-stack inversion. The S-impedance should then correlate perfectly with the $\mathrm{P}$ impedance at the well, and it will also correlate extremely well in the seismic data. Careful comparison of P-impedance values to S-impedance values throughout the volume, but particularly in the areas highlighted for potential reservoir 
rock, we see that the lower P-impedance is not associated with a similar drop in Simpedance; this may distinguish hydrocarbon effects from the lithologic effects caused by lithology or porosity.

One way of investigating the nature of a change in elastic properties is to reduce the evaluation to a basic elastic modulus - the shear modulus. This parameter should not be affected at all by the fluid content in the pores. Our estimation of the shear modulus shows a decrease from the background in the potential reservoir zone. However, density is used to estimate shear modulus from the shear impedance, and we know that our estimate of density based on inversion is probably unreliable, and linked strongly to the P-Impedance. We probably cannot use the shear modulus to settle the question of lithologic (porosity) or fluid content for the source of the low impedance potential reservoir rock.

In any case, this study demonstrates that the data quality in this seismic survey is sufficient to identify anomalies that are consistent with hydrocarbon-bearing zones, based on the AVO attribute (A*B product, Scaled Poisson 's ratio change) and Pre-stack inversion results (low P-impedance, lambda-rho values). The potential target zone is identified (at the well location) at 1535-1565 m (1285-1306 ms). The reliance on these results could have been strongly improved if a shear-wave log had been run in the well. 


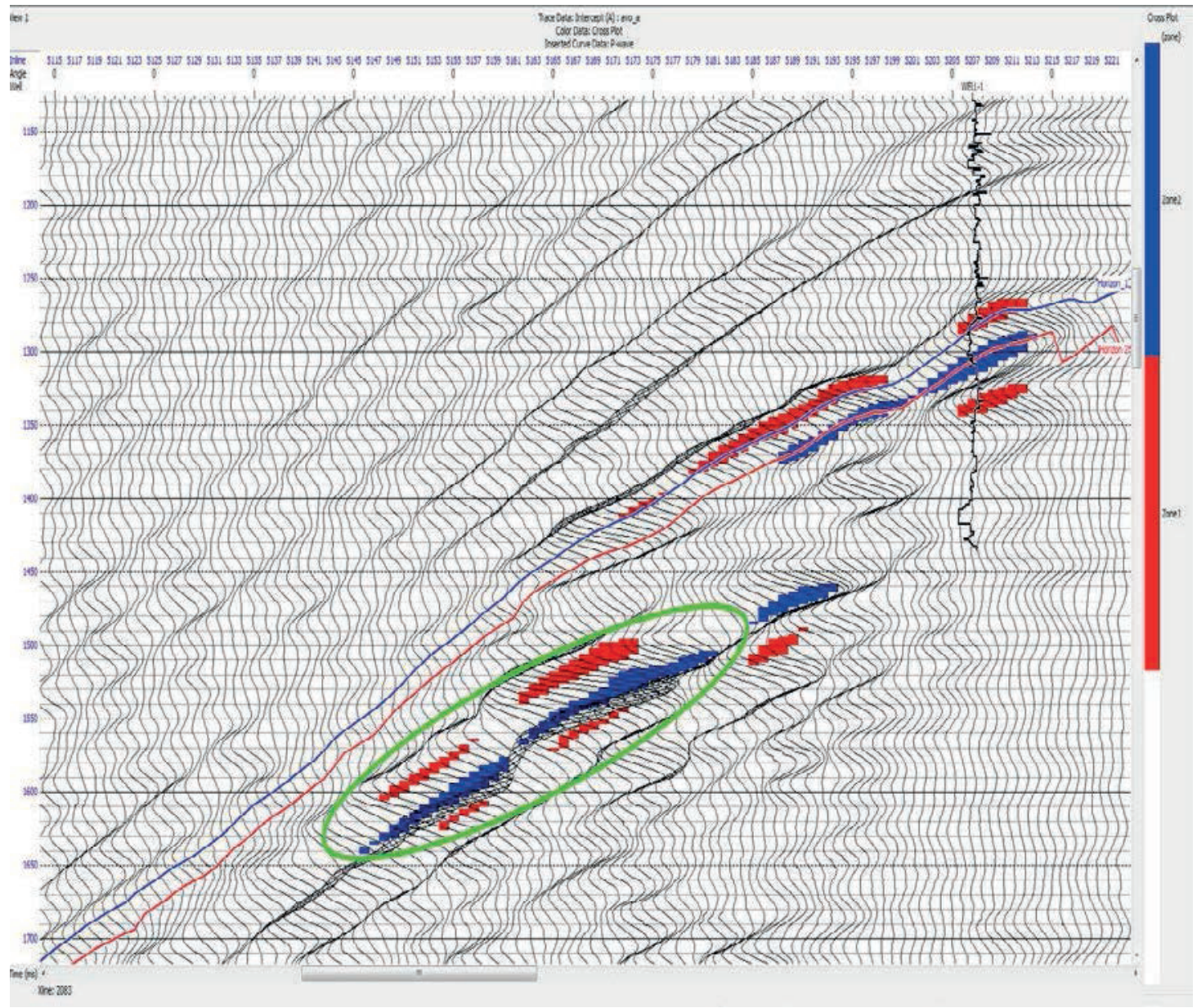

Figure 37. Future target zone estimation. The scale shows AVO cross plot. The top of the horizon is in red and the base of the horizon in blues. The black ellipse shows the possible reservoir zone. 


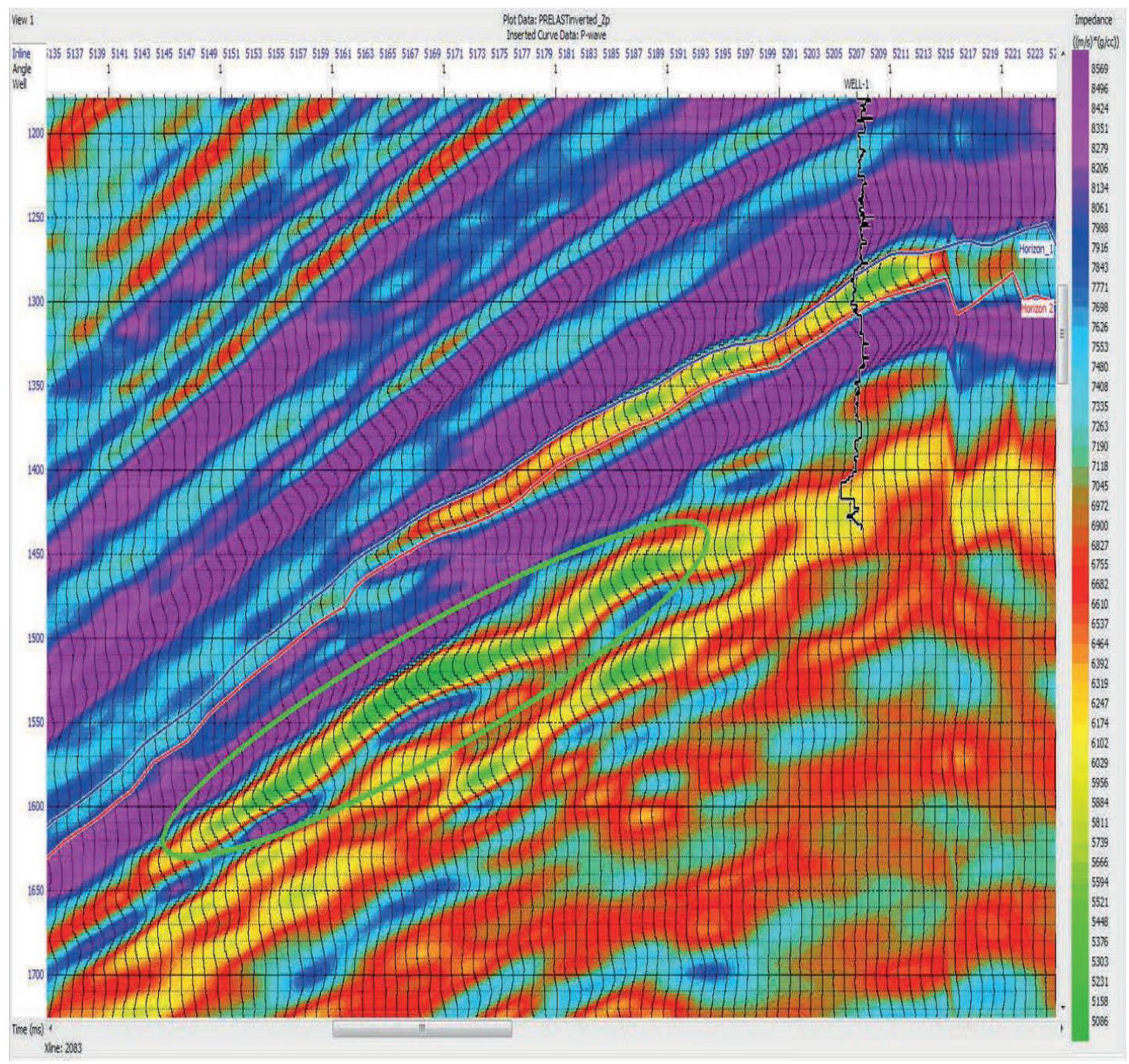

Figure 38. Future target zone estimation. The scale shows P-impedance values. The green is the lowest values and the purple is the highest values. The black circle shows possible reservoir zone. 


\section{References}

Castagna*, J. P., and H. W. Swan, 1997, Principles of AVO Cross-plotting: The Leading Edge, 16, no. 4, 337-342, http://dx.doi.org/10.1190/1.1437626.

Chopra, S., and J.P. Castagna, 2014, AVO. Tulsa, OK: SEG. 124,128,193,212 http://dx.doi.org/10.1190/1.9781560803201

DuBose, J. B., 2003, A modification of the parabolic radon transform for the preservation of AVO effects: 73rd Annual International Meeting, SEG, Expanded Abstracts, 239-241, http://dx.doi.org/10.1190/1.1817856.

Fatti, J.L., G. C. Smith, P. J. Vail, P. J. Strauss, and P. R. Levitt, 1994, Detection of gas in sandstone reservoirs using AVO analysis: A 3-d seismic case history using the geostack technique: Geophysics, 59, no. 9, 13621376, http://dx.doi.org/10.1190/1.1443695.

Huvaz O., H. Sarikaya, and O. M. Nohut, 2005, Nature of a regional dogleg pattern in maturity profiles of the Thrace Basin, northwestern Turkey: A newly discovered unconformity or a thermal anomaly?: AAPG Bulletin, V. 89, no. 10, 13731396, http://dx.doi.org/10.1306/0609050521.

Mahob, P. N., R. Young, and J. P. Castagna, 1997, The Effect of Radon Filtering on a Central Gulf of Mexico AVO Anomaly, SEG, Expanded Abstracts , 154-157, http://dx.doi.org/10.1190/1.1885713.

Bancroft, J. C., A. Richards, and C. P. Ursenbach, 2000, The abusive power of trimming: CREWES Research Report, V. 12, https://www.crewes.org/ForOurSponsors/ResearchReports/2000/2000-50.pdf 
Rickett, J., C. Mosher, and H. Martin, 2002, Improving the amplitude fidelity of Radon demultiple: $72^{\text {nd }}$ Annual International Meeting, SEG, Expanded Abstracts, 2082-2085, http://dx.doi.org/10.1190/1.1817112.

Rutherford, S. R., and R. H. Williams, 1989, Amplitude-versus-offset variations in gas sands: Geophysics, 54, no. 6, 680-688, http://dx.doi.org/10.1190/1.1442696.

Shuey, R. T., 1985b, A simplification of the Zoeppritz equations: Editor's note: Geophysics, 50, no. 9, 1522, http://dx.doi.org/10.1190/1.1442022.

Şen, Ş., and S. Y1llar, 2009, The Korudağ Anticlinorium in the South Thrace Basin, Northwest Turkey: A Super Giant Petroleum Trap Complex?: AAPG Bulletin, V. 93, no. 3, 357-377, http://dx.doi.org/10.1306/09290808072.

Turgut, S., and G. Eseller, 2000, Sequence stratigraphy, tectonics and depositional history in eastern Thrace Basin, NW Turkey: Marine and Petroleum Geology, V. 17, no. 1, 61-100, http://dx.doi.org/10.1016/s0264-8172(99)00015-x.

Turgut, S., Turkaslan M., and Perincek, D., 1991, Evolution of the Thrace 54 sedimentary basin and its hydrocarbon Eocene sediments prospectivity. In: Generation, Accumulation, and Production of Europe's Hydrocarbons (Ed. A.M. Spencer), Spec. Publ. Eur. Assoc. Petrol. Geoscientists, Vol. 1, p. 415-437. 


\section{Appendix}

\section{Copyright Permission}

\section{Figure 1: Location map of northwestern Turkey}

Hi Emre,

I am giving you permission about my Thrace Basin figure/figures in your work.

Assoc Prof Dr. Samil SEN

Istanbul Univ.

samilsen@istanbul.edu.tr

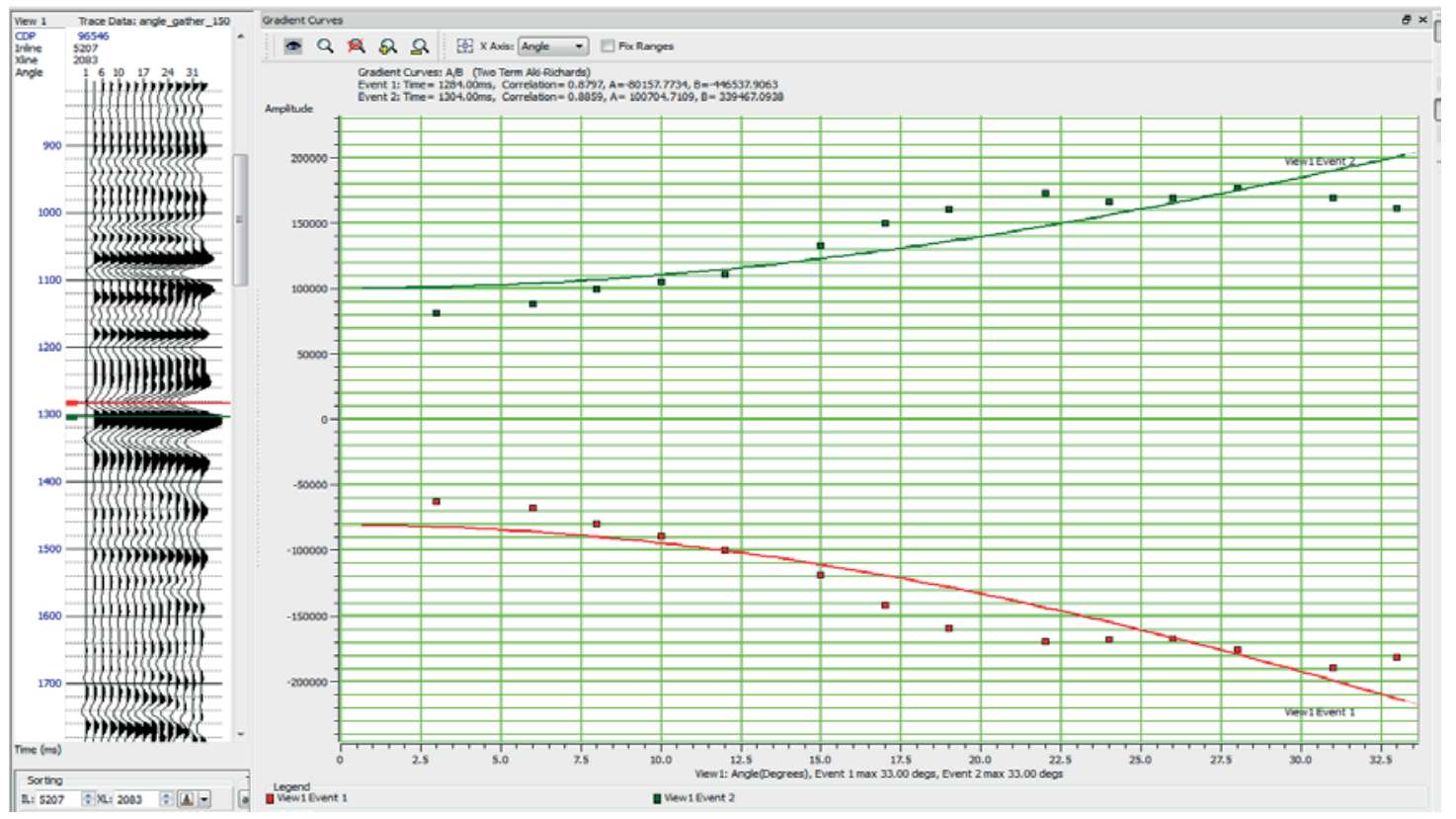

Figure 39. AVO gradient analysis for the Radon filter $(150,-150)$. The red is the top of the target horizon and the green is the base of the target horizon. It shows 0.88 , 0.87 correlation. 


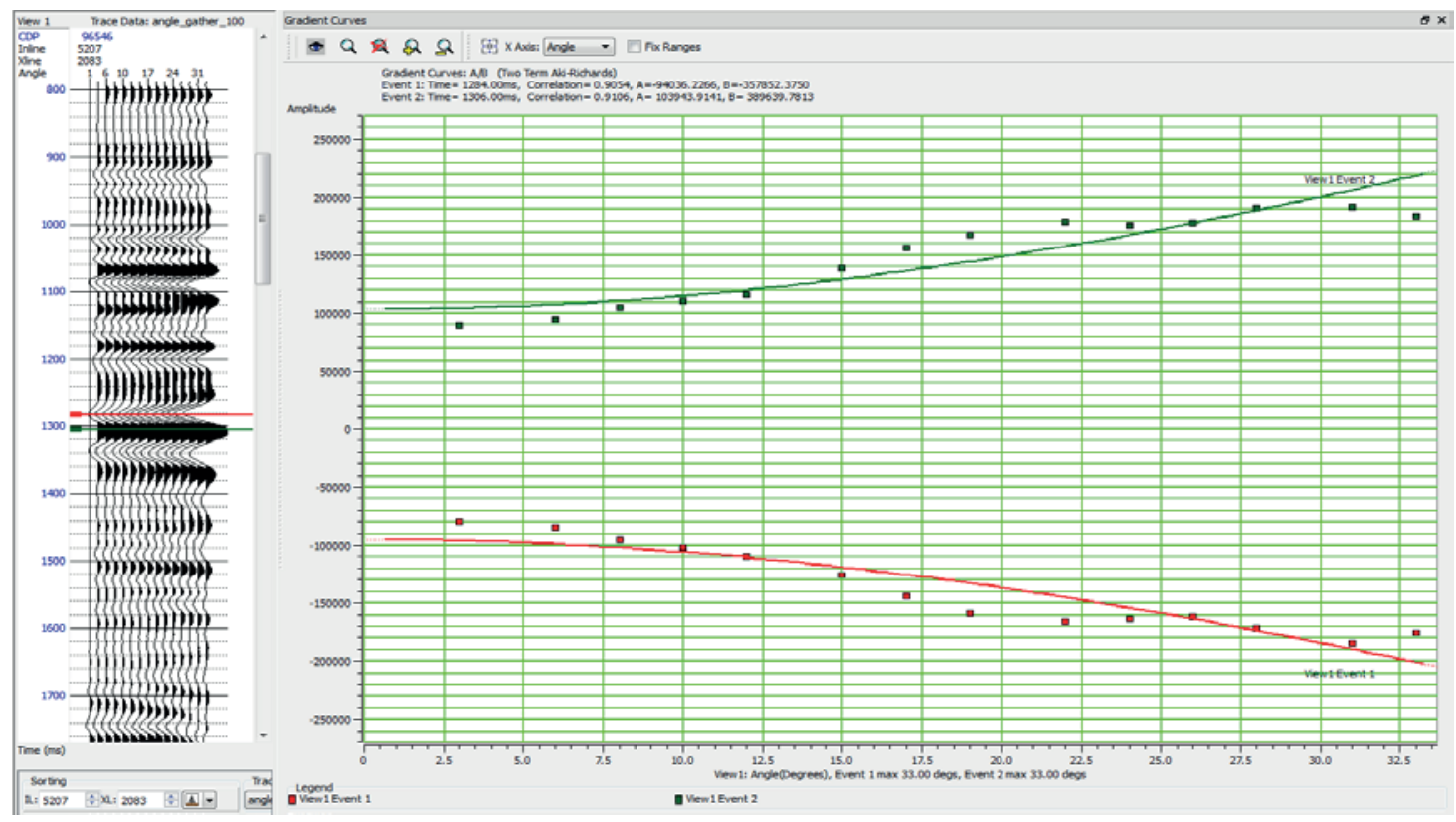

Figure 40. AVO gradient analysis for the Radon filter $(100,-100)$. The red is the top of the target horizon and the green is the base of the target horizon. It shows 0.90 , 0.91 correlation. 


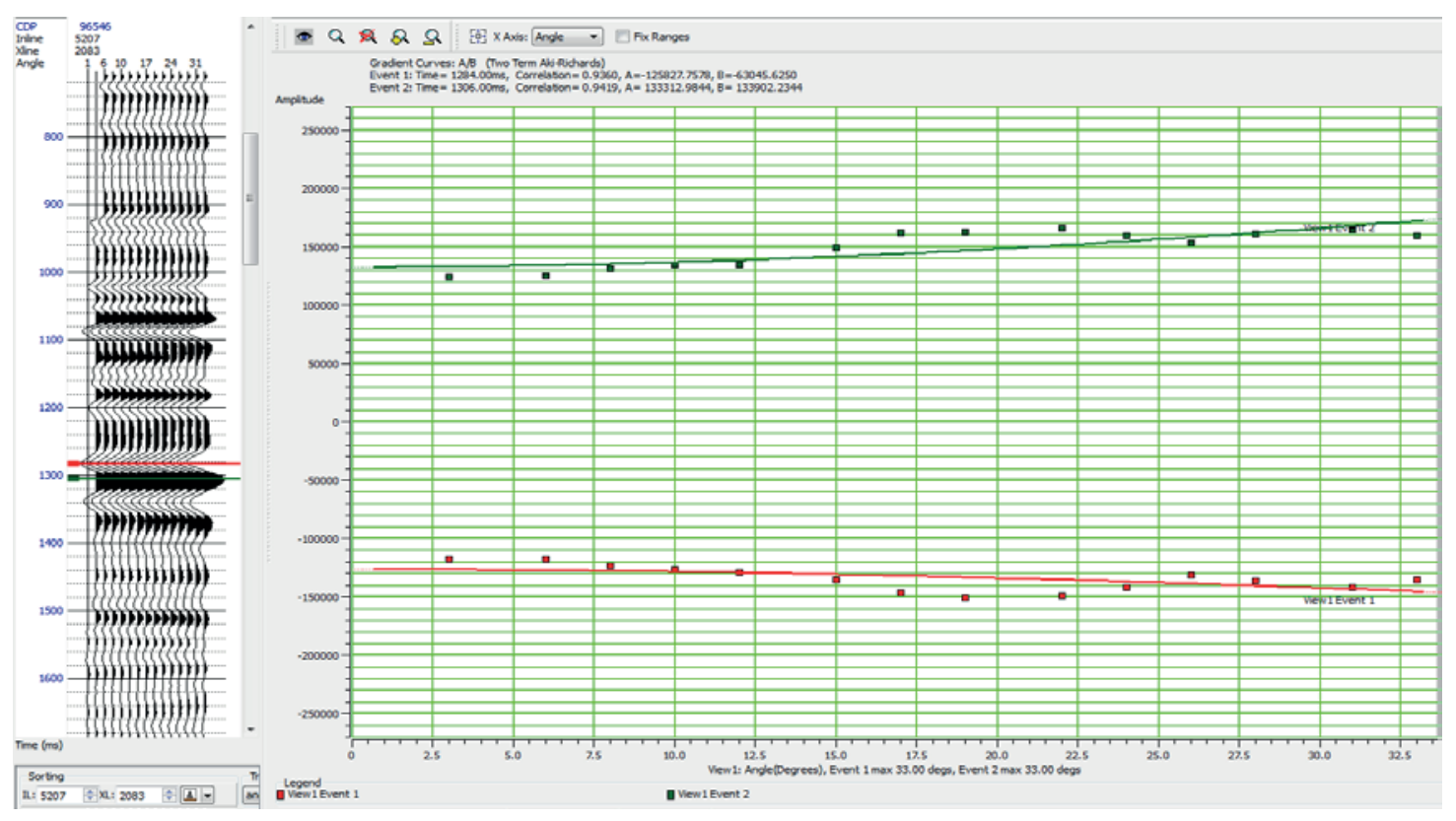

Figure 41. AVO gradient analysis for the Radon filter $(50,-50)$. The red is the top of the target horizon and the green is the base of the target horizon. It shows 0.93 , 0.94 correlation. 


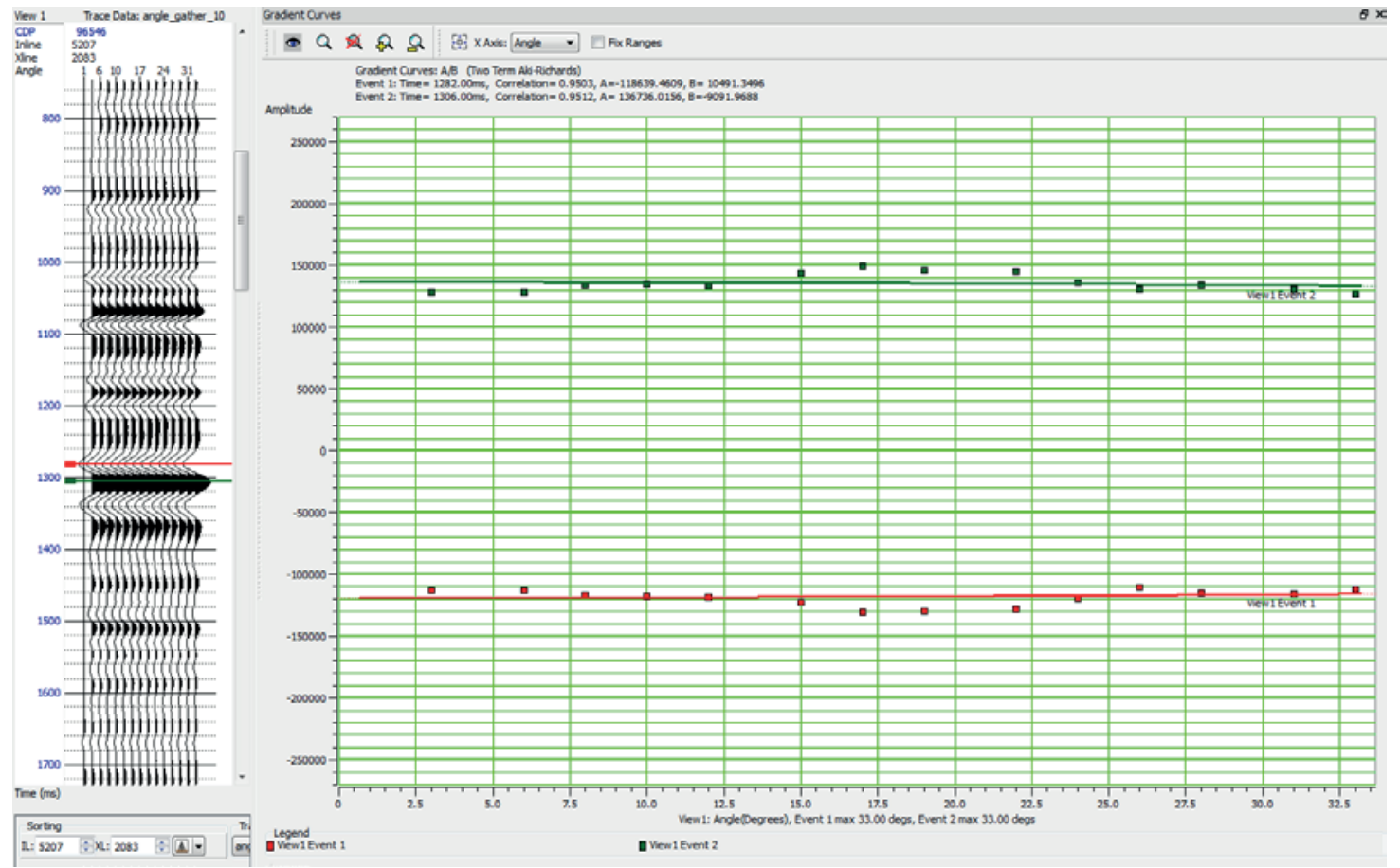

Figure 42. AVO gradient analysis for the Radon filter $(10,-10)$. The red is the top of the target horizon and the green is the base of the target horizon. It shows 0.95 , 0.95 correlation. 


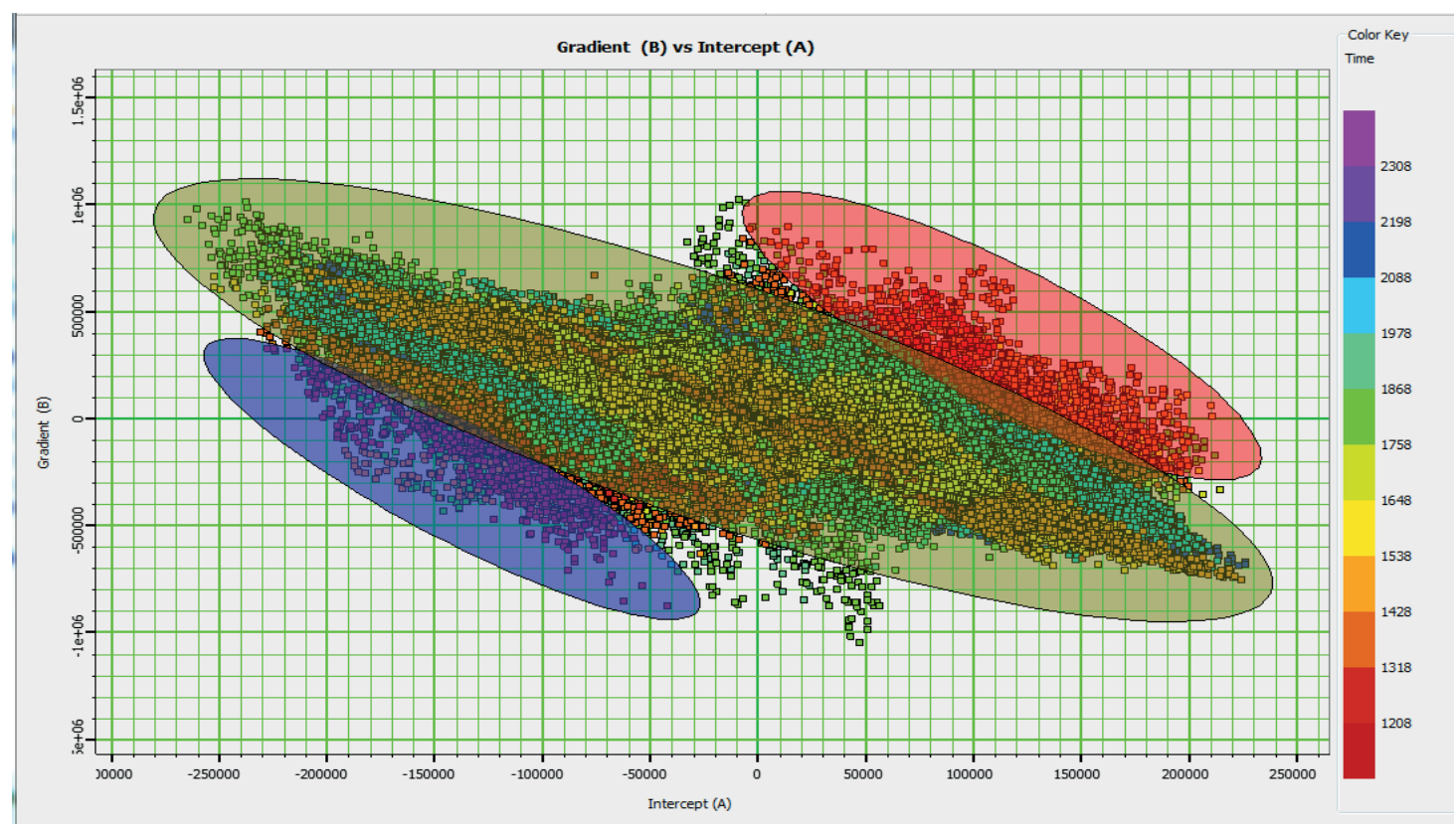

Figure 43. AVO cross plot for the Radon filter (150,-150). The red ellipse represents the base of the reservoir and the blue represents the top of the reservoir. 


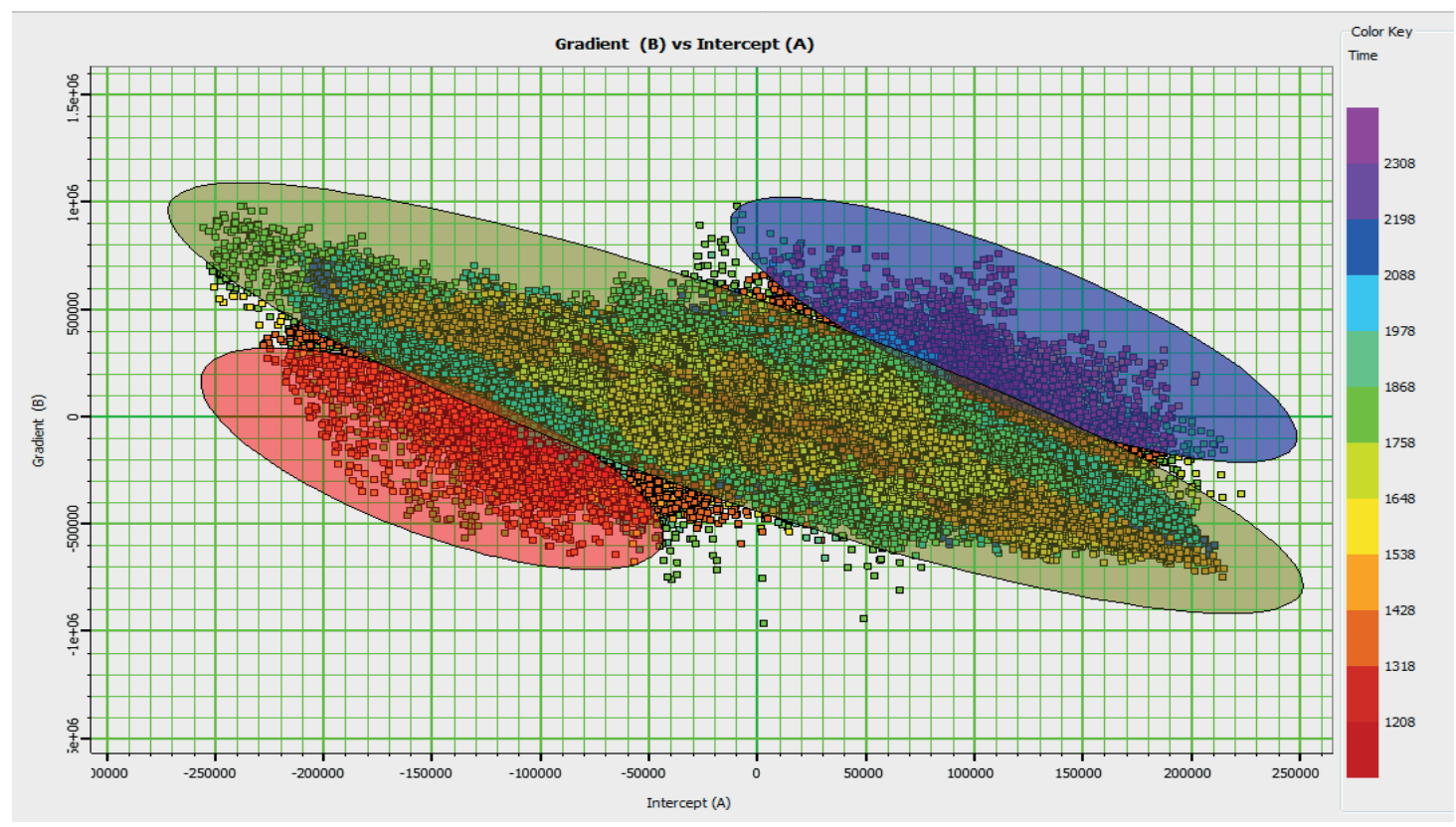

Figure 44. AVO cross plot for the Radon filter (100,-100). The blue ellipse represents the base of the reservoir and the red represents the top of the reservoir. 


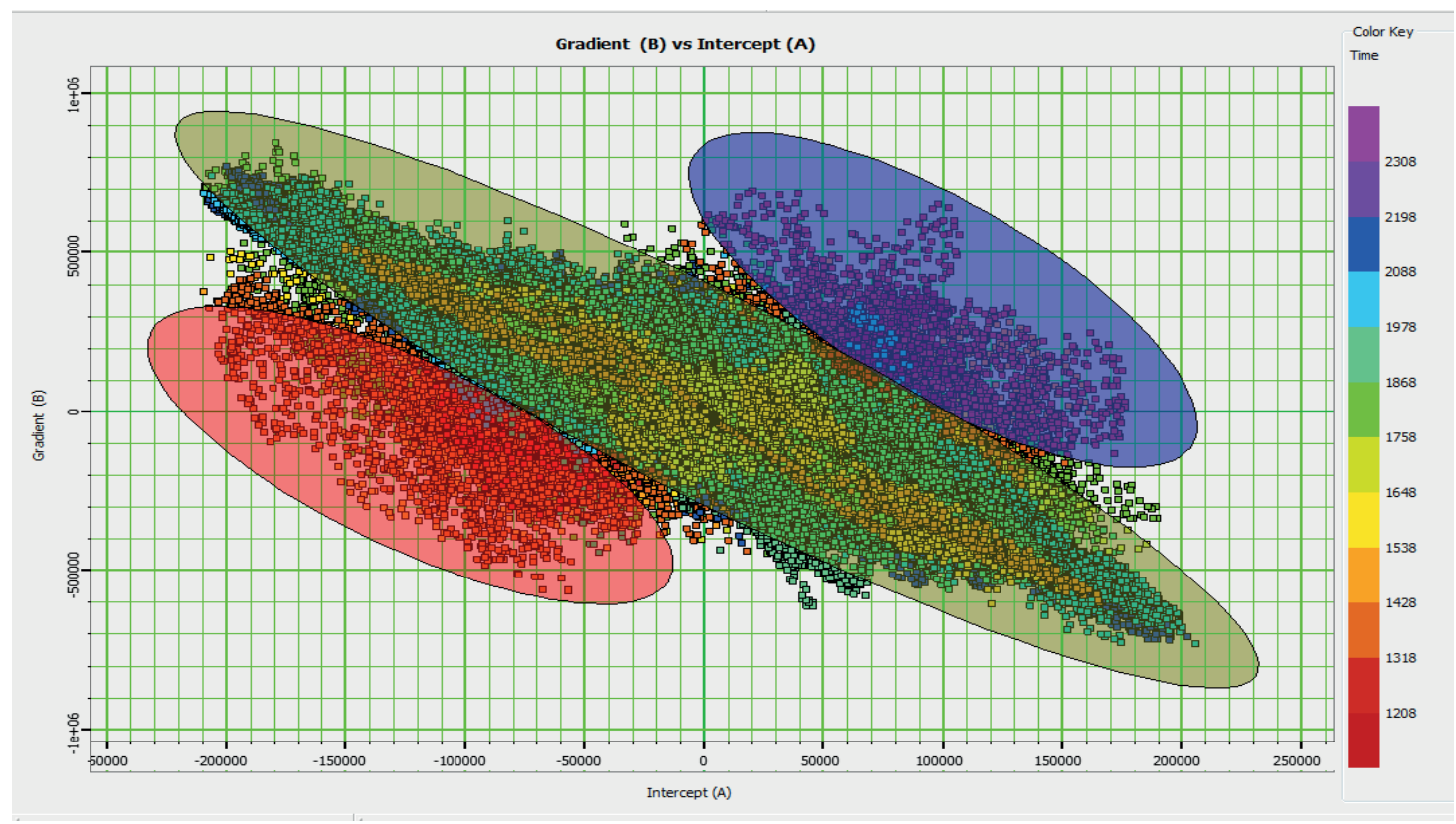

Figure 45. AVO cross plot for the Radon filter (50,-50). The blue ellipse represents the base of the reservoir and the red represents the top of the reservoir. 


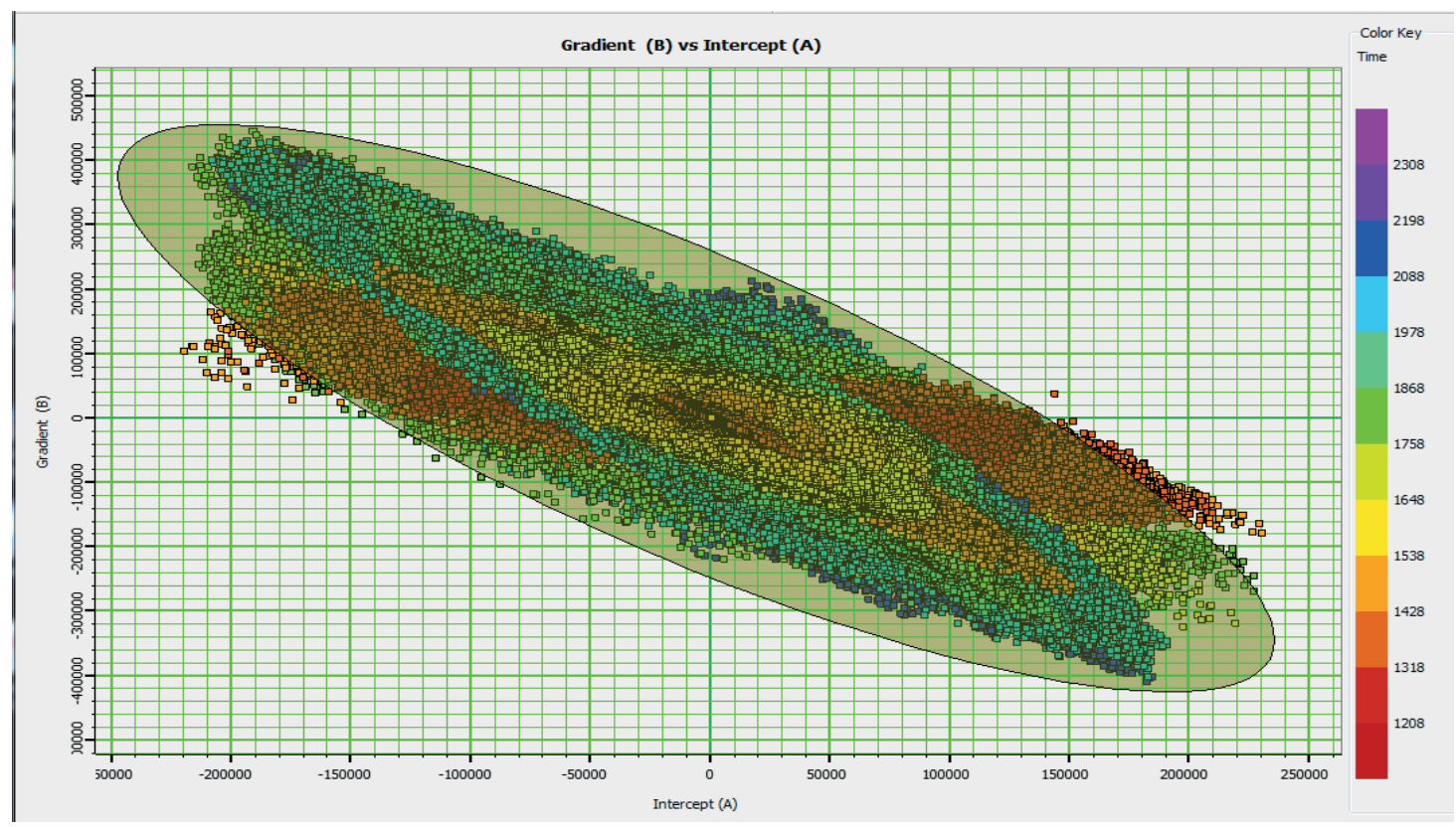

Figure 46. AVO cross plot for the Radon filter (10,-10). The blue ellipse represents the base of the reservoir and the red represents the top of the reservoir. 

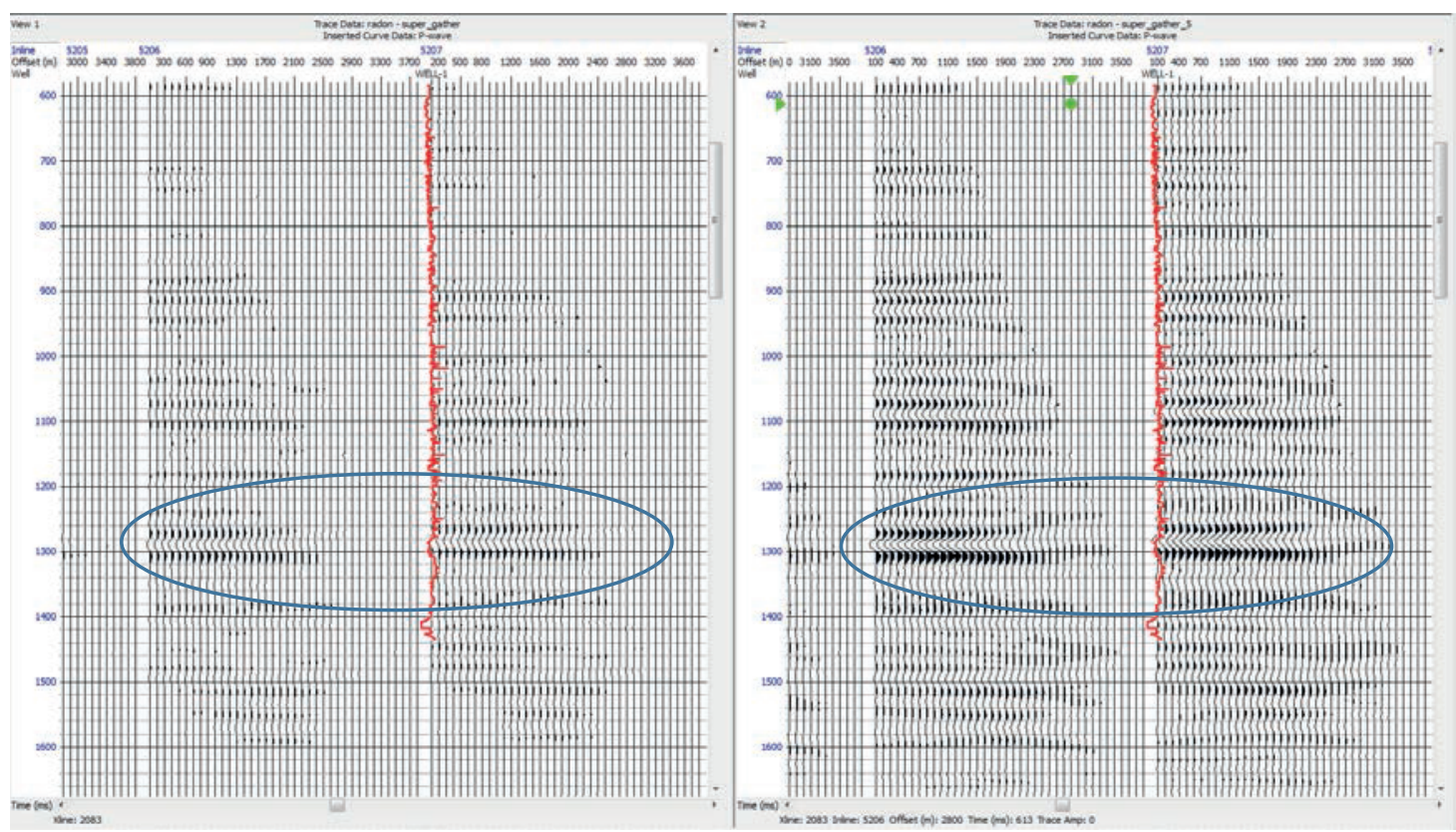

Figure 47. The Radon filter applied data - super gather 3x3 and the Radon filter applied data - super gather $5 \times 5$. 


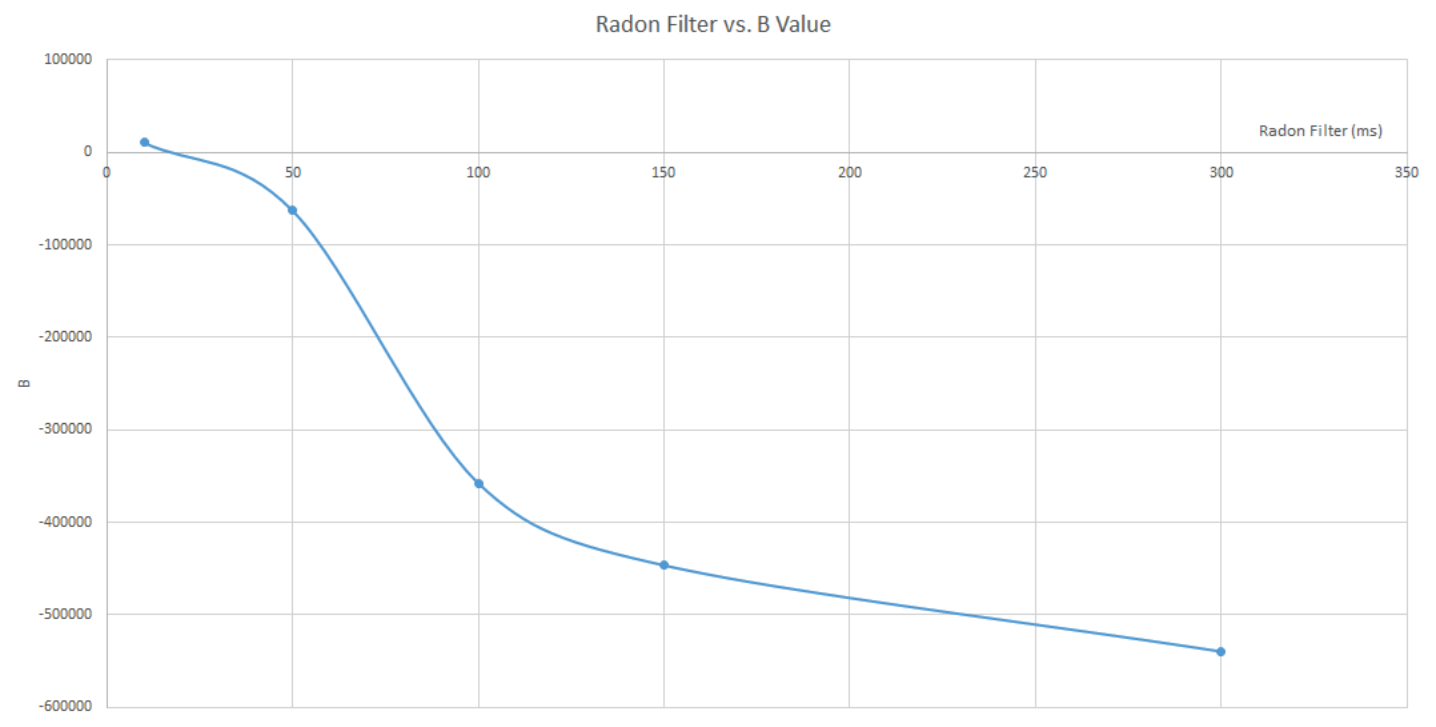

Figure 48. Raw data (approximate value $300 \mathrm{~ms}$ ), 150, 100, 50 and $10 \mathrm{~ms}$ the Radon filters versus AVO gradient values (B). 